\title{
Ultrastructural studies on the innervation of the anterior eye segment and eye related peripheral ganglia
}

Citation for published version (APA):

Beckers, H. J. M. (1993). Ultrastructural studies on the innervation of the anterior eye segment and eye related peripheral ganglia. [Doctoral Thesis, Maastricht University]. Datawyse / Universitaire Pers Maastricht. https://doi.org/10.26481/dis.19931203hb

Document status and date:

Published: 01/01/1993

DOI:

10.26481/dis.19931203hb

Document Version:

Publisher's PDF, also known as Version of record

Please check the document version of this publication:

- A submitted manuscript is the version of the article upon submission and before peer-review. There can be important differences between the submitted version and the official published version of record.

People interested in the research are advised to contact the author for the final version of the publication, or visit the DOI to the publisher's website.

- The final author version and the galley proof are versions of the publication after peer review.

- The final published version features the final layout of the paper including the volume, issue and page numbers.

Link to publication

\footnotetext{
General rights rights.

- You may freely distribute the URL identifying the publication in the public portal. please follow below link for the End User Agreement:

www.umlib.nl/taverne-license

Take down policy

If you believe that this document breaches copyright please contact us at:

repository@maastrichtuniversity.nl

providing details and we will investigate your claim.
}

Copyright and moral rights for the publications made accessible in the public portal are retained by the authors and/or other copyright owners and it is a condition of accessing publications that users recognise and abide by the legal requirements associated with these

- Users may download and print one copy of any publication from the public portal for the purpose of private study or research.

- You may not further distribute the material or use it for any profit-making activity or commercial gain

If the publication is distributed under the terms of Article $25 \mathrm{fa}$ of the Dutch Copyright Act, indicated by the "Taverne" license above, 


\section{ULTRASTRUCTURAL STUDIES ON THE INNERVATION OF THE ANTERIOR EYE SEGMENT AND EYE RELATED PERIPHERAL GANGLIA}


CIP-DATA KONINKLIJKE BIOLIOTHEEK, DEN HAAG

Beckers, Holena Jacqueline Maria

Uttrastruetural studies on the innervation of the anterior eye aegment and eye related peripheral ganglia / Hellena Jacqueline Maria Beckers. - Maestricht : Universitaire Pors Maastricht. - Iill.

Thesis Maestricht. - With rel. - With summary in Dutch. 1SBN 90-5278-112-5

Subject headings: Phaseolus vulgaris-leucoagglutinin / autoradiography / immunohistochemistry.

Omslag ontwerp: Alice Lexis

Produktie: 1\&P Solutions, Rob Jongen

Druk: Datawyse Maastricht - Krips Repro Meppel 


\title{
ULTRASTRUCTURAL STUDIES ON THE INNERVATION OF THE ANTERIOR EYE SEGMENT AND EYE RELATED PERIPHERAL GANGLIA
}

\section{PROEFSCHRIFT}

\author{
ter verkrijging van de graad van doctor \\ aan de Rijksuniversiteit Limburg te Maastricht, \\ op gezag van de Rector Magnificus, Prof. Dr. H. Philipsen, \\ volgens het besluit van het College van Dekanen, \\ in het openbaar te verdedigen \\ op vrijdag, 3 december 1993 \\ om 14.00 uur \\ door
}

Helena Jacqueline Maria Beckers geboren te Echt 
Promotores:

Prof. Dr. W.P.M.A. Lamers

Prof. Dr. G.F.J.M. Vrensen, Rijksuniversiteit Leiden

Beoordelingscommissie: Prof. Dr. J. Drukker (voorzitter)

Prof. Dr. J.W. Arends

Prof. Dr. F. Hendrikse

Prof. Dr. G.L. Ruskell, City University London, U.K.

Prof. Dr. H.A.J. Struijker Boudier 
Grote dingen moeten in één klap voltooid worden. Alle veranderingen roepen vroeger of later controversen op. De beste manier om die te vermijden is het zijn voomemens van het begin af aan openbaar te maken en ze dan, als de eigen beslissing eenmaal genomen is, vastbesloten door te zetten, zonder naar andere meningen te luisteren.

(Josef II van Oostenrijk, 1765. Uit: H.C. Robbins Landon: The Mozant compendum. Thames and Hudson, Londen, 1990.)

Voor Rob, Maaike en Bas Voor mijn ouders 


\section{CONTENTS}

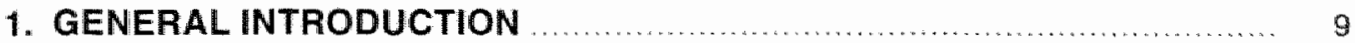

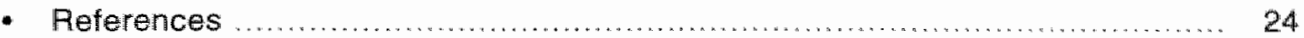

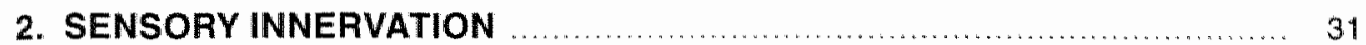

- Ultrastructural Identification of Trigeminal Nerve Terminals in the Pterygopalatine Ganglion of Rats: An Anterograde Tracing and Immunohistochemical Study

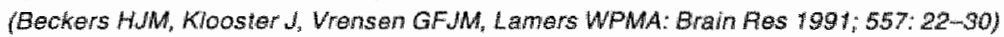

- Ultrastructural Identification of Trigeminal Nerve Endings in the Rat Cornea and Iris

(Beckers HJM, Kloaster J, Vrensen GFMM, Lamers WPMA: Invest Ophthatmol Vis Sci 1992; 33 : 1979-1986)

- Substance P in Rat Corneal and Iridal Nerves: An Ultrastructural Immunohistochemical Study

(Beckers HUM, Klooster J, Vrensen GFJM, Lamers WPMA: Ophthalmic Res 1993; 25: 192-200)

- References

3. SYMPATHETIC INNERVATION

- Sympathetic Innervation of the Rat's Eye and Peripheral Ganglia:

An Electron Microscopic Autoradiographic Tracing Study

(Beckers HJM, Klooster J Vrensen GFMM, Lamers WPMA: Graete's Arch Clin Exp Ophthaimol 1993: in press)

- References

\section{PARASYMPATHETIC INNERVATION}

- Facial Parasympathetic Innervation of the Rat Choroid, Lacrimal Glands and Cillary Ganglion: An Ultrastructural Pterygopalatine Tracing and Immunohistochemical Study

(Bockers HUM, Kboster J Vrensen GF,M, Laners WPMA: Ophthalmic Res 1993; in press)

- The Peripheral Projections of the Edinger-Westphal Nucleus in the Rat

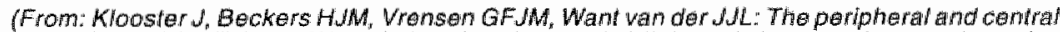
projections of the Edinger- Westphal nucleus in the rat: A light and electron micrascopic tracing sfudy. Brain Res; in press)

- References 


\section{LIST OF ABBREVIATIONS}

3 Hewene

C.AMP

CGRP

ChAT

$D A B$

EM

EW

EWI

EWm

GSSP

HRP

IGSS

IOP

LENK

LM

NNPY

PAP

PBS

PHA-L

POAG

$P P G$

RER

SP

TBS

$T H$

WIP

WGAHAP tritlated leucine

cyclic adenosine $3^{\prime}, 5^{\prime}-$ monophosphate

calcitoningene-related peptide

choline acetyltransferase

3,3 diaminobenzidine tetrahydrochloride

election microscope

Edinger-Westphal nucleus

lateral part of Edinger-Westphal nucleus

medial part of Edinger-Westphal nucleus

gold-substituted silwer peroxidase

horseradish peroxidase

intense gold silver stain

intraocular pressure

leucine-enkephalin

lighit microscope

neuropeptide $Y$

peroxidase-antiperoxidase

phosphate-buffered saline

Phaseolus vulgaris-leucoagglutinin

primary open-angle glaucoma

pterygopalatine ganglion

rough-surfaced endoplasmic reticulum

substance P

Tris-bulfered salline

tyrosine hydraxylase

vasoactive intestinal polypeptide

wheat germ agglutinin conjugated to horseradish peroxidase 


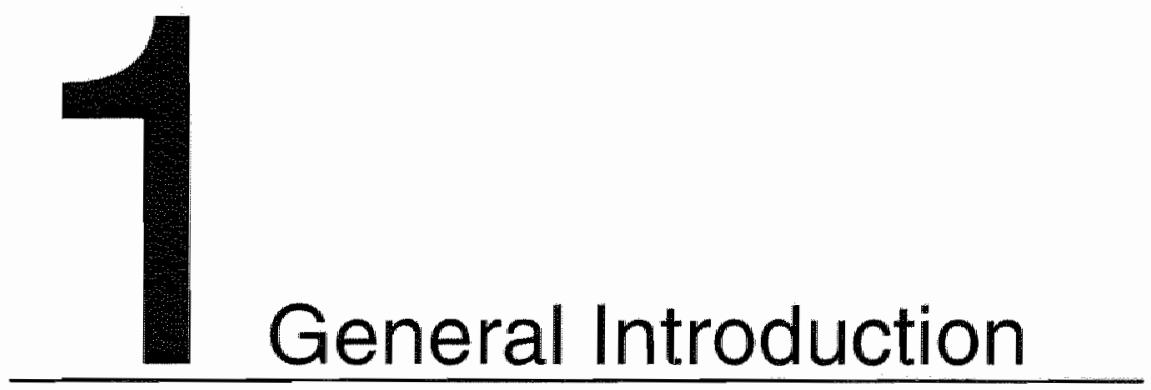


Primary open angle glaucoma (POAG) is one of the group of diseases called glaucoma which is characterized by a progressive form of optic nerve damage. This optic nerve damage is usually accompanied by an elevated intraocular pressure (IOP). An OP above $21 \mathrm{~mm} H \mathrm{Hg}$ should be considered suspicious. However, in about one out of six patients with glaucoma elevated levels of IOP are not found (low-tension glaucoma). Other risk factors for primary open angle glaucoma include a family history of glaucoma, diabetes mellitus, high myopia and systemic vascular disease.

There is increasing evidence that there may be more than one pathogenetic process involved in the onset of glaucoma.

In a recent paper ${ }^{94}$ two separate "clusters' of patients with primary open angle glaucoma have been described using biostatistical methods. One cluster showed IOP-dependent progression of field loss, whereas the other cluster showed field-loss progression independent of IOP. The first cluster of patients showed vasospasmic features, while in the second cluster signs of vascular disease were found, suggesting the possibility of different pathogenetic mechanisms. The groups had been selected without regard to the low-tension/high-tension classification of glaucoma. The pressure-dependent cluster encompassed about one-third of all the cases of POAG studied. This is alarming since at present, the IOP is an important risk factor for developing glaucoma that ophthalmologists are able to identify and treat.

Aqueous humour enters the posterior chamber from the ciliary processes, and flows around the lens and through the pupil into the anterior chamber. The aqueous humour leaves the eye via two pathways.

1. Anterior (trabecular) route: fluid flows from the anterior chamber angle through the trabecular meshwork and enters Schlemm's canal. Via intra- and episcleral venous channels the general circulation is reached.

2. Posterior (uveoscleral) route: fluid flows from the anterior chamber angle into the connective tissue spaces within the cillary muscle, into the suprachorold, and then through the scleral spaces into the episcleral tissues. In humans, the trabecular route predominates, but this differs between species.

Medical treatment to lower IOP is aimed to decrease aqueous humour formation from the ciliary body, to decrease episcleral venous pressure, to increase the trabecular or uveoscleral oufflow, or to bring about some combination of these factors ${ }^{32}$.

To improve current medical treatment for glaucoma the mechanisms regulating aqueous humour outflow and IOP have to be elucidated. It is believed by many ophthalmologists and research workers that, in chronic open-angle glaucoma, the relation between aqueous thumour production and outflow is disturbed by a decreased outflow facility ${ }^{60}$. The main site of outflow resistance is thought to be located in the juxtacanalicular trabecular meshwork. Therefore, numerous studies have been published regarding the mechanisms of outflow regulation by the 
trabecular meshwork $3,18,49,86$. It has been speculated lately that contractions of the trabecular meshwork itself would influence outtlow regulation in the bovine eye 49 .

In contrast, it has long been emphasized that neural mechanisms must be considered as an important regulator of $10 \mathrm{P}^{9}$. In experiments interfering with the peripheral nervous systern, changes in 1OP were recorded after stimulation of sensory, sympathetic and parasympathetic (oculomotor and facial) nerve fibres. The data concerning these experiments were summarized recently ${ }^{113}$. Ganglionectomy or stimulation of the sympathetic superior cervical ganglion, the parasympathetic pterygopalatine and cillary ganglia and the sensory trigeminal ganglion all resulted in a change in IOP (Fig. 1).

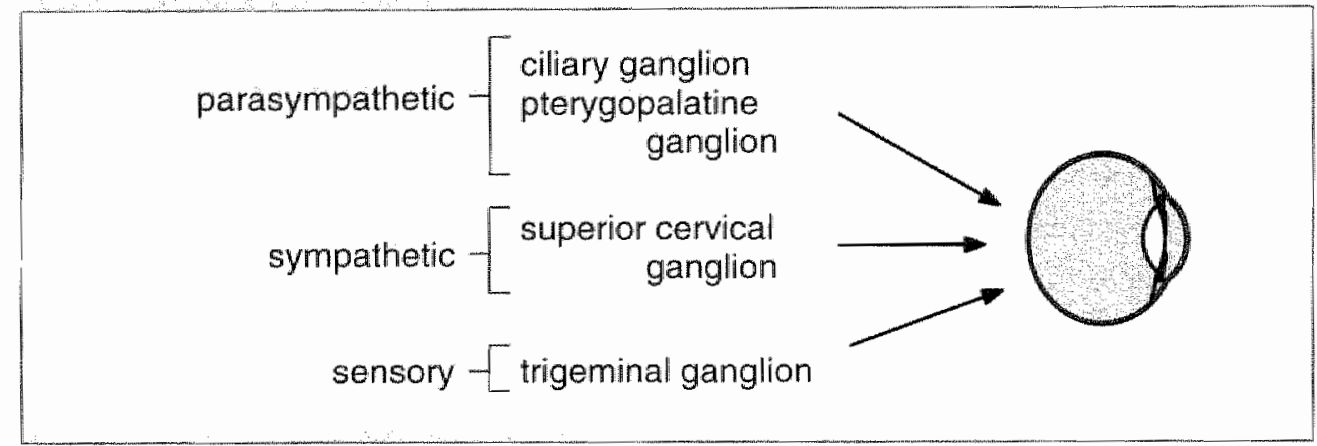

Fig. 1: The main peripheral ganglia innervating the eye (modified after Stone and Kuwayama ${ }^{98}$ ).

In the central nervous system, a specific locus regulating IOP would serve to integrate sensory imput and initiate efferent output to the eye by way of the autonomic nervous system. Stimulation of a discrete area in the medial hypothalamus was found to cause a fall in $\| O P$, accompanied by a rise in blood pressure 24,93 . From these data, it has become very likely that central and peripheral nerve fibres innervating the eyeball play a role in the homeostasis of IOP.

To prove the involvement of the nervous system in the regulation of IOP, the afferent and efferent pathways by which the IOP homeostasis is maintained must be elucidated. Following an overview of the sensory, the sympathetic and the parasympathetic innervation of the anteri or eye segment and the eye related peripheral ganglia, the aim and scope of the present study will be set out.

\section{Sensory Innervation}

In a recent overview ${ }^{113}$, anterograde and retrograde light microscopic tracing studies on the sensory innewation in rats using wheat germ agglutinin coupled to horseradish peroxidase (HAP-WGA) and H-Heucine as tracers were summarized (Fig. 2). 


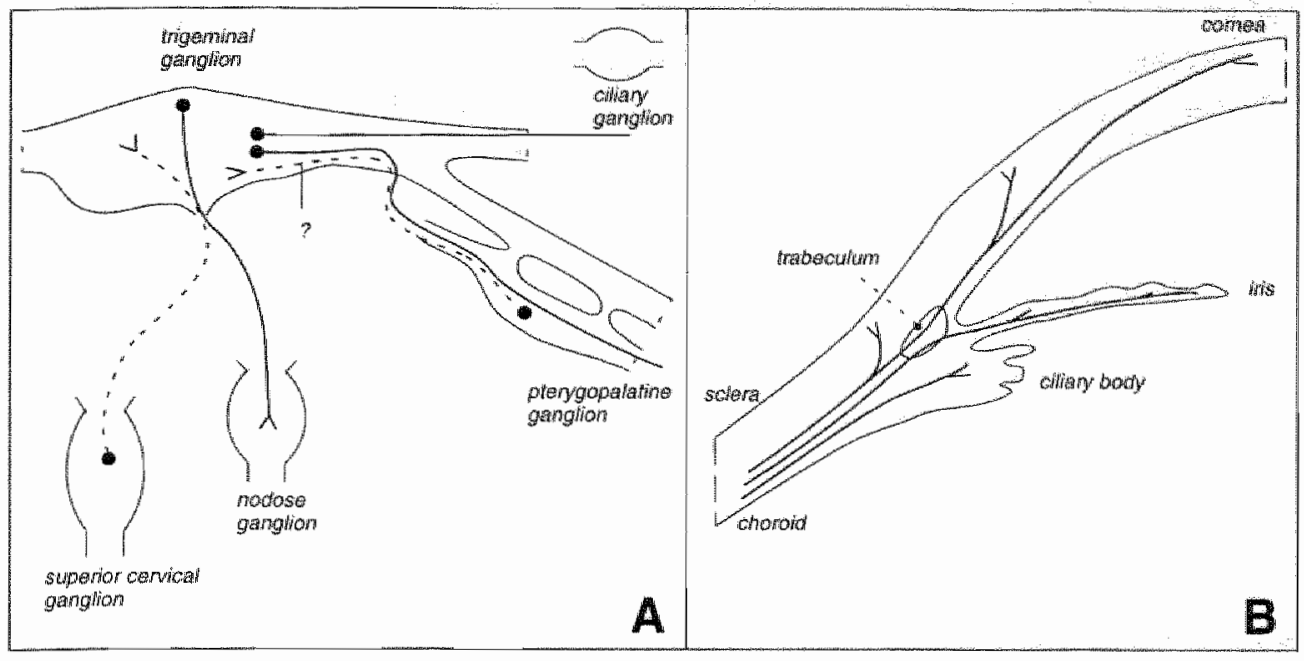

Fig. 2: Schematic drawing of the sensory innervation of the eye related peripheral ganglia (A) and the anterior eye segmeint (B) (modified after ten Tusscher ${ }^{113}$ ).

Anterograde tracing with $3 \mathrm{H}$-leucine showed trigeminal projections to the pterygopalatine and nodose ganglion (Fig. 2A). No projections were found to the cilliary and the superior cervical ganglion. WGA-HRP retrograde tracing from the trigeminal ganglion suggested a projection from the superior cervical ganglion and the pterygopalatine ganglion to the trigeminal ganglion (interrupted lines). However, in a later tracing study using ${ }^{3} \mathrm{H}$-lewcine as an anterograde tracer, no projection was found from the pterygopalatine to the trigeminal ganglion. This discrepancy may be due to the uptake of tracer by passing fibres in the case of the retrograde WGA-HAP study.

Regarding the innervation of the anterior eye segment (Fig. 2B), trigeminal fibres were found in the anterior stroma of the ciliary body, the iris, the cornea and the conjunctiva. The trigeminal fibres of comea "iris and ciliary body were found to traverse the trabeculum on their way to the sclera and the suprachoroid.

At the electron microscopic level, few tracing studies have been performed to unravel the ultrastructure of nerve fibres and terminals in the sensory pathway. Sensory fibres of the mammalian iris were found to be unmyelinated 47,48 . Varicosities of these fibres contain mitochondria, or mitochondria and vesicles. The thin profiles between the varicosities contain neurotubuli and filaments. Routine electron microsicopic studies of the cornea have described several types of nerve terminals containing mitochondria and clear and granular vesicles $31,112$. It is still unciear whether these distinct types of terminals are all sensory. 
In recent years, numerous light microscopic studies have been published regarding the localization of neuropeptides in sensory merves innervating the anterior eye segment and the eye related peripheral ganglia. In the trigeminal ganglion, substance P (SP) and calcitonin gene-related peptide (CGRP) have been demonstrated in cell bodies. In rodents, the number of CGRP immunoreactive cells in the trigeminal ganglion is about two times greater than the number of SP.immunoreactive cells $42,43,46,110$. About $40 \%$ of the ganglion cells have been described to contain CGRP, whereas only $20 \%$ of the cells contain SP. Nearly all the SP-immunoreactive cells were found to be also CGRP-immunoreactive, however, numerous CGRP-immunoreactive cells were not immunoreactive for SP.

In the pterygopalatine ganglion, trigeminal fibres have been shown to contain SP and CGRP108. Few CGRP-immunareactive cells have been found in the pterygopalatine ganglion ${ }^{96}$, which other investigators were unable to confirm 42,108 . Only few SP-immunoreactive cells thave been demonstrated in the pterygopalatine ganglion.

In the anterior eye segment, SP-and CGRP-immunoreactive nerve fibres are of trigeminal origin and contain numerous varicosities $66,96,100,110,116$. In the cornea numerous CGRP-immunoreactive fibres and a modest number of SP-immunoreactive fibres have been demonstrated. Corneal fibres showed collocalization of CGRP and SP, but the CGRP-immunoreactive fibres outnumber the SP-immunoreactive fibres. The iris is densely innervated by CGRP-immunoreactive and SP-immunoreactive axons, which colocalize in the stroma and in the sphincter and dilator areas of the iris ${ }^{110}$. In the ciliary body and the trabecular meshwork, including the canal of Schlemm, CGRP-immunoreactive fibres have been found. In the cillary body, numerous nerve fibres show colocalization with SP, however, some fibres are either SP- or CGRP-immunoreactive. SP-immunoreactive fibres showing colocalization for CGRP also have been found in the choroid ${ }^{42}$. Recently, CGRP-immunoreactive nerve fibres have been demonstrated in the conjunctiva of rats. Mast of these fibres were of trigeminal origin $^{55}$.

SP and CGRP are potent dilators of cerebral and extracranial wessels $30,39,108$. A function as neurotransmitters in trigeminal C-fibres has been described for both SP and CGRP. SP has been suggested to act as an excitatory transmitter on autonomic ganglion cells $17,26,36$. A regulatory loop for the integration of primary sensory input and autonomic function has been hypothesized ${ }^{81,96,108}$. In response to harmful stimuli, sensory nerves modulate the activity of autonomic neurons and trigger protecting reflexes, such as the ocular injury response. The ocular injury response is characterized by miosis, anterior segment vasodilatation, ellevated IOP and breakdown of the blood-aqueous barrier, followed by protonged lowered IOP. In lower mammals, especially the rabbit, these events are the most prominent ${ }^{115}$. Sensory denervation results in a depletion of CGRP and SP immunoreactivity in the anterior eye segment. The depletion of SP and CGRP is related in time to loss of sensitivity of the eye to irritation. SP has no effect on the anterior uveal blood vessels or the blood-aqueous barrier. SP-rellease leads to a strong constriction of the pupil. Antidromic stimulation of the trigeminal nerve causes release 
of CGRP into the aqueous humour and leads to signs of neurogenic inflammation 1,2,30,75,117. Introduction of CGRP into the rabbit anterior chamber causes uveal vasodilatation, increased ciliary vascular permeability, transient consensual rise in IOP and breakdown of the blood-aqueous barrier. CGRP increases the miltic effect of SP. The acute ocular injury response thus appears to be mediated by the joint actions of CGRP and SP, released by antidromic sensory activation, SP and CGRP each eliciting different components of the ocular injury response.

A trophic role for corneal sensory nerves has been found to exist as sensory denervation of the eye results in degenerative changes known as neuroparalytic keratitis ${ }^{\text {a }}$. Neuroparalytic keratitis also develops over a period of 3-4 weeks after new-born rodents had been injected with the sensory neurotoxin capsaicin ${ }^{33}$. It is still unclear how the corneal nerves exert their trophic effects. It has been proposed that the release of axonally transported CGRP and SP is of importance in trophic and regulatory processes ${ }^{99}$. They could stimulate epithelial cells and stromal keralocytes in the process of tissue maintenance and renewal.

It has been suggested that C-AMP is involved in the regulation of intraocular pressure67.95. Prolonged increases in levels of C-AMP in ciliary processes seem either to reduce the rate of aqueous humour secretion into the posterior chamber of the eye, to stimulate reabsorption of fluid by activating transport in the opposite direction, of both. Intracameral injection of CGRP into the rabbit eye causes an increase in C-AMP in the aqueous thumour 37 . Recently, it has been shown that CGRP stimulates C-AMP levels in the rabbit iris/ciliary body complex, suggesting the existence of CGRP receptors linked to the production of C-AMP in the iris and ciliary epithelium of the iris/ciliary body complex 78 . These receptors were unaffected by atropine or propranolol. It was hypothesized that such receptors are involved in the ocular injury response or in the control of intraocular pressure.

\section{Autonomic Innervation}

\section{The sympathetic innervation}

In a recent study ${ }^{113}$, anterograde light microscopic tracing studies on the sympathetic innervation in rats were summarized (Fig. 3). Anterograde tracing with 3 H-leucine from the superior cervical ganglion showed labelled sympathetic nerve fibres in the pterygopalatine ganglion. In the trigeminal ganglion, sympathetic fibres were found to course directly adjacent to ganglion cell bodies, indicating that apart from passing sympathetic fibres, sympathetic terminals may exist in the trigeminal ganglion. Labelled fibres were never found in the ciliary ganglion. Regarding the innervation of the anterior eye segment, labelled fibres were found in the iris and cillary body. Only few labelled fibres were observed in the trabeculum. Although labelled fibres were found in the sclera, labelling was never observed in the cornea. 


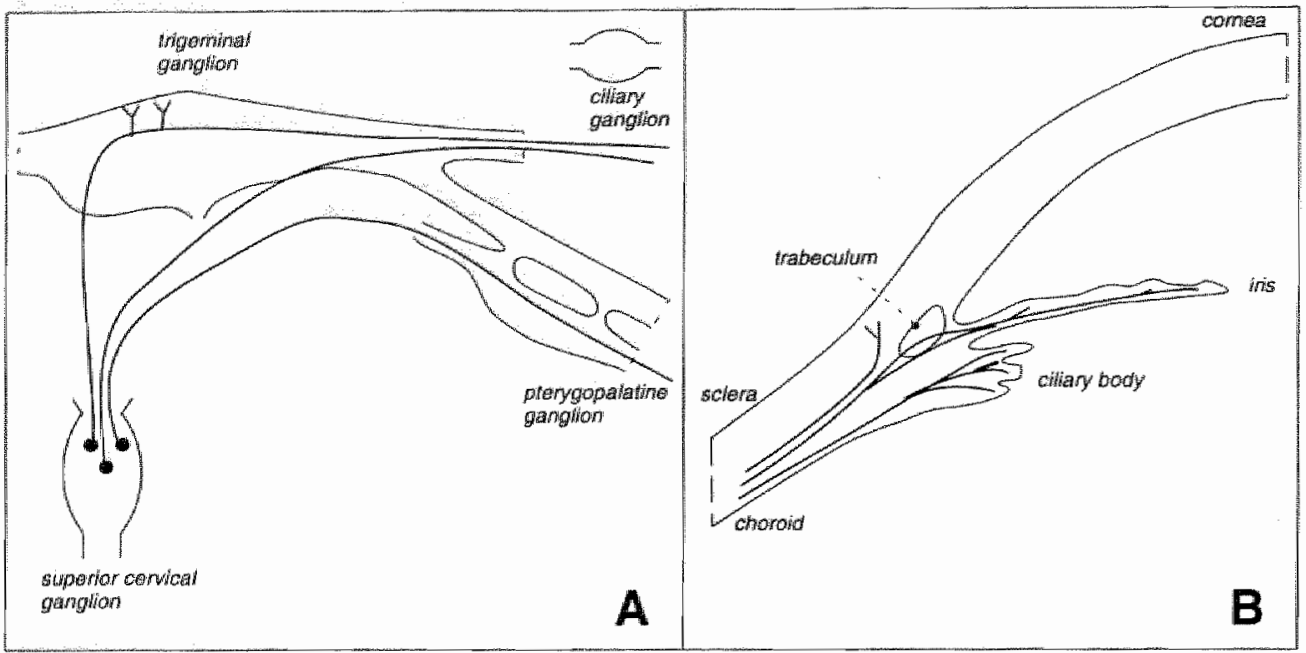

Fig. 3: Schematic drawing of the sympathetic inmervation of the eye related peripheral ganglia (A) and the anteriar eye segment (B) (modified after ten Tusscher ${ }^{113}$ ).

The absence of a sympathetic innervation of the cornea is in contradiction with earlier mainlly light microscopic tracing studies from the superior cervical ganglion using HRP and WGA-HRP labelling in rats and cats ${ }^{64,68}$. This contradiction may well be of methodological origin. Labelling obtained with autoradiography represents exclusive anterograde transport of 3 H-proteins. Tracing with HRP and WGA-HRP has the drawback of uptake of the tracer by terminals and passing fibres at the injection site. Histofluorescence studies ${ }^{11}$ have described catecholaminergic fibres in the cornea. These catecholaminergic nerve fibres were supposed to be of sympathetic origin. It has been demonstrated, however, that primary sensory neurons express catecholaminergic characteristics in rats ${ }^{35}$. In a recent study it has been hypothesized that catecholaminergic sensory fibres regulate sensory transmission through the dorsal horm of cats $^{7}$. Thus, the catecholaminergic fibres in the cornea may well be of sensory origin.

The finding of sympathetic fibres in the trigeminal and pterygopalatine ganglion 113 is unprecedented. Although synaptic contacts are suggested in that study by the finding of isolated nerve fibres in close proximity to cell bodies in the trigeminal ganglion, no symapses have ever been described in the trigeminal ganglion 50 .

Serotonin-immunoreactive nerve fibres have been found in the cat trigeminal ganglion ${ }^{6}$, with varicosities surrounding non-immunoreactive trigeminal cell bodies. No cell bodies in the trigeminal ganglion were serotonin-immunoreactive, which implies that the serotonin-immunoreactive nerve fibres are of an extra-ganglionic source. It has been suggested that sympathetic serotonergic fibres could modulate trigeminal sensory fibres following irritative stress ${ }^{38}$. 
In the pterygopalatine ganglion, trigeminal fibres closely associate with ganglion cells, forming basket-like arrangements ${ }^{108}$, indicating a regulatory loop between the sensory and the parasympathetic system. Since sympathetic fibres were found to traverse the pterygopalatine ganglion, it remains to be elucidated whether sympathetic fibres influence the parasympathetic system as well.

There is evidence that neuropeptide $Y$ (NPY) is preferentially expressed in noradrenergic sympathetic neurons $57,58,59$. At the light microsicopical level, NPY-immunoreactive neurons have been demonstrated in the superior cervical ganglion ${ }^{85}$. NPY-containing neurons are abundant in the rat pterygopalatine ganglion $40,45,105$. Numerous NPY-immunoreactive cells also contained immunoreactivity to choline acetyltransferase (ChAT), suggesting that they are cholinergic. Vasoactive intestinal polypeptide (VIP) is preferentially expressed in cholinergic neurons and has been demonstrated in cell bodies of the pterygopalatine ganglion ${ }^{56}$. NPY coexists with VIP and acetylcholine in parasympathetic cerebrovascular nerves originating in the pterygopalatine ganglion ${ }^{105}$. The functional significance of the colocalization of the vasoconstrictor NPY" with two vasodilatators, acetylcholine and VIP, remains unclear.

At the ultrastructural level, mainly catecholaminergic fluorescence studies and degeneration studies on the mammalian iris innervation have been published. It has been shown that catecholamine-fluorescent nerve fibres of superior cervical origin 14 enter the iris from the choroid membrane through the ciliary body, branch and give rise to a plexus of terminals in the areas of the dilator and sphincter muscles $12,63,76$. Terminals were found in close apposition to the smooth muscle cells of the dilator and sphincter muscles $27,28,29,70$. In addition, terminals are located in close proximity to blood vessels. Adrenergic terminals were also found in close apposition to the iridic melanocytes ${ }^{13,27}$. It has been suggested that there are axo-axonal contacts between adrenergic and cholinergic nerve terminals in the iris ${ }^{15}$.

The deep cillary cleft found in rodents is different from the shallow trabecular meshwork found in primates ${ }^{44}$. Adrenergic neve terminals have been described for the trabecular meshwork of primates, but differences were found regarding the number and distribution of these terminals ${ }^{73,92,101,104}$.

The enzyme tyrosine hydroxylase (TH) is a specific marker for adrenergic nerves. It is rate-limiting in the biosynthesis of catecholamines. At the light microscopical level, a dense TH-immunoreactive fibre plexus has been found to exist in the iris ${ }^{4}$. One day after removal of the superior cervical ganglion. TH immunoreactivity in the iris disappears almost completely. The distribution and the amount of TH-immunoreactive fibres appeared to be identical to the noradrenaline- containing nerve fibres in the iris, as demonstrated by catecholaminergic fluorescence studies. The ciliary body and the choroid membrane also are densely innervaled by TH-immunoreactive nerve fibres. 
At the lighit microscopical level, in addition to the described noradrenergic nerve plexus in the Iris, a system of catecholaminergic nerve fibres has been described in the iris that remained after total superior cervical ganglionectomy 7 . Since these fibres disappear after lesions of the trigeminal ganglion, a sensory origin has been suggested for these fibres.

Light microscopic immunohistochemistry using antibodies raised against NPY also revealed a dense fibre plexus in the rat iris and choroid membrane $4,109,118$. The distribution of the NPY immunoreactivity showed great similarities to the distribution of fibres found with TH mmunohistochemistry and catecholaminergic histofluorescence, although the total number of fibres and the staining intensity was found to be somewhat lower. An explanation for this might be the observation that not all catecholaminergic cell bodies in the superior cervical ganglion contain NPY58. After removal of the superior cervical ganglion, however, approximately $99 \%$ of the NPY-immunoreactive nerve terminals disappear. NPY has been described to potentiate noradrenergic vasoconstriction 10,16 and to potentiate contractions of the isolated rabbit iris dilator muscle ${ }^{79}$.

Recently, it has been demonstrated that NPY is a potent inhibitor of C-AMP accumulation in the rabbit iris, ciliary body, cillary processes and epithelium ${ }^{34}$. Similar inhibition of c-AMP by NPY has been described in severall tissues, including blood vessels ${ }^{19}$. NPY depresses the synaptic release of rioradrenaline from intraocular sympathetic nerves ${ }^{74}$. Several potential roles for NPY in the anterior uwea have been suggested. NPY could function as a feedback modulator of sympathetic neurotransmission, mediating inhibition of noradrenaline release and inthibition of B-adrenergic (C-AMP-dependent) responses of target cells. C-AMP is involved in the relaxation of muscles. Therefore, the NPY-mediated reduction of c-AMP might account for the potentiating effects of NPY on noradrenergic ( $\alpha$-adrenergic) contractions of the dilator pupillae and vascular smooth muscle. It has been proposed that a prominent feature of the mechanism of action of adrenergic agents in lowering aqueous humour formation and IOP is the stimulation of the adenylate cyclase complex in the cillary epithelium ${ }^{95}$. Inhibitory NPY receptors exist in the isolated rabbit ciliary epithelium. This suggests a direct role for NPY in aqueous humour regulation.

\section{The parasympathetic innervation}

The parasympathetic innervation of the ariterior eye segment is supplied by nerve fibres running along with the oculomotor nerve. In addition to this pathway, a parasympathetic nerve supply by nerve fibres running along with the facial nerve has been found to exist $51,88,89,90$ The latter parasympathetic nerve fibres form synaptic contacts on ganglion cells in the pterygopalatine ganglion.

In comparison to the sympathetic and sensory innervation, the parasympathetic innervation of the anterior eye segment has been studied less well. The pterygopalatine and ciliary ganglia are smail and have been described to contain passing sensory and sympathetio nerve fibres 
in dogs and primates $9,25,91$ which makes tracing studies and degeneration experiments technically difficult and non-selective in determining parasympathetic nerve fibres.

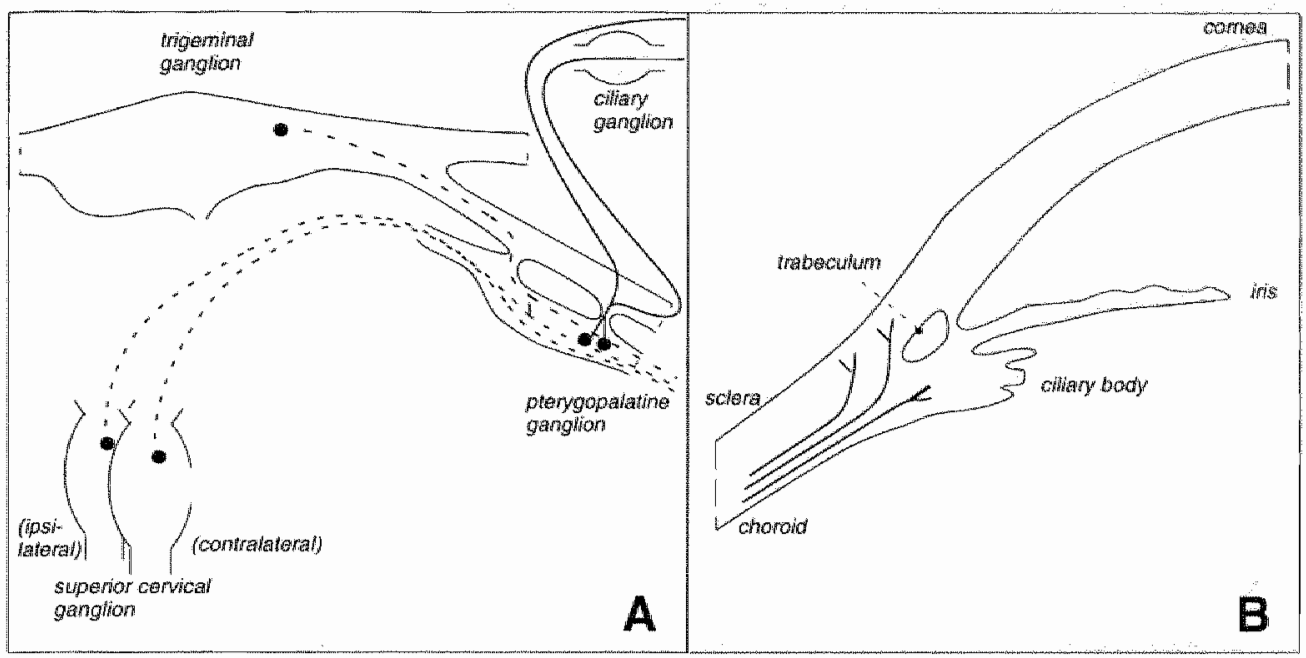

Fig. 4: Schematic drawing of the parasympathetic innervation of the eye related peripheral ganglia (A) and the anterior eye segment ( $(B)$ (modified after ten Tusscher ${ }^{113}$ ).

Recently ${ }^{113}$, retrograde and anterograde light microscopic tracing studies from the pterygopalatine ganglion in rats were summarized (Fig. 4). Anterograde tracing with ${ }^{3} \mathrm{H}$-leucine from the pterygopalatine ganglion showed labelled parasympathetic nerve fibres in the cillary ganglion and the eye. In the eye, labelled fibres were found in the conjunctiva, the limbic area and the choroid (Fig. 4B). Retrograde tracing with WGA-HRP showed a projection from the ipsilateral trigeminal and the ipsilateral and contralateral superior cervical ganglion to the pterygopalatine ganglion (dashed lines) (Fig. 4A).

The finding of a projection from the contralateral superior cervical ganglion to the pterygopalatine ganglion was not confirmed in an anterograde tracing study using ${ }^{3}$ H-leucine ${ }^{113}$ from the superior cervical ganglion. The contrallateral labelling found in the WGA-HRP study may have been the result of uptake of tracer by passing fibres.

The pterygopalatine ganglion consists of a rostral triangular cell mass with numerous additional perikarya in the nerve fibres extending from the ganglion entering the orbit, and perikarya surrounding the major petrosal nerve up to the level of the trigeminal ganglion. Retrograde tracing with WGA-HRP 113 from the lacrimal gland and from the arterior eye segment showed a somatotopical organization along the rostral-caudal axis of the pterygopalatine ganglion. Pterygopalatine somata projecting to the lacrimal gland were exclusively located in the distal cell mass, whereas somata projecting to the anterior eye 
segment were found in the proximal extension between the distal cell mass and the trigeminal ganglion. Both areas of cell bodies were found to project to the coniunctiva.

In addition to the already mentioned projections, fibres of pterygopalatine origin project to the nasial and palatal mucous membrane, and to the cerebral blood vessels. Nerve fibres supplying the cerebral blood vessels contain VIP and ChAT' ${ }^{107}$. Selective postganglionic stimulation of the parasympathetic nerve fibres has been shown to cause markedly increased blood flow in the brain 06 . Since atropine and scopolamine did not alter this increase in flow, it was suggested that this neurogenic inflammation most likely is not the resuit of release of acelylcholine from the parasympathetic nerve endings, but probably is due to the liberation of VIP and/or some other vasodilative agents stored in these neves.

VIP-immunoreactive fibres have also been demonstrated in the choroid, the posterior third of the ciliary muscle and the ciliary processes of cats ${ }^{114}$. Since pterygopalatine ganglionectomy resulted in the disappearance of all VIP-immunoreactive fibres, these fibres are most likely of pterygopalatine origin. SP and CGRP-immunoreactive trigeminal fibres form basket-like arrangements around VIP - and ChAT-immunoreactive pterygopalatine ganglion cells ${ }^{108}$, indicating a regulatory loop between the sensory and the parasympathetic system. It may thus be hypothesized that parasympathetic pterygopalatine ganglion neurons projecting to the choroid are sensory modulated, with the suggestion of VIP acting as a neurotransmitter or neuromodulator in this pathway. However, VIP-immunoreactive nerve fibres have also been described to originate in the ciliary ganglion of rats ${ }^{41}$ and in the choroid of guinea pigs ${ }^{111}$.

In the rabbit eye, intravitreous injections of VIP have been described to cause a reduction in intraocular pressure67. The ciliary processes contain VIP binding sites and show a significant adenylate cyclase activity in response to VIP. This activity is located on the nonpigmented epithelial cells, occurring in membranes together with B-adrenergic receptor-coupled adenylate cyclase. Together with the immunocytochemical findings of VIP-immunoreactive nerve fibres in cillary processes, it was suggested that endogenous VIP may participate in the regullation of IOP at the level of the ciliary epithelial cell. However, vascullar mechanisms could also play a role in the IOP changes. Intravenous injection of VIP has been described to cause an increase in choroidal blood flow that was associated with a rise in IOP71. High doses of VIP introduced directly into the anterior chamber have been reported to cause a rise in IOP associated with breakdown of the bload-aqueous barrier ${ }^{72}$.

It has been shown that a number of neurons located in the parasympathetic Edinger-Westphal nucleus (EW), located in the midbrain, project to the ciliary ganglion via the oculomotor nerve. Additionally, neurons located in the periaquaductal gray and the ventral tegmental area have been found to project to the ciliary ganglion $53,54,102$. In turn, the cillary ganglion inmervates the ciliary body, the iris sphincter muscle, and the smooth muscle of choroidal blood
vessels $65,80,82$. 
Apart from projecting to the ciliary ganglion. EW neurons have been light microscopically described to project to the spinal cord, the cerebellum and several brainstem nuclei, including the dorsal accessory olive and the caudal division of the trigeminal complex $5,53,62,67,103$.

In pigeons, the EW is a well-defined structure in the dorsal mesencephalon. Therefore, studies regarding the EW have mainly been performed in this species. On the basis of cell size and morphology, the EW of pigleons can be divided into a medial (EW/M) and a lateral (EWI) part 21,22 . The cells of the lateral part contain larger and more spherical cells than the mediall subdivision. Both parts project to the ciliary ganglion 61,69 . Cells in EWI project to the neurons of the ciliary ganglion that innervate the iris sphincter muscle and the ciliary body, whereas cells in EWm project to the ciliary ganglion neurons that innervate choroidal blood vessels ${ }^{84}$. Thus neurons in the EWI mediate pupilloconstriction and accommodation, whereas neurons in the EWm modulate choroidal blood flow.

In the avian ciliary ganglion, two morphologically distinct types of preganglionic nerve endings have been observed at the light microscopical level ${ }^{83}$. Boutonal nerve endings synapse on ciliary ganglion cells innervating choroidal blood vessels. These boutonal nerve endings originate from EWm neurons and have been described to contain SP, leucine-enkephalin (LENK) and acetylcholine. Capulike nerve endings synapse on ciliary ganglion cells innervating the iris and ciliary body. The cap-like nerve endings originate from EWI neurons and consist of three distinct subgroups: nerve endings containing SP, LENK and acetylcholine "nerve endings containing SP and acetylcholine, and nerve endings solely containing acetylcholine. The diversity of these neurons may be related to the fact that some neurons innervate the iris and other the ciliary body.

It is not clear whether mammals possess a subdivision of the EW that is comparable to the EWm in the pigeon. However, physiological studies have shown that clear increases in choroidal blood flow occur following electrical stimulation of the EW or oculomotor nerve 23,97 . Additionally, it is likely that some accommodation-related midbrain cells project monosynaptically to the EW of primates 20 . The absence of a clear, separate choroidal subdivision of the mammalian EW that corresponds to the avian EWm may result from the fact that all the cells in the mammalian ciliary ganglion innervate smooth muscles. In birds, cillary neurons innervate striated muscle, whereas choroldal neurons innervate smooth muscles ${ }^{80}$.

\section{Aim and scope of the present study}

The recent results regarding the innervation of the anterior eye segment and the interganglionic circuitry can be summarized as follows ${ }^{113}$ (Fig. 5). Sensory trigeminal nerve fibres (interrupted lines) project to the sensory nodose ganglion and the parasympathetic pterygopalatine ganglion (Fig. 5A). Within the anterior eye segment, trigeminai nerve fibres were found in the cornea, the iris, the anterior stroma of the ciliary body and the conjunctiva. 
Most sensory nerve fibres course through the trabeculum. Sympathetic nerve fibres (uninterupted lines) originating from the superior cervical ganglion traverse the trigeminal ganglion and the pteryopalatine ganglion, with the possibility of forming synaptic contacts in the trigeminal ganglion. Within the pterygopalatine ganglion, nerve fibres originating from both the ipsilateral and contralateral superior cervical ganglion were found. Sympathetic nerve fibres were found in the ciliary body, the rils, the conjunctiva and, only occasionaliy, in the trabeculum (Fig. 5B). Parasympathetic nerve fibres (dashed lines), originating from the pterygopalatine ganglion, project to the ciliary ganglion, the choroid, the limbic area and the conjunctiva.

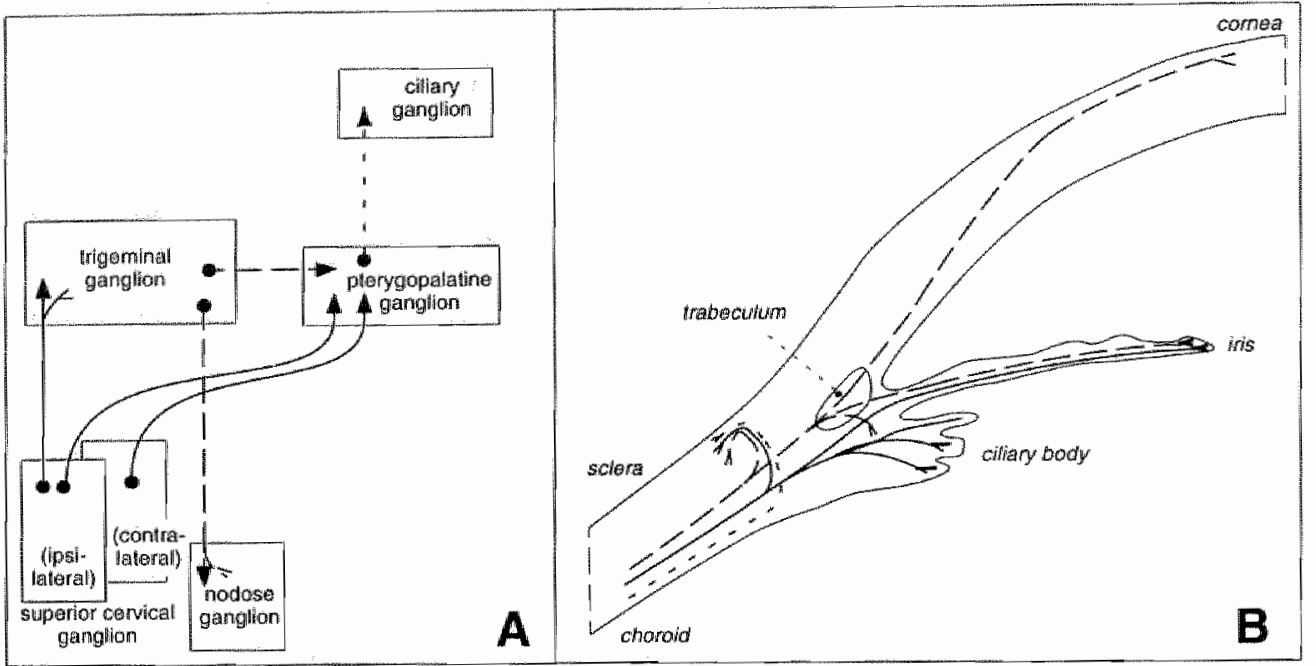

Fig. 5: Schematic drawing of the interganglionic circuitry (A) and the innervation of the ainterior eye segment (B) (modified after ten Tusscher ${ }^{14}$ ).

Light microsicopic tracing studies have the limitation that they cannot prove whether distinct peripheral nerve tibres in the peripheral ganglia only pass these ganglia on the way to target structures, or also symaptically innervate ganglion cell bodies. Moreover, it is still unclear whether the sensory trigeminal and nodose ganglia contain synaptic contacts. Up till now, symaptic contacts were never found in the trigeminal ganglion. Recently, synaptic contacts have been described in the nodose ganglion of primates 52 . It also remains unclear where nerve terminals from sensory, sympathetic or parasympathetic origin are localized within the anterior eye segment. In addition, their ultrastructure has to be determined.

In the present study, electron microscopic anterograde tracing was performed to determine whether sensory and autonomic nerve tibres synaptically innervate peripheral ganglia. Funthemore, the ultrastructure of these nerve terminals was investigated. Regarding the innervation of the anterior eye segment, ultrastructural anterograde tracing was performed to 
investigate the exact localization and ultrastructure of sensory and autonomic nerve terminals innervating the different structures of the anterior eye segment. In these terminals, several neuropeptides likely serve as neurotransmitters. Therefore, in addition to the tracing studies, immunohistochemical studies were undertaken at the ultrastructural level to investigate the presence and localization of the neuropeptides SP, CGRP and VIP in peripheral nerve fibres and terminals innervating the anterior eye segment and peripheral ganglia. 


\section{REFERENCES} and capsaicin in the rat eye. Acta Physiol Scand 1987; 131:371-376.

Bill $A_{i}$ Stjemschantz $d$, Mandahl $A$, Brodin $E$, Nisson $G$ : Substance P: release on trigeminal nerve stimulation, effects in the eye. Acta Physiol Scand 1979; 106: 371-373.

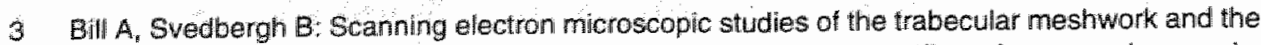
canal of Schlemm - an attempt to localize the main resistance to outflow of aqueous humour in man. Acta Ophthalmol 1972; 50: 295-320.

4 Björklund $H$, Hôkfelt $T$, Goldstein $M$, Terenius L, Olson L: Appearance of the noradrenergic markers tyrosine hydroxylase and neuropeptide $Y$ in cholinergic nerves of the iris following sympathectomy. J Neurosci 1985; 5: 1633-1643.

5 Burde $\mathrm{AM}$ : Parelman Jil, Luskin M: Lack of unity of Edinger-Westphal nucleus projections to the ciliary ganglion and spinal cord: a double-tabeling approach. Brain Res 1982; 249: 379-382.

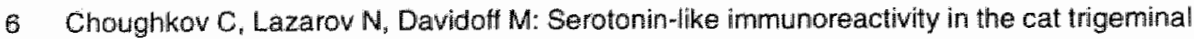
ganglion. Histochemistry 1988; 88: 637-639.

7 Doyle CA, Maxwell D.: Catecholaminergic innervation of the spinal dorsal horn: a correlated light and electron microscopic analysis of tyrosine hydroxylase-immunoreactive tibres in the cat. Neuroscience $1991 ; 45 ; 161-176$.

8 Duke-Elder S, Leigh AG: Neurotrophic keratitis. In: Duke-Elder (Ed), System of Ophthalmology Vol. VIII, Kimpton, London, 1965, pp. 803-810.

9 Duke-Elder S, Wybar KC: The autonamic system. In: Duke-Elder (Ed.), System of Ophthalmalogy Voll. II, Kimpton, London, 1961, pp. 805-874.

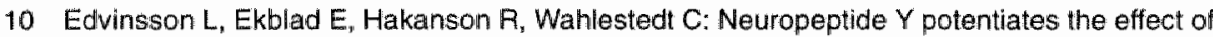
various vasoconstrictor agents on rabbit blood vessels. Br J Pharmacol 1984; 83: 519-525.

11 Ehinger B: Ocular and orbital vegetative nerves. Acta Physiol Scand (Suppl.) 1966; 67: 1-35.

12 Ehinger B, Falck B: Concomitant adrenergic and parasympathetic fibres in the rat iris. Acta Physiol Scand 1966; 67: 201-207.

13 Ehinger B, Falck B: Innervation of iridic melanophores. Z Zellforsch 1970; 105: 538-542.

14 Ehinger $B$, Falck $B$, Rosengren $E$ : Adrenergic denervation of the eye by unilateral cervical sympathectomy. Albr v Graefes Arch Klin Exp Ophthalmol 1969; 177: 206-211.

15 Ehiriger B. Falck B, Sporrong B: Possible axo-axonal synapses between peripheral adrenergic and cholinergï nerve terminalls. $Z$ Zellitorsch $1970 ; 107: 508-521$.

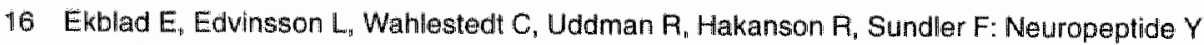
co-exists and cooperates with noradrenaline in perivascular nerves. Regul Pept 1984; 8: 225-235.

17 Ekbom $K_{n}$ Hardebo JE, Waidenlind E: Mechanisms of cluster headache. In: Olesen J and Edvinsson L. (Eds.), Basic Mechanisms of Headache. Elsevier, Amsterdam, 1988, pp. 463-476.

18 Fiügal $C$, Tamm E, Lütjen-Drecoll E: Different cell populations in bovine trabecular meshwork: an ultrastructural and immunohistochemical study. Exp Eye Res 1991; 52: 681-690.

19 Fredholm BB, Jansen I, Edvinsson L: Neuropeptlde Y is a potent inhibitor of cyclic AMP accumulalion in feline blood vesseis. Acta Physiol Scand 1985; 124: 467-469.

20 Gamlin PDR, Reiner A: The Edinger-Westphal nucleus: sources of input influencing accommodation, pupilloconstriction, and choroidal blood flow. J Comp Neurol 1991; 306: 425-438.

21 Gamlin PDR, Reiner A, Karten HU: Substance P-containing neurons of the avian suprachiasmatic nucleus project directly to the nucleus of Edinger-Westphal. Proc Natl Acad Sci 1982; 79 : $3391-3895$ 
22 Gamlin PDR, Reiner A, Erichsen JT, Cohen DH, Karten Hy: The neural substrate for the pupthary light reflex in the pigeon (Columba ifva). J Comp Neurol 1984: 226: 523-543.

23 Gherezghiser $T$, Hey J, Koss M: Cholinergic contral of intracoular pressure. Invest Ophthalmol vis Sci 1989; 30 (suppli.): 20.

24 Gloster $J$, Greaves DP: Effect of diencephalic stimulation upon intraocular pressure. Brit d Ophthalmol 1957; 41:513-532.

25 Hara $S$, Kobayashi S, Sugita K, Tsukahara S: Innemation of dog ciliary ganglion. Histochemistry 1982; 76: 295-301.

26 Hardebo JE: The involvement of trigeminal substance P neurons in cluster headache. An hypothesis. Headache 1984; $24: 294-304$.

27 Hedlund $\mathrm{K}-\mathrm{O}$, Ayer-Lelievre $\mathrm{C}$, Björklund $\mathrm{H}$, Hultgren L, Seiger A: Ultrastructural and histochemical studies of the rat iris: identified neuronal inputs and supportive glia. $J$ of Neurocytol 1984; 13: $703-725$.

28. Hökfelt T: Electron microscopic observations on nevve terminals in the intrinsic muscles of the albino rat iris. Acta Physiol Scand 1966; 67: 255-256.

29 Hökfelt $T$, Nilsson $O$ : The relationship between nerves and smooth muscle cells in the rat Iris. II. The sphincter muscle. Z Zellforsch 1965; 66: 848-853.

30 Holzer P: Local effector functions of capsaicin-sensitive sensory nerve endings: involvement of tachykinins, calcitonin gene-related peptide and other neuropeptides. Neuroscience 1988; 24: $739-768$.

31 Hoyes $A D$, Barber $P$ : Ultrastructure of the corneal nerves in the rat. Cell Tissue Res 1976; 172: $133-144$.

32 Hurvitz LM, Kaufman PL, Robin AL, Weinreb RN, Crawford K, Shaw B: New developments in the drug treatment of glaucoma. Drugs 1991; 41: 514-532.

33 Jones MA, Marfurt CF: Calcitonin gene-related peptide and corneal innervation: a developmental study in the rat. J Comp Neurol 1991; 313: 132-150.

34 Jumblatt JE, Gooch JM: Neuropeptide $Y$ modulates adlenylate cyclase in the rabbit iris, ciliary body and ciliary epithelium. Exp Eye Res 1990; 51:229-231.

35 Katz DM, Adler JE, Black IB: Catecholaminergic primary sensory neurons: autonomic targets and mechanisms of transmitter regulation. Federation Proc 1987; 46: 24-29.

36 Konishi $\mathrm{S}$, Tsunoo $\mathrm{A}$, Yanaihara $\mathrm{N}_{n}$ Otsuka $\mathrm{M}$ : Peptidergic excitatory and inhibitory synapses in mammalian sympathetic ganglia: roles of substance $P$ and enkephalin. Biomed Fes 1980; 1: 528-536.

37 Krootila K: CGRP in relation to neurogenic inflammation and C-AMP in the rabbit eye. Exp Eye Res $1988 ; 47: 307-316$.

38 Krootila K, Uusitalo $H$, Lehtosalo JI, Palkama A: Recovery of the blood-aqueous barrier after topical chemical irritation in the rabbit eye. Alb Grael Arch Clin Exp Ophthalmol 1987; 225: 272-276.

39 Kruger L, Mantyh PW, Sternini C, Brecha NC, Mantylh CR: Calcitonin gene-related peptide (CGIPP) in the rat central nervous system: patterns of immunoreactivity and receptor binding sites. Brain Res 1988; 463: 223-244.

40 Kuwayama $Y$, Emson PC. Stone RA: Pterygopalatine ganglion cells contain neuropeptide $Y$, Brain Ries 1988; 446: 219-224.

41 Kuwayarna $Y_{n}$ Grimes PA, Ponte $B$, Stone RA: Autonomic neurons supplying the rat eye and the intraorbital distribution of vasoactive intestinal peptide (VIP)-like immunoreactivity. Exp Eye Fos 1987; 44: 907-922.

42 Kuwayama $Y$, Stone RA: Distinct substance $P$ and calcitonin gene-nelated peptide immunoreactive nerves in the guinea pig eye. Invest Ophthalmol Vis Sci 1987; 28: 1947-1954. 


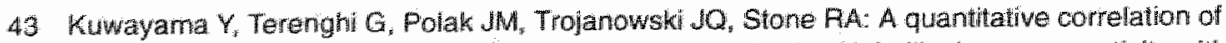
substance $P$. catcitonin gene related peptide-and cholecystokinin-like immunoreactivity with retrogradely labeled trigeminal ganghon cells innervating the eye. Brain Res 1987; 405: 220-226.

44 Lamers WPMA, De innervatie van het trabeculum comeosclerale. Ph-D thesis, Nimegen, Centrale Drukkeril, 1982.

45 Leblanc $\mathrm{GG}$. Trimmer BA, Landis SC. Neuropeptide Y-like immunoreactivity in ral cranial parasympathetic neurons: coexistence with vasoactive intestinal peptide and choline acetyltransterase. Proc Nall Acad Sci USA 1987; 84: 3511-3515.

46 Lee $Y$, Kawai $Y$, Shiosaka S, Takami K, Kyama H. Hilyard CJ, Girgis S, Macintyre I, Emson PC, Tohyama M: Coexistence of calcitonin gene-related peptide and substance P-like peptide in single cells of the trgeminal ganglion of the rat; immunohistochemical analysis. Brain Res 1985; 330; $194-196$.

47 Lehtosalo dl, Uusitalo H. Palkama A: Sensory supply of the anterior uwea: a light and electron microscope study. Exp Brain Fies 19B4; 55: 562-569.

48 Lehtosalo Jl, Uusitalo H, Uusitalo R. Poranen A, Palkama A: Electron microscopic identification of frigeminal merve fibers in the cilliary body and the iris. Neurosci Lett 1983; 42: 239-242.

49 Lepple-Wienhues A, Stah! F, Wiederholt M: Differential smoolt muscle-like contractile properties of trabecular meshwork and ciliary muscle. Exp Eye Res 1991; 53: 33-38.

so Liebermanm AR, Sensory ganglia. In: Landon DN (Ed.). The peripheral nerve. Chapman and Hall, London, John Wiley \&ons, inc, New York, 1976, pp. 188-278.

51 Lin T, Grimes A, Stone RA: Nerve pathways between the pterygopalatine ganglion and the eye in cats. Anat Rec 1988; 222: 95-102.

52 Ling $E-A$, Wong W-C: An electron microscopic study of the nodose (inferior vagall) ganglion cells in the monkey. J of Neurocytol 1988; 17: 845-857.

53 Loewy AD, Saper CB: Edinger-Westphal nucleus: projections to the brain stem and spinal cord in the cat. Biain Res 1978; 150: 1-27.

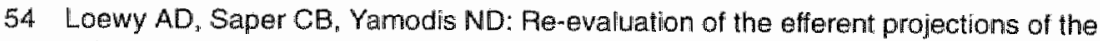
Edinger-Westphal nucleus in the cat. Brain Res 1978; 141: 153-159.

55 Luhtala 4 , Palkama A. Uusitalo $\mathrm{H}$ : Calcitonin gene-related peptide-immunoreactive nerve fibres in the rat conjunctiva. Inv Ophthalmol Vis Sci 1991; 32: 640-645.

56. Lundberg JM, Hökfeit T, Änggard A, Lvmäs-Wallensten K, Brimijoin S, Brodin E, Fahrenkrug d: Poripheral peptide neurons: distribution, axonal transport and some aspects on possible function. In: Costa E. and Trabucchi MM (Eds.), Neural peptides and neuronal communication, Raven Press, New York, 1980, pp. 25-36.

57 Lundberg $J M$, Terenius L. Hökfelt $T$, Goldstein M: High levels of neuropeptide $Y$ in peripheral noradrenergic neurons in various mammals including man. Neurosci lett 1983; 42: 167-172.

58. Lundberg JM, Terenius L, Hökfelt T, Martling CR. Tatemoto K, Mutt V. Polak J Bloom S, Goldstein M: Neuropeptide Y (NPY) like immunoreactivity in peripheral noradrenergic neurons and effects of NPY" on sympathetic tunction. Acta Physiol Scand 1982; 116: 477-480.

59 Lundbarg JM, Terenius L, Hokfelt T, Tatemoto K: Comparative immunohistochemical and biochemical analysis of pancreatic polypeptide-like peptides with special reference to presence of neuropeptide $Y$ in central and peripheral neurons. J Neurosci 1984; 4: 2376-2386.

60 Lütjen-Drecoll E. Rohen J: Morphology of aqueous pathways in normal and glaucomatous eyes. In:

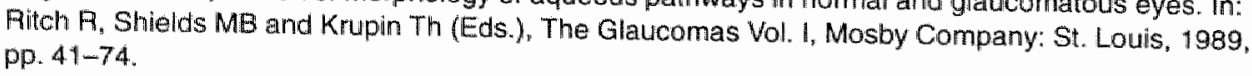

61 Lyman D, Mugnaini E: The avian accessory oculomotor nucleus. Soc Neurosci Abstr 1980; 6: 479.

62 Maciewicz R. Phipps BS, Gienier $₫$, Poletti CE: Edinger-Westphal nucleus: cholecystokinin immunocytochemistry and projections to spinal cord and trigeminal nucleus in the cat. Brain Fes $1984 ; 299: 139-145$. 
63 Maimfors T, Sachs $\mathrm{C}$. Direct demonstration of the system of ferminals belonging lo an individual adrenergic neuron and their distribution in the rat iris. Acta Phystol Scand 1965: 64: 377-382.

64 Marfurt CF: Sympathetic innervation of the rat cornea as cemonstrated by the retrograde and anterograde transport of horseradish peroxidase-wheatgerm agglutinin. J Comp Neurol 1988; 268: $147-160$.

65 Marwitt $R$, Pilar $G$, Weakly JN: Characterization of two ganglion cell populations in avian ciliary ganglion. Brain Res 1971; 25: 317-334.

66 Miller $A_{1}$ Costa M, Furness JB, Chubb IW: Substance P-immunoreactive sensory nerves supply the rat iris and cormea. Neurosici Lett 1981; 23: 243-249.

67 Mittag WT, Tormay A, Podos SM: Vasoactive intestinal peptide and intraocular pressure: adenylate cyclase activation and binding sites for vasoactive intestinal peptide in membranes of ocular cillary processes, J Pharmacol Exp Ther 1987; 241: 230-235.

68 Morgan C, DeGroal WC, Jannetta PJ: Sympathetic innervation of the cornea from the stuperior cervical ganglion. An HRP study in the cat. J Auton Nerv Syst 1987; 20: 179-183.

69 Narayanan $\mathrm{CH}$, Narayanan $\mathrm{Y}$ : An experimental inquiry into the central source of preganglionic fibers to the chick ciliary ganglion. I Comp Neurol 1976; 166:101-110.

70 Nilsson 0 : The relationship between nerves and smooth muscle cells in the rat iris. 1 . the dilator muscle. ZZ Zelliorsch 1964; 64: 166-171.

71 Nilsson SFE, Bill A: Vasoactive intestinal polypeptide (VIP): Effects in the eye and on regional blood flows. Acta Physiol Scand 1984; 121: 385-392.

72 Nishiyama A, Masuda K, Mashizuki M: Ocular effects of vasoactive intestinal polypeptide (Abstract no. 4). Invest Ophthalmol Vis Sci 1980; 20 (suppl.): 64.

73 Nomura T, Smeiser GK: The identification of adrenergic and cholinergic nerve endings in the trabecular meshwork. Inv Ophthalmol 1974; 13: 525-532.

74 Ohia $S E$, Jumblatt JE: Effect of neuropeptide $\gamma$ on norepinephrine release in the rabbit iris-ciliary body. Invest Ophthaimol Vis Sci 1989; 30 (suppl.): 21 .

75 Oksalla 0 , Stjernschantz $\mathrm{J}$ : Effects of calcitonin gene-related peptide in the eye. A study un rabbits and cats. Invest Ophthalmol Vis Sci 1988; 29: 1006-1011.

76 Olson L, Ayer-Le Lievre C, Björklund H, Ebendal T, Granholm A-Ch, Hedlund K-O, Hökfelt T, Melander T, Seiger A, Strömberg l: The innervation apparatus of the rodent iris, in: Bjorklund A, Hökfelt $T$ and Owman $C$ (Eds.), Handbook of chemicall neuroanatomy, Vol. 6 : The peripheral nervous system, Elsevier, Amsterdam, 1988, pp. 545-597.

77 Olson $L$, Seiger $A$, A system of atypical catechalamine-containing nerve fibres in the rat iris present after total superior cervical ganglionectomy. Med Biol 1980; 58: 94-100.

78 Osbome NN, Barnett NL: Calcitonin gene-related polypeptide stimulates C-AMP production in the iris/ciliary body complex. Exp Eye Res 1991; 53: 131-133.

79 Piccone M, Littzi J, Krupin T, Stone RA, Davis M, Wax MB: Eflects of neuropeptide $Y$ on the isolated rabbit iris dilator muscle. Invest Ophthalmol Vis Sci 1988; 29: 330-332.

BO Pilar G, Tuttle JB: A simple neuronal system with a range of uses: the avian ciliary ganglion. In: Goldberg $A$ and Hanin I (Eds.). "Progress in cholinergic biology: model cholinergic symapses, Raven Press, 1982, pp. 213-247.

81 Prechtl JC. Powley TL: B-afferents: A fundamental division of the nervous system mediating homeostasis? Behavioral and Brain Sci 1990; 13: 289-331.

82 Reiner A: The presence of substance P/CGRP-containing fibers, VIP-containing fibers and numerous cholinergic fibers on blood vessels of the avian choroid. Invest Ophthalmol Wis Sci 1987; 28 (suppl.): 81.

83 Reiner A, Erichsen JT, Cabot JB, Evinger C, Fitzgerald MEC, Karten HJ: Neurotransmilter organization of the nucleus of Edinger-Westphal and its projection to the avian cillary ganglion. Visual Neurosci 1991; 6: 451-472. 
84. Feiner Kanen HJ, Gamtin POA, Erichsen AT: Parasympathetic ocular control: Funcional subdivisions and circuitry of the avian nucleus of Edinger-Westiphal. Trends in Neurosci 1963; 6: $140-145$.

BS Reuss $\mathrm{S}_{\text {, Moore }} \mathrm{A}$ : Neuropeptide Y-containing neurons in the rat superior cervical ganglion: projections to the pineal gland. I Pineal Res 1989; 6:307-316.

86 Fonen , Futa $R_{v}$ Lutjen-Drecoll E: The Iine structure of the cribriform meshwork in normal and glaucomatous eyes. Inivest Ophthaimol Vis Sci $1981 ; 21: 574-585$.

87 Roste GK, Dietrichs E: Cerebellar contical and nuclear afferents from the Edinger-Westphal nucleus in the cat. Anat Embryol 1988; 178 : 59-65.

98 Rusikell GL: An ocular parasympathetic nerwe pathway of facial newe origin and its influence on intraocular pressure. Exp Eye Res 1970; 10:319-330.

89 Ruskell GL: The orbital branches of the pterygopalatine ganglion and their relationship with internal carotid nerve branches in primates. J Anat 1970; 106: 323-329.

90 Ruskell GL: Facial parasympathetic innervation of the choroidal blood vessels in monkeys. Exp Eye Res 1971: 12: 166-172.

91 Fuskell GL: Peripheral nerve analysis using Wallerian degeneration: nerves relating to the ciliary ganglion. Exp Eye Res 1974; 18: 417-418.

92 Ruskell GL: The source of nerve fibres of the trabeculae and adjacent structures in monkey eyes. Exp Eye Res 1976; $23: 449-459$

93 Schmerl E, Steinberg B: Separation of diencephalic centers concerned with pupillary motility and ocular tension. Am J Ophthal 1950; 33: 1379-1381.

94 Schuizer $M_{1}$ Drance SM, Carter CJ, Brooks DE, Douglas GR, Lau W: Biostatistical evidence for two distinct chronic open angle glaucama populations. B J Ophthaimol 1990; 74: 196-200.

95 Sears ML: Regulation of aqueous flow by the adenylate cyclase receptor complex in the ciliary epithelium. Am J Ophthalmol 1985; 100: 194-198.

96 Silverman JD, Kruger L: Calcitonin gene-related peptide immunoreactive innervation of the rat head with emphasis an specialized sensory structures. J Comp Neurol 1989; 280: 303-330.

97 Stjernschantz , Bill A: Effect of intracranial stimulation of the oculomotor nerve on ocular blood flow in the monkey, cat and rabibit. Invest Ophthalmol Vis Sci 1979; 18: 99-103.

98 Stone RA, Kuwayama $Y$ : The nervous system and intraocular pressure. In: Ritch R, Shields MB and Krupin Th (Eds.), The Glaucomas Vol. I, Mosby Company: St. Louis, 1989, pp. 257-279.

99 Stone RA, Kuwayama $Y$, Laties A: Regulatory peptides in the eye. Experentia 1987; 43: 791-800.

100 Stone RA, Kuwayama $Y$, Terenghi G, Polak JM: Calcitonin gene-related peptide: occurrence in coneal sensory nerves. Exp Eye Res 1986; 43: 279-283.

101 Stone RA, Laties AM: Neuroanatomy and neuroendocrinology of the chamber angle. In: Krieglstein GK (Ed.), Glaucomed Update III, Springer-Vertag, Berlin Heidelberg, 1987, pp. 1-16.

102 Sugimoto T, Itoh K, Mizuno N: Lacalization of neurons giving rise to the oculomotor parasympathetic outflow: a HRP study in cats. Neurosci Lett 1977; 7: 301-305.

103 Sugimoto $T$, Itoh $K_{2}$ Mizuno $N$ : Direct projections from the Edinger-Westphal nucleus to the cerebellum and spinal cord in the cat: an HRP study. Neurosci Lett 1978; $9: 17-22$.

104 Sugita A, Hisaharu Y: Nerve libers in trabecular meshwork surface. Jpn J Ophthalmol 1984; 28: 248-253.

705 Suzuki $N$. Hardebo JE, Kảhrström J, Owman C: Neuropeptide-Y co-exists with vasoactive intestinal polypeptide and acetylcholine in parasympathetic cerebrovascular nerves originating in the sphenopalatine, otic, and internal carotid ganglia of the rat. Neuroscience 1990; 36: 507-519.

106 Suzuki N, Hardebo JE Kährström J, Owman $\mathrm{C}$ : Selective electrical stimulation of postganglionic cerebrovascular parasympathetic nerve fibers originating from the sphenopalatine ganglion enthances cortical blood flow in the rat. J Cereb Blood Flow Metab 1990; 10: 383-391. 
107 Suzuki N, Hardebo JE, Owman Ch: Origins and pathways of cerebrovascular vasoactive intestinal polypeptide-positive nerves in rat. J Cereb Blood Flow Metab 1988; 8:697-712.

108 Suzuki $N$, Hardebo JE, Owman Ch: Trigeminal fibre collaterals storing substance $P$ and calcitonin gene-related peptide associate with ganglion cells containing choline acetyltransferase and vasoactive intestinal polypeptide in the sphenopalatine ganglion of the ral. An axon reflex modulating parasympathetic ganglionic activity? Neuroscience 1989; $30: 595-604$.

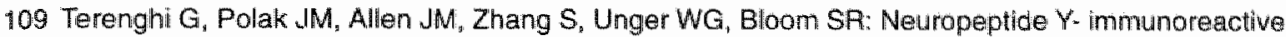
neves in the uvea of guimea pig and rat. Neuroscil Lett 1983; $42: 33-38$.

110 Terenghi G, Polak JM, Ghatei MA, Mulderiy PK Butter UM, Unger WG, Bloom SA: Distribution and origin of calcitonin gene-related peptide (CGRP) immunoreactivity in the sensory innervation of the mammalian eye. J Comp Neurol 1985; 233: 506-516.

111 Terenghi G, Polak JM, Probert L, McGregor GP, Ferri GL, Blank MA, Butler JM, Unger WG, Zhang $S$, Cole DF, Bloom SR: Mapping, quantitative distribution and origin of substance $\mathrm{Pa}$ and VIP.containing nerves in the uvea of guinea pig eye. Histochemistry 1982; 75: 399-417.

112 Tervo T, Joo F, Huikuri KT, Toth I, Palkama A: Fine structure of sensory neves in the rat cornea: an experimental nerve degeneration study. Pain 1979;6: 57-70.

113 Tusscher ten MPM: Peripheral ganglia and the eye, Ph-D thesis, 1989.

114 Uddman $\mathrm{F}_{1}$ Alumets $\mathrm{J}$, Ehinger $\mathrm{B}$, Håkanson $\mathrm{F}$, Lorến $\mathrm{I}$, Sundler $\mathrm{F}$ : Vasoactive intestinal peptide nerves in ocular and orbital structures of the cat. linvest Ophthalmol Vis Sci 1980; 19: 878-885.

115 Unger WG: Rewiew: Mediation of the ocular response to injury. J Ocular Pharmacol 1990; 6: $337-353$.

116 Uusitalo $\mathrm{H}$, Krootila $\mathrm{K}$, Palkama A: Calcitonin gene-related peptide (CGRP) immunoreactive sensory nerves in the human and guinea pig uvea and comea. Exp Eye Res 1989; 48:467-475.

117 Wahlestedt C, Beding B, Ekman R, Oksala O, Stjernschantz J, Håkanson R: Calcitonin gene-related peptide in the eye: release by sensory nerve stimulation and effects associated with neurogenic inflammation. Regul Pept 1986; 16: 107-115.

118 Zhang $S$, Terenghi $G_{n}$ Unger WG, Ennis KW, Polak J: Changes in substance $P$ - and neuropeptide $Y$-immunoreactive fibers in rat and guinea-pig irides following unilateral sympathectomy. Exp Eye Res 1984; 39: 365-372. 
Sensory Innervation 


\title{
Uitrastructural Identification of Trigeminal Nerve Terminals in the Pterygopalatine Ganglion of Rats:
}

\author{
An Anterograde Tracing and \\ Immunohistochemical Study
}

\section{Abstract}

Trigeminal nerve terminals in the rat pterygopalatine ganglion (PPG) were ultrastructurally identified using anterograde tracing with Phaseolus vulgaris-leucoagglutinin (PHA-L). Electron microscopic immunohistochemistry was used to demonstrate the presence of substance $P$ (SP) and calcitonin gene-related peptide (CGRP) in nerve terminals of the PPG.

Adjacent to the rostral part of the PPG an additional minor area was described. Perikarya in this minor rostral part were more spherical and had irregular outlines. Ultrastructurally, the glial enwrapment of the nerve terminals seemed to be more loosely arranged in compapison to that in the major rostral part of the PPG.

With PHA-L, numerous labelled nerve fibres and terminals were found in all parts of the PPG. The ultrastructure of these terminals was uniform, many of them showing synaptic contacts.

Numerous terminals in the PPG were SP-immunoreactive, whereas only a few were CGRP-immunoreactive. Fibres stained positive for both neuropeptides.

The PPG is shown to be synaptically innervated by sensory fibres arising in the trigeminal ganglion, with the strong suggestion of SP and CGRP acting as neurotransmitters. A modulatory interaction between the autonomic and sensory system, resembling an axon reflex mechanism in the peripheral nervous system is endorsed.

\section{Introduction}

The parasympathetic pterygopalatine ganglion (PPG) of rats is an elongated structure situated mediocaudal to the maxillary nerve. The ganglion consists of a rostral triangular cellular mass with numerous additional perikarya in the nerve fibres extending from the ganglion entering the orbit, and perikarya surrounding the major petrosal nerve up to the level of the trigeminal ganglion. The PPG is somatotopically organized along the rostral-caudal axis 40 .

In rats, preganglionic nerve fibres run from the ipsilateral salivatory nucleus, through the major petrosal and Vidian nerves ${ }^{36,40}$.

Pterygopalatine somata project to the secretory elements and blood vessels of the lacrimal glands, to the nasal and palatal mucous membrane, and to the cerebral blood vessels. Fibres originating from the PPG supplying the eye project to the choroid, the limbal area and the 
conjunctiva 28,40 . In the retrobubar structures adjacent to the optic nerve, small fibres pass through the cillary ganglion ${ }^{40}$.

Nerve fibres supplying the cerebral blood vessels have been shown to contain vasoactive intestinal polypeptide (VIP) and choline acetyltransferase (ChAT) 33,34 . in the choroid of cats, VIP-like inmunoreactive fibres were found ${ }^{43}$.

Sympathetic nerve fibres, originating in the psilateral and contralateral superior cervical ganglion, have beer described in the $\mathrm{PPG}^{39}$. Sensory nerve fibres originating from the ipsilateral ophthalmo-maxillary compartment of the trigeminal ganglion have been demonstrated in the PPG by light microscopic anterograde and retrograde tracing studies $34,38,40$.

The sensory nerve fibres are localized in both the rostral cell mass and the caudal string of cells of the PPG. Trigeminal fibre collaterals closely associate with VIP-and ChAT-immunoreactive ganglion cells in the pterygopalatine ganglion. where they form basket-like arrangements. These fibres contain substance P (SP) and calcitonin gene-related peptide (CGRP) ${ }^{34}$. A small population of CGRP-immunoreactive cells has been described in the PPG in one light microscopic study 30 , which was not confirmed by other light microscopic studies 34,35 . Only few SP-immunoreactive cells have been demonstrated in the PPG 34,35

The existence of a direct synaptic relation between sensory nerves of trigeminal origin and parasympathetic neurons, as suggested by the light microscopical observations ${ }^{34}$, would indicate a regulatory loop between the sensory and parasympathetic system. To prove this, Phaseolus vulgaris-leucoagglutinin (PHA-L) was injected into the trigeminal ganglion and the distribution of the tracer in sensory merve terminals in the PPG was studied at the ultrastructural level.

The number of SP- and CGRP-immunoreactive somata in the trigeminal ganglion ${ }^{18}$ and the presence of numerous SP- and CGRP-immunoreactive fibres in the PPG ${ }^{34}$ suggest that SP and CGRP could serve as neurotransmitters. To further elaborate this, the localization of SP and CGPP in the PPG was studied ultrastructurally using immunohistochemical methods.

\section{Materials and Methods}

Thirteen adult male Wistar rats, weighing between 200 and $300 \mathrm{~g}$, were used.

\section{PHA-L tracing experiments}

Five animals were anaesthetized with Nembutal $0.3 \mathrm{ml} / \mathrm{kg}$ i.p. (Rousselot, Paris, France) and Hypnorm $0.3 \mathrm{ml} / \mathrm{kg}$ i.m. (Janssen. Tilburg, The Netherlands). The rats were placed in a stereotaxic frame. After dissection of the calvarium and dura mater, a small part of the parietal 
contex covering the anterior part of the trigeminal ganglion was removed by suction. Injections were placed in the antero-median comparment of the left trigeminal ganglion. A $2.5 \%$ solution of PHA-L (Vector, Burlingame, CA) in sodium phosphate-bufferred saline, pH 8, was injected iontophoretically $(6.5-7.5 \mu \mathrm{A}, 20 \mathrm{~min})$ using glass micropipettes with an inner tip diameter of 20 $\mu \mathrm{m}$.

Following a 6-8 day survival period, the animals were killed with an overdose of Nembutal and transcardially perfused with $150 \mathrm{ml}$ phosphate-buffered saline (PBS) followed by 1 liter fixative containing $2.5 \%$ glutaraldehyde and $1 \%$ paraformaldehyde in $0.05 \mathrm{M}$ phosphate buffer, $\mathrm{pH} 7.4$. at room temperature.

\section{SP and CGRP immunohistochemistry}

Eight animals were killed with an overdose of Nembutal and transcardially perfused with 150 $\mathrm{ml}$ PBS followed by 1 liter fixative containing $2.5 \%$ glutaralidehyde (CGRP) or $4 \%$ paraformaldehyde (SP), in $\mathrm{PBS}_{\text {, }} \mathrm{pH} 7.4$, at room temperature.

The heads were postfixed overnight in the same fixative. The trigeminal ganglia and the pterygopalatine ganglia were dissected and rinsed in PBS. The tissues were sectioned at 20-50 $\mu \mathrm{m}$ thickness in a freezing microtome. Subsequently, the sections were transferred into the diluted primary antisera containing $0.05 \%$ Triton $X-100$ (anti-PHA-L (Vector): 1/2000, anti-CGRP (Cambridge Research Biochemicals): 1/2000 and anti-SP (Serva): 1/1000) and incubated free floating for one night at room temperature, or one weekend at $4^{\circ} \mathrm{C}$.

The peroxidase-antiperoxidase method was used to visualize the antigens ${ }^{46}$. The sections were incubated in $0.05 \%$ w/v diaminobenzidine (DAB) in Tris-buffered saline (TBS), pH 7.6 , supplemented with $0.01 \%$ hydrogen peroxide $\left(\mathrm{H}_{2} \mathrm{O}_{2}\right)$ for 10 minutes. After rinsing in TBS, the $\mathrm{DAB}$ reaction product was intensified with a gold-substituted silver peroxidase technique 26 . The sections were pastfixed in $1 \%$ osmium tetroxide $\left(\mathrm{OsO}_{4}\right)$ supplemented with $11 \%$ potassium

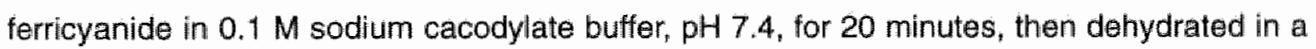
graded series of ethanols and flat embedded in epoxy resin. Control experiments were carriled out in which the incubation in the primary antisera was left out of the procedure.

In the sections, nerve fibres containing peroxidase were localized light microscopically after which these areas were cut out and mounted on prepolymerized epoxy resin blocks. Finally. ultrathin sections were cut and stained with uranyl acetate and lead citrate. These sections. were studied in Philips EM 400 and EM 201 electron microscopes. 

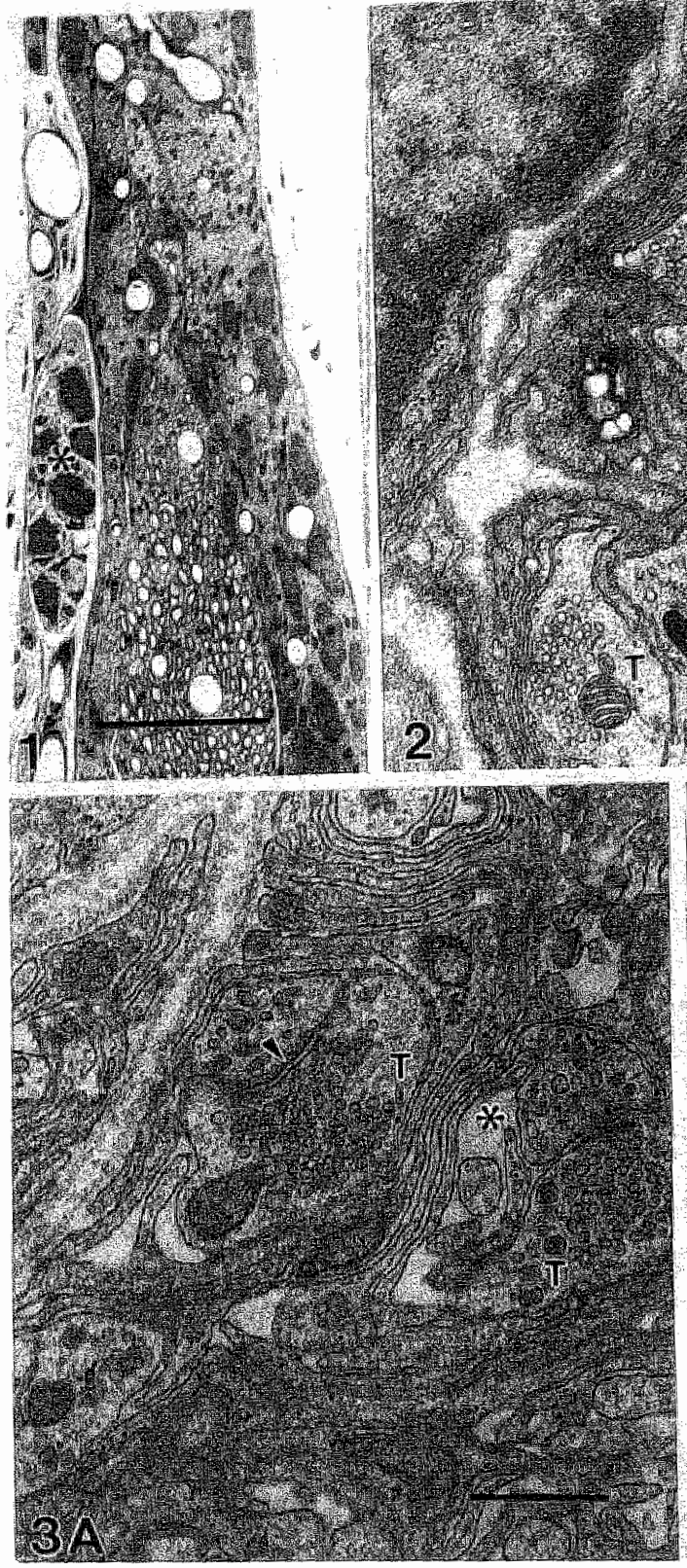
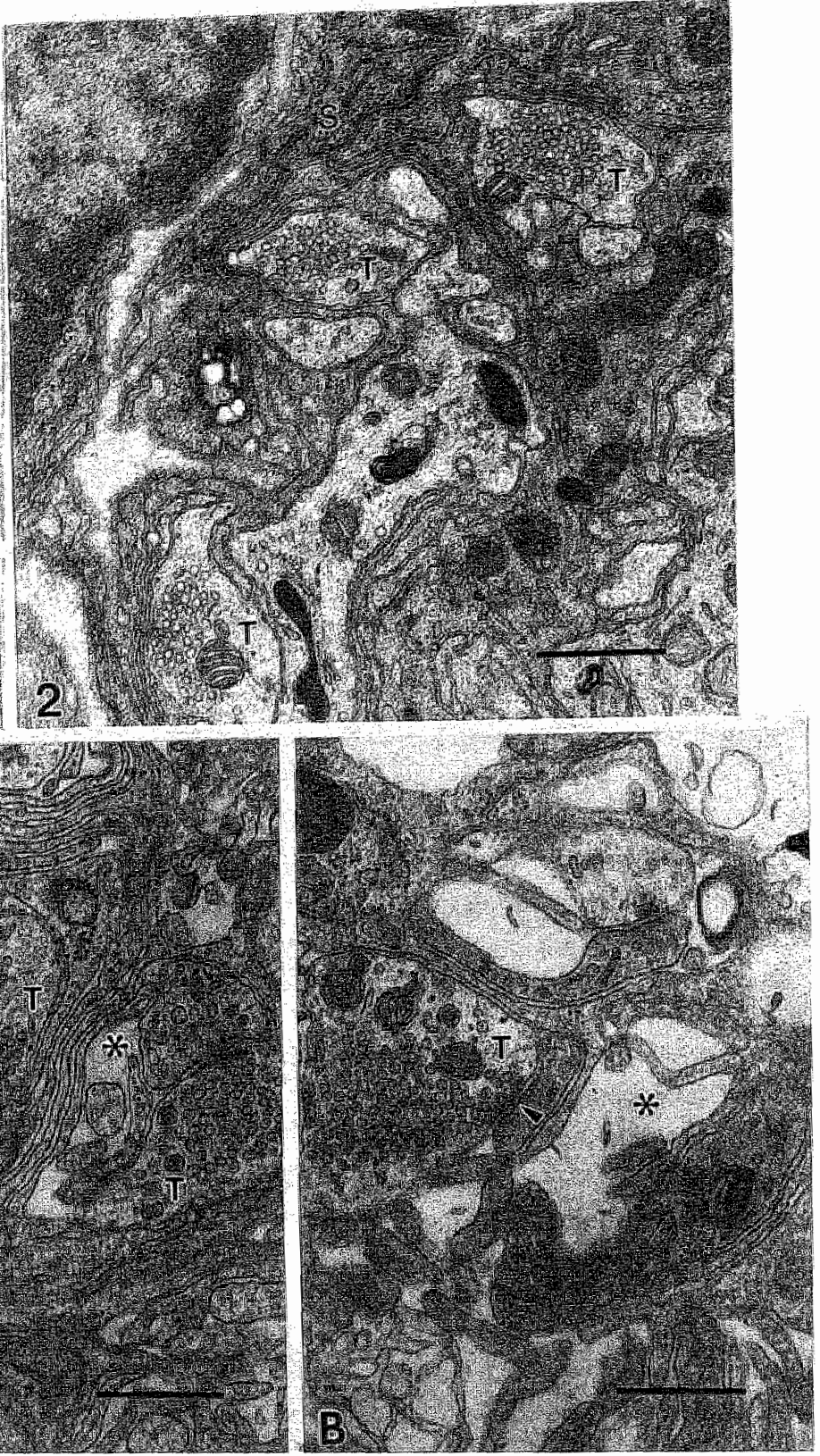


\section{Results}

\section{Ultrastructural evaluation of the pterygopalatine ganglion}

As illustrated in a cross-section of the rostral triangular part of the PPG, this part proved to consist of two areas of neuronal perikarya, intermingled with bundles of nerve fibres and blood vessels (Fig. 1). The major part contained numerous elongated cells, with dark cytoplasm and relatively light nuclei. The minor part, not described up till now, contained nerve cells with a more spherical outline and irregular contour. In this area, no myelinated nerve fibres were found. In the caudal string of cells of the PPG, axons were more numerous between the somata.

The fine structure of the perikarya was essentially identical to that described for other parasympathetic ganglion cells ${ }^{31}$. It seemed that the perikarya in the minor part were more abundantly provided with rough-surfaced endoplasmic reticulum (RER). With respect to the neurop $\|_{s}$ a remarkable difference between the major and minor part was observed. In the major part, the nerve terminals contained numerous synaptic vesicles, a few dense-cored vesicles and dark mitochondria, with electron-lucent cristae. The glial sheath was tightly packed with no extracellular spaces (Fig. 2). In the minor part, the synaptic terminals also contained numerous synaptic vesicles and few dense-cored vesicles. The mitochondria were of the dense type, but the cristae were electron-opaque. As in the major part, the terminals were enwrapped by glial elements, but this enwrapment was more loose with numerous large intercellular spaces (Fig. 3A-B).

In both areas, the terminals mainly formed synaptic contacts with short dendritic processes. Occasionally, symaptic contacts with the soma were formed.

\section{PHA-L anterograde tracing}

In the injected trigeminal ganglia, labelling of somata was restricted to a circumscribed area within the antero-median compartment.

Fig. 1: Light micrograph ol a ciross-section of the rostrall triangular area of the PPG. The minor compartment (asterisk) adjacent to the major compartment is shown. Note the differences in cell shape between neurons in the major and minor part. Scale bar represents $0.1 \mathrm{~mm}$.

Fig. 2: Electron micrograph showing the ultrastructure of a pericellular area in the major rostral area of the $P P G$. The terminals (T) contain numerous clear wesicles, a few dense-cored vesicles and dark mitochondria with electron-lucent cristae. The terminals are enwrapped by a firm glial sheath. S, soma. Scale bar represents $0.5 \mu \mathrm{m}$.

Fig. 3: Electron micrographs showing the pericellular ultrastructure of the minor rostral area of the PPG. The terminals (T) contain numerous clear vesicles, a few dense-cored wesicles and dark mitochondria with electron-opaque cristae. Synaptic contacts with short dendritic processes are shown (arrows). The glial sheath is loose with numerous large intercellular spaces (asterisks). Scalle bar represents $0.5 \mu \mathrm{m}$. 
In the ipsilateral pterygopalatine ganglion, labelling was observed in myelinated and unmyelinated nerve fibres (Fig. 4), and in teminals (Figs. 5-8). In the major rostral area, the ultrastructure of the labelled terminals was identical to the ultrastructure described for the unlabelled PPG, and the firm glial enwrapment was also observed. Synaptic contacts with short dendritic processes were frequent. In the minor rostral area, the labelled terminals contained small and large vesicles with dark mitochondria, often forming synaptic contacts with dendritic processes. In addition, the loosely arranged glial sheath was still evident.

\section{SP and CGRP immunohistochemistry}

In the semithin sections of the PPG, numerous SP-immunoreactive nerve fibres were observed containing varicosities (Fig. 9). Occasionally, SP-immunoreactive cells were found, however, no cells were found to stain positive for CGRP.

Uitrastructurally, myelinated as well as unmyelinated SP-immunoreactive fibres were found (Fig. 10) and numerous SP-immunoreactive terminals (Figs. 11-13). These terminals were localized in all parts of the PPG. In the major rostral area, the terminals contained small clear vesicles with a few dense-cored vesicles, and dark mitochondria with electron-lucent cristae. In the minor rostral part, the terminals also contained clear and dense-cored vesicles, and dark mitochondria. In serial sections, positively stained terminals were abserved in consecutive sections (Fig. 13A-B). The difference in glial enwrapment between positively stained terminals in the major and minor area was striking. In both rostral parts, synaptic contacts with short dentritic processes were often observed.

Numerous CGRP-immunoreactive fibres, myelinated as well as unmyelinated, were found in the PPG (Fig. 14). However, very few terminals stained positive for CGRP (Fig. 15). These terminals usually were small in size in comparison to the terminals labelled with SP, and they did not exhibit synaptic contacts. Labelled terminals were densely packed with vesicles and contained dark mitochondria.

\section{Discussion}

Ultrastructural studies of the pterygopalatine ganglion are scarce. The minor rostral cell mass of the PPG is newly described in the present study. This area could clearly be distinguished from the other parts of the ganglion. Cutting the PPG in different planes always revealed the same picture. As the material was well-fixed, the presence of this distinct region of ganglion somata cannot be explained as being a fixation artefact.

The ultrastructure of the nerve terminals in the PPG is in accordance with earlier descriptions of nerve terminals in parasympathetic ganglia of the rat ${ }^{31}$. Since for PHA-L, SP and CGRP immunohistochemistry the sections were treated with Triton $X-100$, the ultrastructure of these 

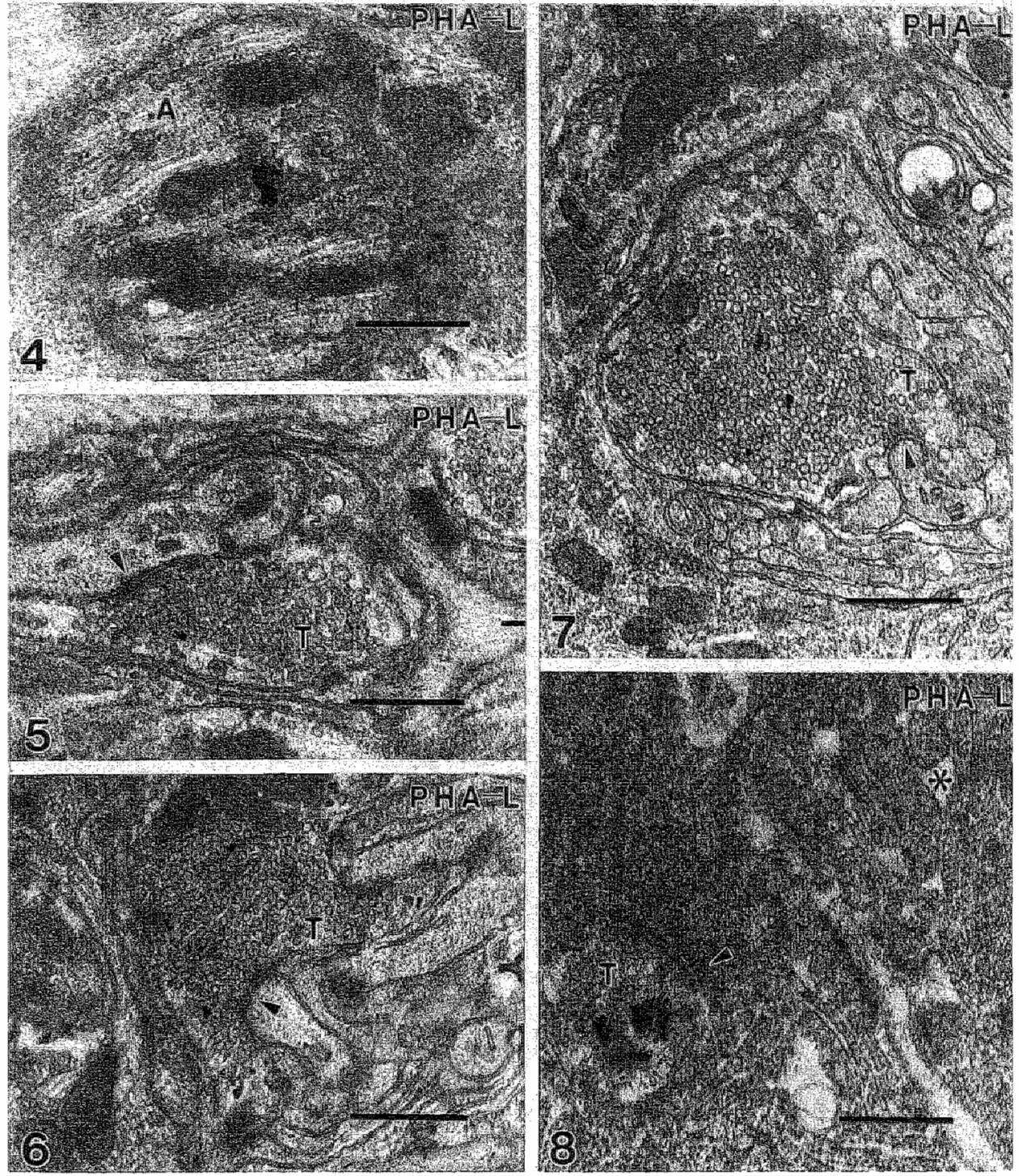

Fig. 4: Ellectron micrograph of a llongitudinal section of an unmyelinated axon in the PPG, labelled with PHA-L. The axon is characterized by numerous neurofilaments, neurotubuli and mitochondria. Scale bar represents $0.5 \mu \mathrm{m}$.

Fig. 5-7: Electron micrographs of terminals in the major rostral area of the PPG, labelled with PHA-L. The terminals (T) contain clear vesicles, a few dense-cored vesicles and dark mitochondria. Numerous synaptic contacts with short dendritic processes are formed (arrowheads). Scale bar represents $0.5 \mu \mathrm{m}$.

Fig. 8: Electron micrograph of a terminal (T) in the minor rostral area of the PPG, labelled with PHA-L. The terminal contains small and large vesicles and dark mitochondria. A synaptic contact with a dendritic process is shown (arrowhead). Note the loosely arranged glial sheath (asterisk).

Scale bar represents $0.5 \mu \mathrm{m}$. 


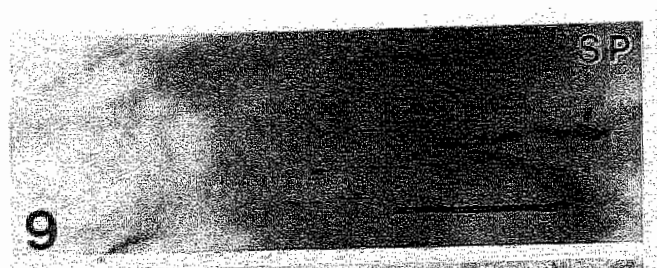

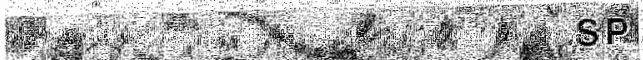
C.

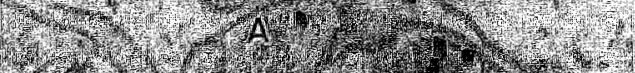

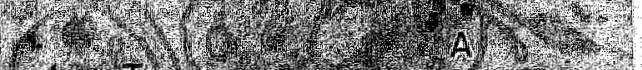

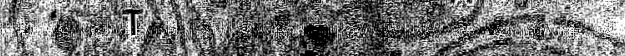

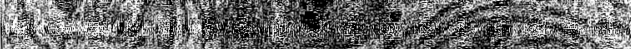

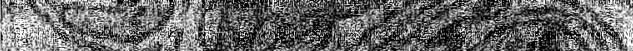

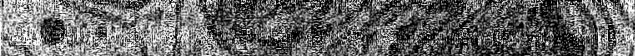

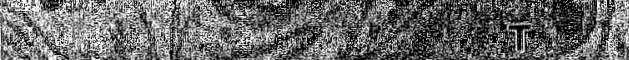

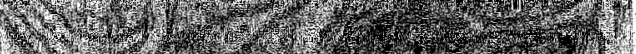

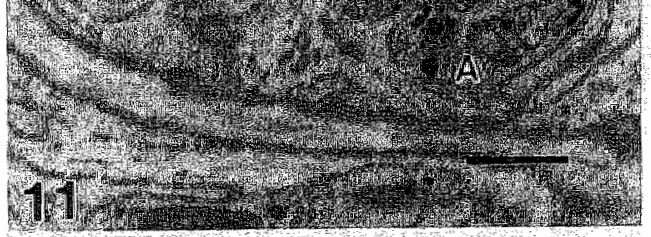

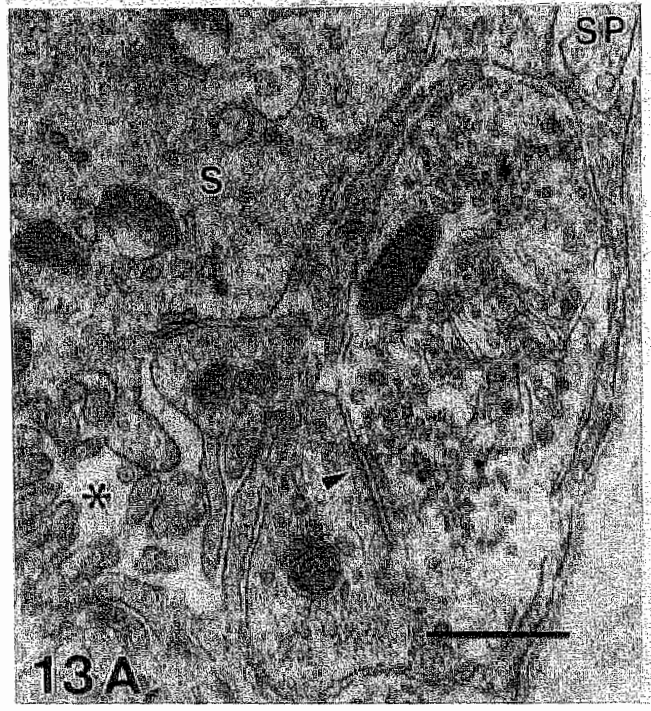
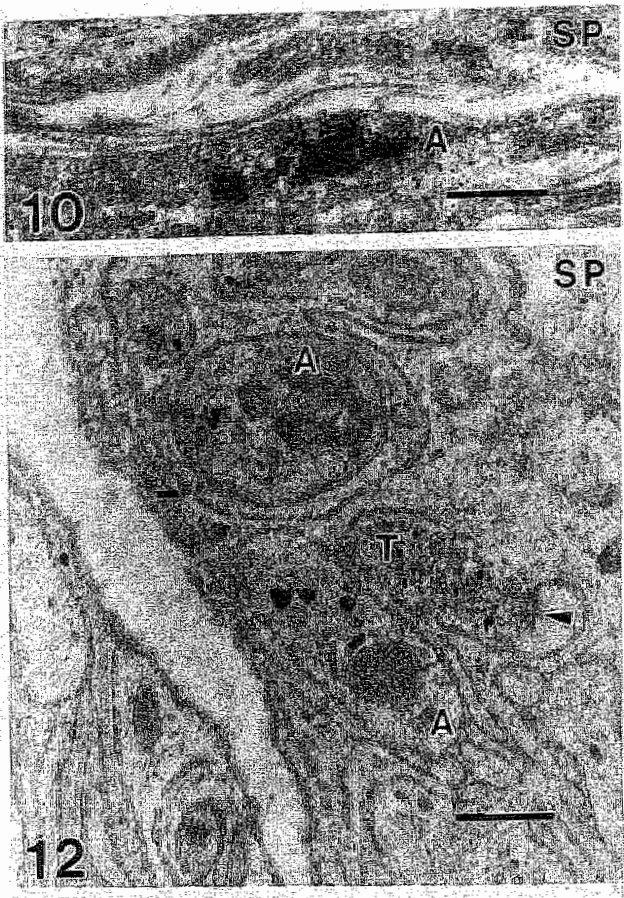

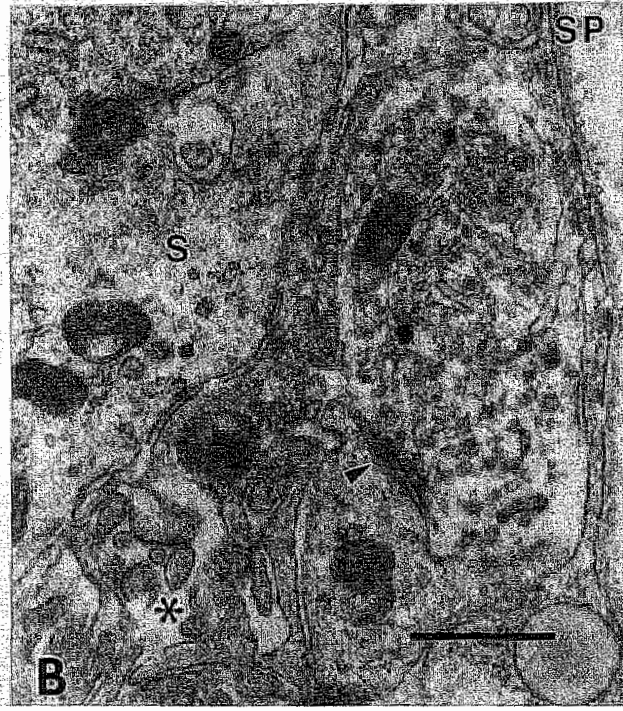


specimens was less well preserved compared to the nomal untreated material of Figs. 1,2 and 3. In other fight microscopic studies using immunohistochemical procedures, the staining of structures was usually more dense. Since it was aimed to study the ultrastructural aspects, procedure was used which optimally preserved the ultrastructure. As the treatment with Triton $X-100$ is most deteriorating for the ultrastructure, a Triton $X-100$ concentration of $0.05 \%$ was deliberately chosen instead of the in light micrascopic studies commonly used concentrations between 0.1 and $0.5 \%$. A consequence of this was a less pronounced staining. The fact that positively stained terminals were observed in consecutive sections implies that this less intense staining did not affect the sensitivity of the procedure. Compared to electron microscopic immunohistochemical studies of structures in the central nervous system showing optimal ultrastructure, the present results show light staining in the PPG. It might be that the penetration of the antibodies was hampered by the histological organization of the pterygopalatine tissue, especially the connective tissue sheath of the PPG. Furthermore, a light initial DAB reaction product was used which results in smaller-size gold deposits ${ }^{26}$.

When applied properly, PHA-L is an almost exclusive anterograde tracer ${ }^{7}$. It is suggested by some authors that PHA-L is transported both anterogradely and retrogradely from the peripheral to the central nervous system ${ }^{8}$. As labelled somata were found in the trigeminal ganglion, labelling in the PPG must be the result of anterograde transport, so the labelled nerve terminals in the PPG must be of trigeminal origin. Hence, the present study provides strong evidence of the rat PPG being synaptically innervated by sensory nerve fibres originating in the ophthalmic compartment of the trigeminal ganglion. Previous anterograde and retrograde light-microscopic studies concerning this pathway are hereby confirmed and extended $34,38,40$. As suggested by these studies, the rat PPG may also be innervated by sensory nerve fibres originating in the maxillary compartment of the trigeminal ganglion. Considering the labelling of terminals with PHA-L in the minor rostral area of the PPG, it must be assumed that this area also receives sensory information.

Fig. 9: Light micrograph of a nerve fibre positive for SP in the PPG. The fibre contains numerous varicosities. Scale bar represents $0.1 \mathrm{~mm}$.

Fig. 10: Electron micrograph of part of the fibre illustrated in Fig. 9 which proved to be unmyelinated and showed heavy staining for SP. Scalle bar represents $0.5 \mathrm{\mu m}$.

Fig. 11,12: Electron micrographs of axons (A) and terminals (T) in the major rostral area of the PPG, stained positive for SP. The terminals contain small clear vesicles with a few cdense-cored vesicles and dark mitochondria with electron-lucent cristae. Synaptic contacts with short dendritic processes are shown (arrowheads). Note the firm glial sheath. Scale bar represents $0.5 \mu \mathrm{m}$.

Fig. 13: Electron micrographs of consecutive sections of the minor rostral area of the PPG showing a terminal stained positive for SP. The terminal contains numerous clear vesicles, a few dense-cored vesicles and dark mitochondria. A synaptic contact with a dendritic process is shown (arrowhead). Note the loosely arranged glial sheath (asterisk). S, soma. Scale bar represents $0.5 \mu \mathrm{m}$. 

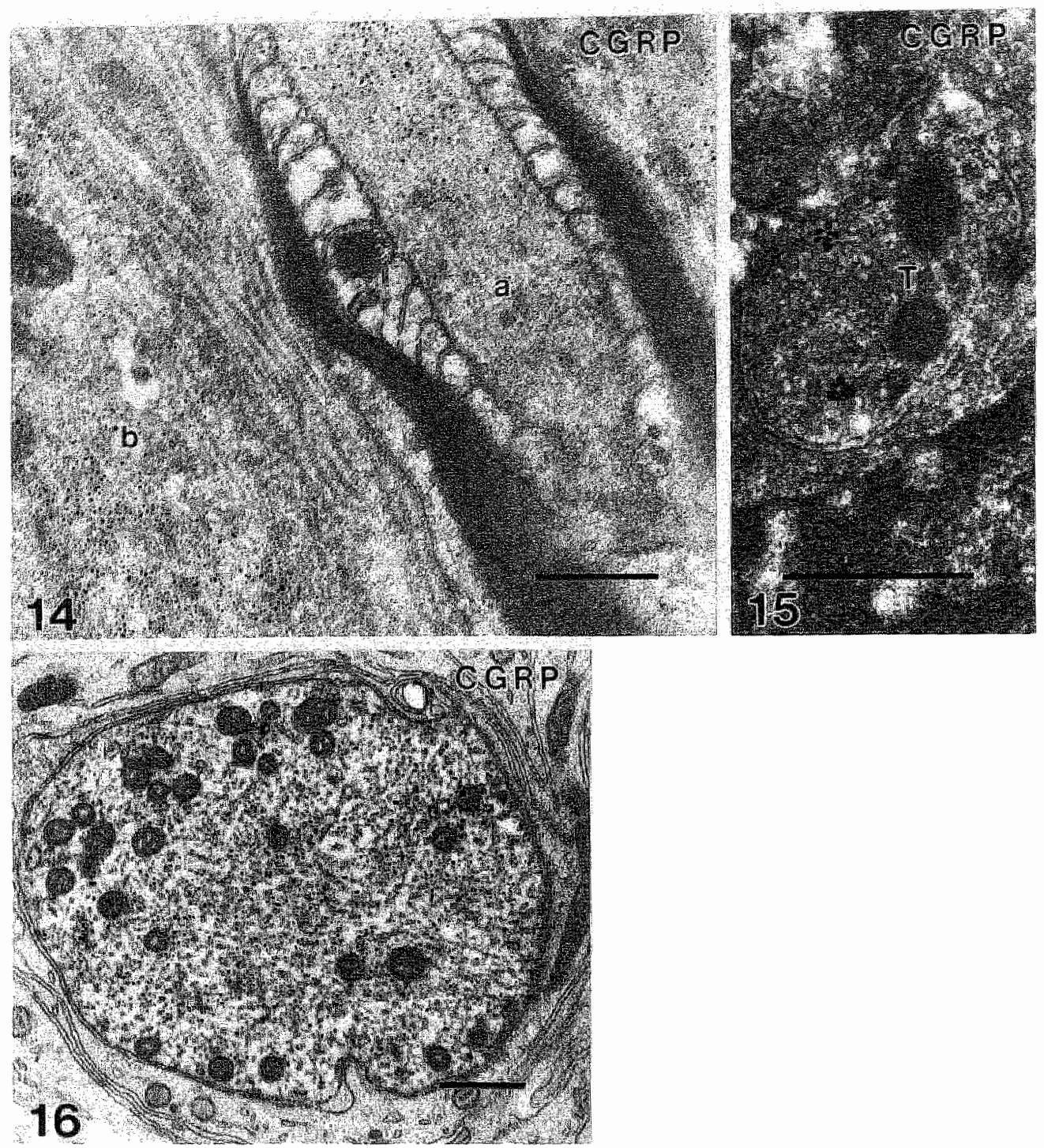

Fig. 14: Electron micrograph of a myelinated (a) and an unimyelinated nerve fibre (b) in the PPG stained positive for CGRP. Scale bar represents $0.5 \mu \mathrm{m}$.

Fig. 15: Electron micrograph of a small terminal (T) in the PPG stained positive for CGRP. The terminal is densely pecked with vesicles and contains dark mitochondria. Scale bar represents $0.5 \mu \mathrm{m}$.

Fig. 16: Electron micrograph of an axon in the trigeminal ganglion, heavily stained for CGRP. Scale bar represents $0.5 \mu \mathrm{m}$. 
Taken into account the ultrastructural aspect and distribution of the SP. and CQRP. immunoreactive nerve terminals in the PPG, it must be assumed that many trigeminal nerve endings in the PPG are SP- or CGRP-immunoreactive. The SP-immunoreactive nerve terminals, however, largely outnumber the CGRP-immunoreactive terminals. This cannot be explained as a technical artefact as in control experiments of the trigeminal ganglion, many CGAP-immunoreactive ganglion cells and nerve fibres were observed (Fig. 16). Positive staining of neurons, nerve fibres and terminals was unambiguous.

Suzuki et $a^{34}$ described in a recent paper two types of CGRP-and SP-immunoreactive nerve fibres originating in the maxilary part of the trigeminal ganglion: one type somewhat thicker, taking a straight course through the ganglion, and one, relatively thin type forming the pericellular baskets (around VIP/ChAT-immunoreactive cells). The CGAP-immunoreactive fibres outnumbered the SP-immunoreactive fibres. In several studies, a coexistence of CGRP and SP in single cells of the trigeminal ganglion of the rat has been demonstrated $18,19,41$. Where cell bodies showed colocalization of CGRP and SP, the arising nerve also showed positive immunostaining for both peptides. Only a proportion of CGRP-immunoreactive cells showed immunostaining for SP. Apparently, a considerable amount of SP-immunoreactive neurons in the trigeminal ganglion gives off nerve fibres that make synaptic contact with neurons in the PPG, whereas many CGRP-immunoreactive fibres pass through the PPG without making synaptic contact.

SP and CGRP are potent dilators of cerebral and extracranial vessels ${ }^{11,16,35}$. In the eye, release of both neuropeptides after trigeminal nerve stimulation leads to signs of neurogenic inflammation $1,4,11,25,47$. A function as neurotransmitters in trigeminal C-fibres for both neuropeptides, and a rolle for SP as an excitatory transmitter on autonomic ganglion cells has been described ${ }^{6,10,14}$.

Suzuki et al. ${ }^{33,34}$ suggest that the connection by trigeminal SP/CGRP fibres with VIP/ChAT-immunoreactive ganglion cells in the PPG could function as an alternative pathway to a reflex arc over the brainstem by which trigeminal nerves mediate cerebrall vasodilatation, since many of these VIP/ChAT cells project to the pial vessels, and VIP and acetylcholine are potent dilators of these vessels.

A regulatory loop for the integration of primary sensory afferent input and autonomic efferent function has been suggested by several authors $15,30,34$. In such a system, stimulated sensory nerve fibres influence the activity of autonomic ganglion cells and associated effector organs. Several processes, for example protecting responses to aversive stimuli could be triggered by this. The present study provides further evidence for the existence of such a regulatory loop outside the central nervous system. With respect to the innervation of the eye, sensory input from the anterior eye segment is transported to somata located in the anteromedian compartment of the trigeminal ganglion 37 . These somata project to the PPG to activate parasympathetic neurons with the strong suggestion of $\mathrm{SP}$ and CGRP acting as 
neurotransmitters in this pathway. The parasympathetic neurons of the PPG then, to complete the 100 , project to the choroid, limbal area and conjunctiva. In this pathway, VIP could function as a neurotransmitter. It has been emphasized that the nervous system must be considered as an important regulator of intraocular pressure. Especially the projection to the choroid, as a part of the described regulatory loop, suggests the existence of a nervous regulation of intraocular presisure.

The function of the minor cell population in the rostral triangullar area of the PPG remains to be established. It is tempting to suggest an alternative destination or function for the sensory modulated fibres arising from this area of the ganglion. 


\section{Ultrastructural Identification of Trigeminal Nerve Endings in the Rat Cornea and Iris}

\section{Abstract}

Trigeminal nerve terminals in the rat cornea and iris were ultrastructurally identified using anterograde tracing with Phaseolus vulgaris-leucoagglutinin (PHA-L). Electron microscopic immunohistochemistry was used to demonstrate the presence and localization of calcitonin gene-related peptide (CGRP) in cornea and iris.

In the cornea and iris, nerve fibres were labelled with PHA.L throughout the stroma. Labelling was most obvious within varicosities, densely packed with mainly clear and a few granular vesicles, and containing dark mitochondria.

Numerous fibres in the stroma of cornea and iris were CGRP-immunoreactive. CGRP-immunoreactive staining was most intense within varicosities, containing mainly clear and incidentally granular vesicles and dark mitochondria, similar to the structures labelled with PHA-L. CGRP-immunoreactive varicosities packed with mainly clear and few granular vesicles also were demonstrated in fibres adjacent to the sphincter and dilator muscles of the iris. In the corneal epithelium, small terminals containing vesicles were CGRP-immunoreactive.

Trigeminal nerve fibres innervating the rat comea and iris contained numerous varicosities packed with vesicles. These areas are CGRP-immunoreactive, so it can be implied that CGRP is released from these varicosities as a response to triggering impulses. This agrees with the hypothesis that in addition to their afferent function, sensory fibres also exert an efferent modulating function.

\section{Introduction}

The rat cornea and iris are innervated by sensory nerve fibres that originate in the antero-median area of the trigeminal ganglion 22,23 . The nerve fibres radially enter the limbal border of the cornea in the deep stroma and branch, coursing toward the anterior stroma. Centrally, a rich plexus with numerous epithelially and subepithelially located nerve-endings is formed ${ }^{38}$. Sympathetic fibres originating in the rostral pole of the superior cervical ganglion have been reported to innervate the comea ${ }^{23}$. In the iris, trigeminal nerve fibres are localized throughout the stroma, mostly coursing radially ${ }^{3 i 8}$.

Few tracing studies of cornea and iris have been performed at the ultrastructural level to elucidate the kind of nerve ferminals involved in the sensory pathway. Ultrastructural studies of the mammalian iris have shown that the sensory fibres are unmyelinated 20,21 . Varicosities of 
these fibires contain mitochondrla or mitochondria and vesicles. The thin profiles of the fibres between the varicosities have been shown to contain neurotubuli and filaments. Nontracing electron micrascopic studies of the rat cornea describe several types of nerve terminals, containing mitochondria and clear and granular vesicles ${ }^{12,42}$. Whether these distinct types of terminals are made up of fibres from different origins is still unclear. Moreover, neuropeptides have not been demonstrated ultrastructurally within these terminals. In light microscopic studies, trigeminal varicose nerve fibres that supply the iris and comea have been shown to contain calcitonin gene-related peptide (CGRP) $17,30,32,41,45$.

To further elaborate upon this, the sensory innervation of cornea and iris was studied ultrastructurally for the present report. Phaseoius vulgaris-leucoagglutinin (PHA-L) was injected into the ophthaimic area of the trigeminal ganglion, and the distribution of the tracer in sensory nerve fibres and terminals of cornea and iris was studied using electron microscopy.

The localization of CGRP in these ocular structures was studied ultrastructurally with immunohistochemical methods.

\section{Materials and Methods}

Fifteen adult male Wistar rats, weighing between 200 and $300 \mathrm{~g}$, were used.

\section{PHA-L tracing experiments}

Five animals were anaesthetized with Nembutal $0.3 \mathrm{~m} / \mathrm{kg}$ i.p. (Rousselot, Paris, France) and Hypnorm $0.3 \mathrm{ml} / \mathrm{kg}$ i.m. (Janssen. Tilburg, The Netherlands). The rats were placed in a stereotaxic frame. After dissection of the calvarium and dura mater, a small part of the parietal cortex covering the anterior part of the trigeminal ganglion was removed by suction. Injections were placed in the antero-median compartment of the left trigeminal ganglion. A $2.5 \%$ solution of PHA-L. (Vector, Burlingame, $\mathrm{CA}$ ) in sodium phospthate- bufferred saline, $\mathrm{pH} 8.0$, was lontophoretically injected $(6.5-7.5 \mu \mathrm{A}, 20 \mathrm{~min})$ using glass micropipettes with an inner tip diameter of 20 un.

After a $6-8$ day survival period, the amimals were killed with an overdose of Nembutal and were transcardially perfused with $150 \mathrm{ml}$ phosphate-buffered saline (PBS) followed by 1 liter of a fixation solution containing $2.5 \%$ glutaraldehyde and $1 \%$ paraformaldehyde in $0.05 \mathrm{M}$ phosphate buffer, pH 7.4, at room temperature.

\section{CGRP experiments}

Ten animals were killed with an overdose of Nembutal and were transcardially perfused with $150 \mathrm{ml}$ PBS followed by 1 liter fixation solution containing $2.5 \%$ glutaraldehyde in PBS, $\mathrm{pH} 7.4$, at room temperature. 


\section{PHA-L and CGRP immunohistochemistry}

After decapitation, the heads were postfixed overnight in the same fixation solutions. The: trigeminal ganglia and the comeas and irides of both eyes were dissected and rinsed in PBS. The comeas were cleaved at the stromal level into an anterior and a posterior part, after which both parts were separately infiltrated with $20 \%$ sucrose and frozen. The sucrose-infiltrated indes and trigeminal ganglia were sectioned at 20-50 um using a freezing microtome. After rinsing in PBS, the cleaved comeas and sections were transferred into buffered solutions containing diluted (1/2000) primary antisera (anti-PHA-L (Vector) and anti-GGRP (Cambridge Research Biochemicals, Northwich, (LK)), supplemented with $0.05 \%$ Triton $X-100$ (Merck, Darmstadt. Germany). They were incubated tree floating for $20 \mathrm{hr}$ at room temperature, of for $70 \mathrm{hr}$ at $4^{\circ} \mathrm{C}$.

The peroxidase-antiperoxidase (PAP) method was used to visualize the PHA-L and CGRP antigens 46 . The tissues were incubated in $0.05 \% \mathrm{w} / \mathrm{V}$ diaminobenzidine (DAB) in Trisubuffered saline (TBS) supplemented with $0.01 \%$ hydrogen peroxide $\left(\mathrm{H}_{2} \mathrm{O}_{2}\right)$ for $10 \mathrm{~min}$. After rinsing in TBS, the DAB reaction product was intensified with a gold-substituted silver peroxidase technique 26 . The corneas and sections were postfixed in $1 \%$ osmium tetroxide $\left(\mathrm{OsO}_{4}\right)$ supplemented with $1 \%$ potassium ferricyanide in $0.1 \mathrm{M}$ sodium cacodylate buffer, $\mathrm{pH} 7.4$, for $20 \mathrm{~min}$. Subsequently, they were dehydrated in a graded series of ethanols and flat embedded in epoxy resin. In control experiments, the primary antisera were left out of the procedure.

Nerve fibres containing the peroxidase reaction product were light microscopically identified, after which these areas were dissected and mounted on prepolymerized epoxy resin blocks. Finally, ultrathin sections were cut and stained with uranyl acetate and lead citrate. These sections were inspected and photographed with EM 201 and EM 400 electron microscopes (Philips Industries, Eindhoven, The Netherlands).

\section{Results}

\section{PHA-L anterograde tracing}

In the injected trigeminal ganglia, labelling was restricted to cell bodies in a circumscribed area within the antero-median compartment of this ganglion.

Connea: In the cleaved corneas, labelled nerve libres were identifled light microscoplcally (Fig. 1). Ultrastructurally, these labelled tibres appeared to be unmyelinated and were mainly found in the corneal stroma (Figs, 2-5). They contained numerous neurotubuli, neurofilaments, and dark mitochondria. In some sections, the glial ensheathment of the fibres by Schwann cells could be distinguished. Labelling was most evident within varicosities, which contained dark mitochondria and numerous clear and incidental vesicles with small granules (Figs. 2, 3 and 5 ). 
Iris: In semithin sections of the ins, numerous labelled nenve fibres were found (Fig. 6). Ulrastructurally, the labelled nerve fibres were unmyelinated and localized throughout the iris stroma (Flgs. 7 and 8). They contained numerous neurotubuli, neurofilaments, and dark mitochondria. Similar to the labelling with PHA-L of corneal nerves, the most intense staining was found within varicosities containing dark mitochondria. However, larger numbers of these swellings were found that were more densely packed with clear and granular vesicles.

In all five animals, labelling of iridal nerves was more pronounced compared to the labelling of corneal nerves. No labelling was obsened in the contralateral cornea and iris.

\section{CGRP immunohistochemistry}

Connea: Numerous CGRP-immunoreactive nerve fibres were found in the cleaved corneas (Fig. 9). Ultrastructurally, unmyelinated CGRP-immunoreactive fibres containing neurotubuli. neurofliaments, and dark mitochondria were observed in the corneal stroma (Figs. 10 and 11). As after labelling with PHA-L, the most intense staining was found within varicosities containing dark mitochondria, numerous clear vesicles, and a few granular vesicles. After the cornea was sectioned at an angle of $45^{\circ}$, stromal nerve fibres entering the epithelium could be seen in untreated material (Fig. 12). In the epithelium, numerous nerve terminals could be distinguished, often containing vesicles. Small terminals localized in the corneal epithelium and containing vesicles were CGRP-immunoreactive (Fig. 13).

Iris: In the semithin sections of the iris, numerous CGRP-immunoreactive nerve fibres containing varicosities were found (Fig. 14). Ultrastructurally, these unmyelinated CGRP-immunoreactive tibres that contained numerous neurotubuli, neurofilaments, and dark mitochondria, often with electron lucent cristae, were localized throughout the iris stroma (Fig. 15). Positive staining of fibres was most intense within varicosities, packed with clear and some granular vesicles, as after labelling with PHA-L. The CGRP-immunoreactive staining of nerve fibres was more pronounced in the iris compared to the cornea.

CGRP-immunoreactive varicosities containing numerous clear and some granular vesicles were observed in some small fibres in areas adjacent to the sphincter and dilator muscles (Figs. 16 and 17 ).

Fig. 1: Nomarski interterence micrograph of a PHA-L_labelled nerve fibre (arrowheads) in a cleaved cornea.

Figs. 2-5: Electron micrographs of unmyelinated nerve fibres in the corneal stroma, labelled with PHA-L. The fibres contain numerous neurotubuli $(T)$, neurofilaments ( $F$ ), and dark mitochondria (M). The glial ensheathment of the fibres by Schwann cells is shown (asterisk). Labelling is especially dense within varicosities, containing dark mitochondria and numerous clear vesicles, a few with small granules (arrowheads). S, nucleus of a Schwann cell. Scale bars represent $0.5 \mu \mathrm{m}$ 

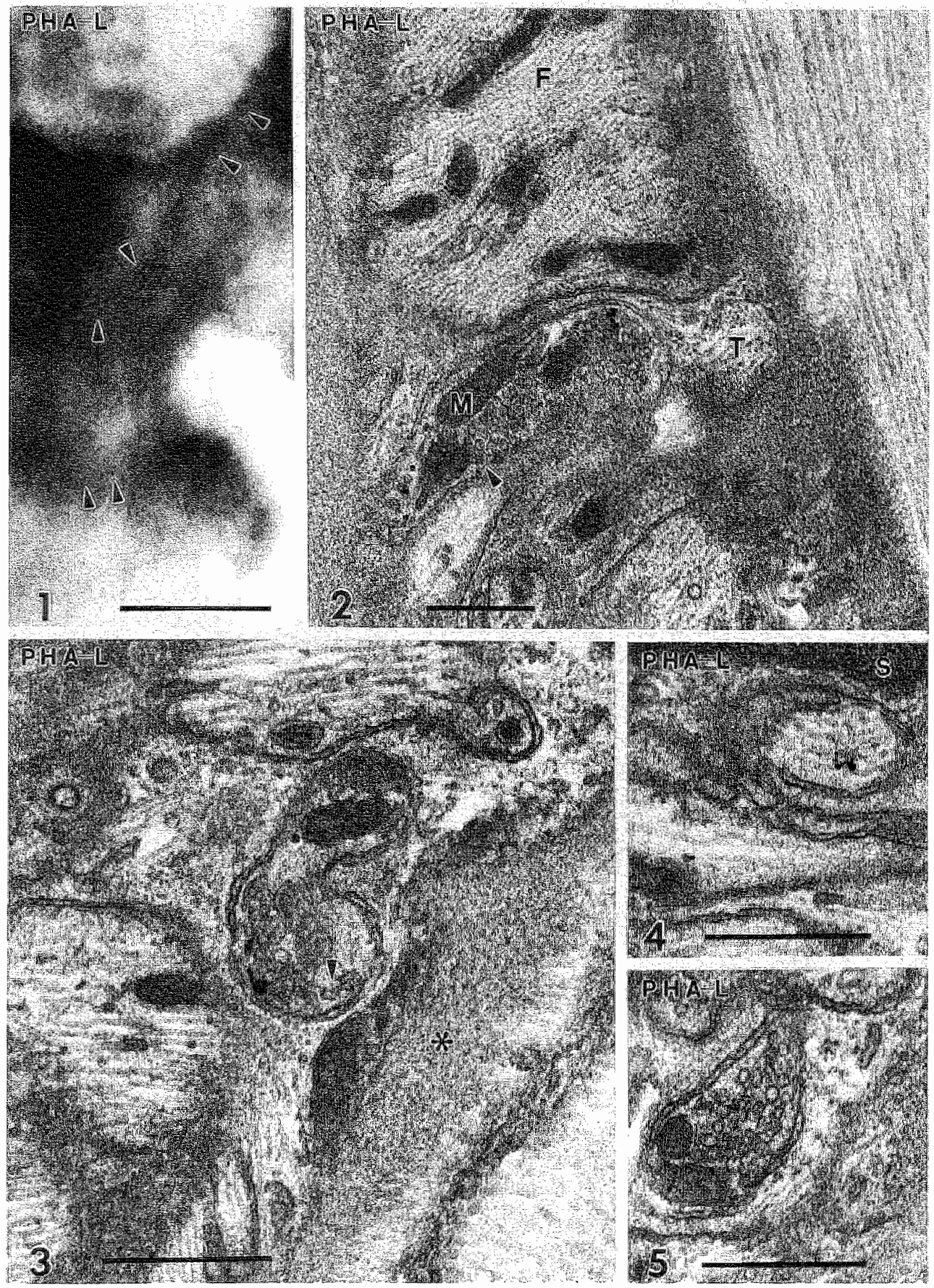

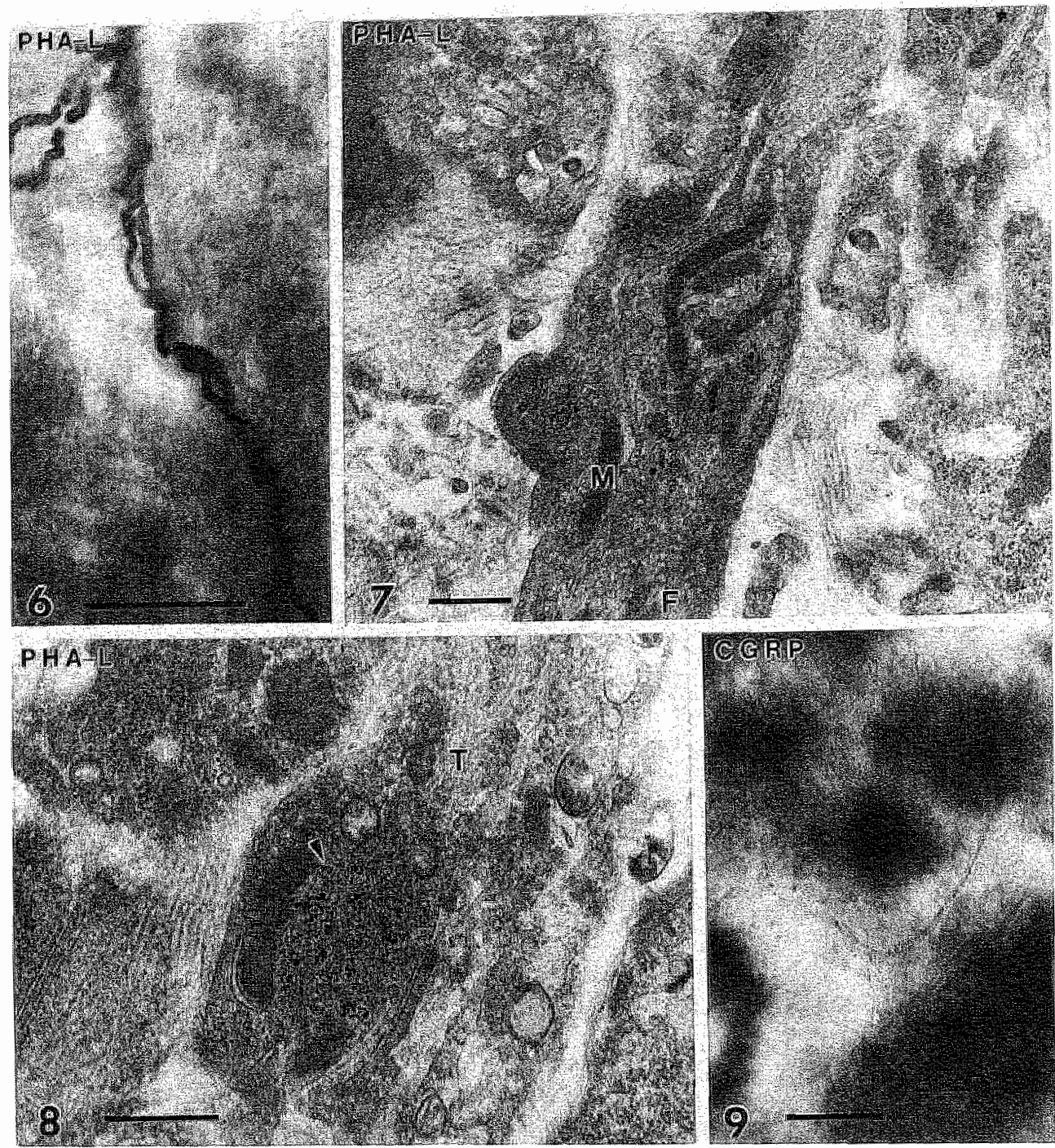

Fig. 6: Nomarski interference micrograph of a PHA-lL-labelled nerve fibre in the iris. Scale bar represents $0.05 \mathrm{~mm}$.

Figs: 7,8: Electron miorographs of unmyelinated nerve tibres in the iris stroma, labelled with PHA-L. The fibres contain numerous neurotubul: (T), neurofilaments ( $F$ ), and dark mitochondria (M). Labelling is most intense within varicosities containing dark mitochondria and numerous clear and fewer granular vesicles (arrowhead). Scale bars represent 0.5 um.

Fig. 9" Nomarski interference micrograph of a CGRP-immunoreactive nerve fibre in a cleaved cornea. Scale bar represents $0.05 \mathrm{~mm}$. 

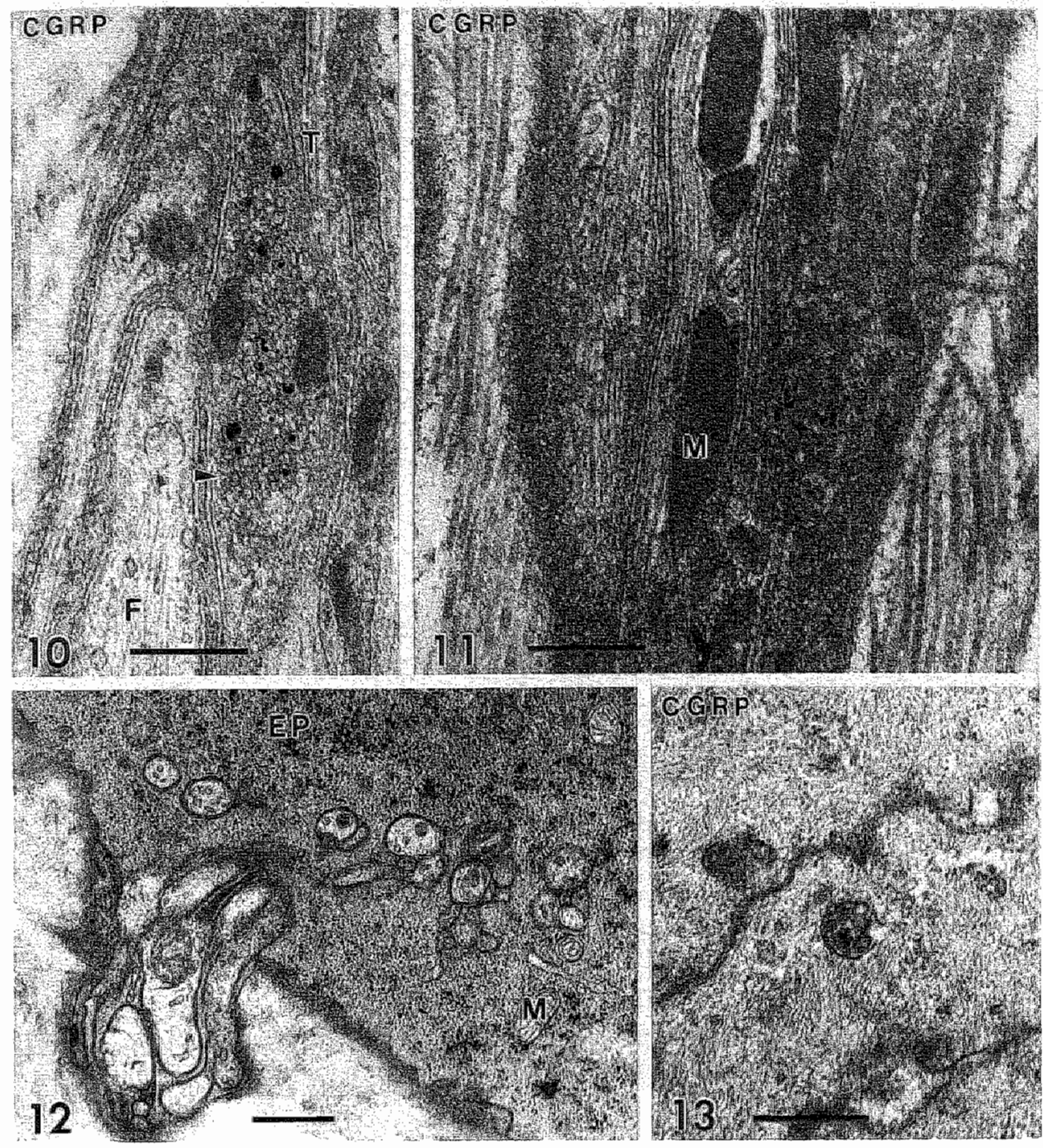

Figs. 10, 11: Electron micrographs showing CGRPaimmunoreactive nerve fibres in the corneal stroma. The fibres contain neurotubuli $(T)_{n}$ neurofilaments $(F)$, and dark mitochondria $(M)$. Staining is most intense in varicosities containing dark mitochondria, numerous clear vesicles, and incidental vesicles with small granules (arrowhead). Scale bars represent $0.5 \mu \mathrm{m}$.

Fig. 12: Electron micrograph of a comea sectioned at an angle of $45^{\circ}$ showing a stromal nerve fibre entering the epithelium. In the epithelium, numerous nerve terminals are formed "often containing vesicles. EP, epithelium; $M_{*}$ mitochondrion. Scale bar represents $0.5 \mu \mathrm{m}$.

Filg. 13: Electron micrograph of the corneal epithelium showing a small CGAP-immunoreactive nerve terminal containing vesicles. Scale bar represents $0.5 \mu \mathrm{m}$. 

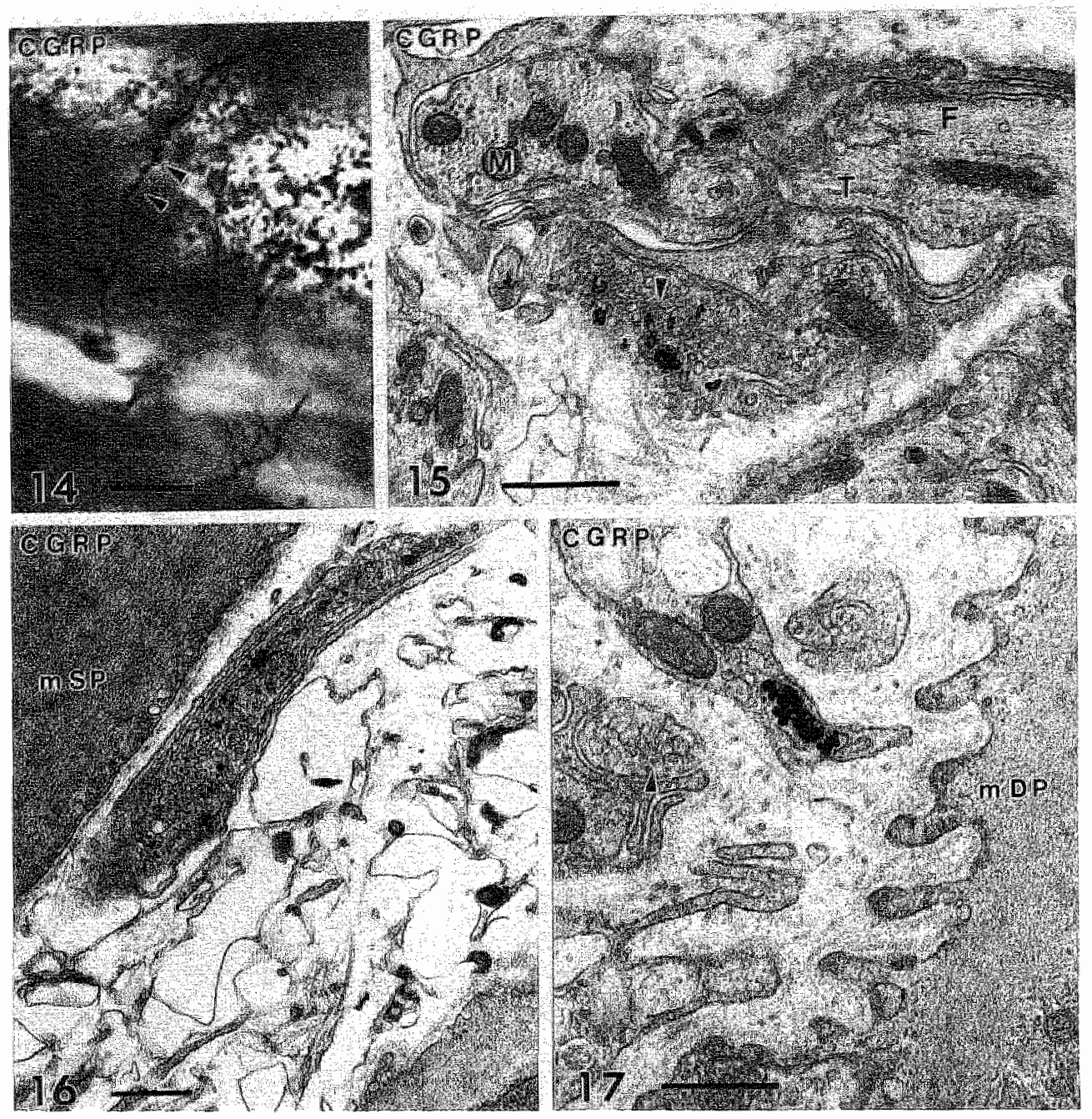

Fig. 14: Light micrograph of a CGRP-immunoreactive nerve fibre containing varicosities (arrowheads) in the iris. Scale bar represents $10 \mu \mathrm{m}$.

Fig. 15: Electron micrograph of a CGRP-immunoreactive nerve fibre in the fris stroma. The fibre is unmyelinated and contains numerous neurotubuli $(T)$, neurofilaments $(F)$ and dark mitochondria $(M)$, often with electron-lucent cristae. Positive staining is almost exclusively localized within varicosities containing clear and incidental granular vesicles (arrowhead). Scale bar represents $0.5 \mu \mathrm{m}$.

Figs. 16, 17: Electron micrographs showing CGRP-immunoreactive nerve varicosities containing mainly clear vesicles, and a few with small granules (arrowheads) in areas adjacent to the sphincter (Fig. 16) and dillator muscles of the iris. $\mathrm{mSP}, \mathrm{m}$. sphincter pupillae; $\mathrm{mDP}, \mathrm{m}$. dilatator pupillae.

Scale bars represent $0.5 \mu \mathrm{m}$. 


\section{Discussion}

Ultrastructural tracing studies with PHA-L of comea and inis have not been published. The electron microscopic demonstration of CGRP in cornea and iris is also unprecedented. according to the authors' knowledge.

The results of the present study show a much denser labelling with PHA-L of iridal nerves compared to the labelling of corneah nerves. A similar phenomenon was observed using CGRP immunohistochemistry. Triton $X-100$ is used in immunohistochemical procedures to facilitate the penetration of the primary antibodies into the tissue. However, il also deteriorates the fine structure of tissue. To optimally preserve the ultrastructure, a Triton $X-100$ concentration of $0.05 \%$ was used in this study instead of the 0.1 to $0.5 \%$ concentrations commonly used in light microscopic studies. A consequence of this is a less pronounced staining, especially in the cornea. Using higher concentrations of Triton $X-100$ in pilot experiments resulted in more pronounced staining of corneal nerves but was devastating to the ultrastructure. Because positively stained structures could be observed in consecutive sections, it can be implied that the sensitivity of the procedure was not affected. Background staining was very low. In addition, it may be concluded that the penetration of antibodies is hampered by the organization of the corneal stroma. A similar problem was described in an ultrastructural tracing and immunohistochemical study of the pterygopalatine ganglion?2.

PHA-L is an almost exclusive anterograde tracer ${ }^{7}$. In previous light microscopic studies, it has been demonstrated that sensory nerve fibres of cornea and iris originate in the antero-median area of the trigeminal ganglion 22,23 . A circumscribed area of somata labelled with PHA-L was found in the ophthalmic area of the trigeminal ganglion. Labelling of fibres in cornea and iris must be the result of anterograde transport, so these fibres must be of trigeminal origin. The present study demonstrates that sensory nerve fibres of cornea and iris contain numerous varicosities packed with vesicles. These structures in particular were labelled with PHA-L. CGRP-immunoreactive staining of fibres also was most dense in varicosities containing numerous vesicles. Considering the ultrastructural similarity and distribution of the CGRP-immunoreactive nerve fibres in comea and iris and PHA-L-labelled fibres, it can be assumed that these CGRP-immunoreactive fibres are of trigeminal origin. The trigeminal origin of CGRP-immunoreactive fibres in the anterior eye segment also has been found in light microscopic tracing and sensory denervation studies $18,32,41,44,45$. In the trigeminal ganglion, numerous somata contain CGRP $17,18,30,41,45$. In a recent light microscopic anterograde tracing study using autoradiographic techniques, it was emphasized that the innervation of the comea is exclusively sensory ${ }^{39}$. In that study, after injection of the tracer into the rostral pole of the superior cervical ganglian, no sympathetic fibres were labelled in the cornea.

In the areas of the sphincter and dilator muscles of the iris, CGRP immunoreactive varicosities. of nerve fibres have been shown. This agrees with earlier light microscopic findings $41,44$. CGRP-immunoreactive terminals also were demonstrated in the corneal epithelium. These 
structures were nol labelled with PHA-L. An explanation for this may be that only a restricted number of somata in the trigeminal ganglion was labelled with PHA-L. A consequense of this would be that not all sensory fibres were labelled in cornea and iris.

In several studies, it has been hypothesized that sensory nerves not only serve an afferent role, but also have an efferent function in response to noxious stimuli, permitting sensory axon modulation of autonomic neuron activity and triggering of protecting reflexes, such as the ocular injury response 27,30 . In the eye, release of CGRP after trigeminal nerve stimulation leads to signs of neurogenic inflammation 1,11,25,47. Depletion of CGRP after destruction of the trigeminal ganglion by capsaicin is related to loss of responsiveness of the eye to noxious stimuli:44.

It can be hypothesized that the vesicle-packed varicosities of nerve fibres localized in the corneal and iris stroma described in the present study represent sensory terminals, from which CGRP is released in response to triggering impulses. The CGRP-immunoreactive terminals in the corneal epithelium most likely exert a similar function. 


\title{
Substance $\mathbf{P}$ in Rat Corneal and Iridal Nerves:
}

\section{An Ulltrastructural Immunohistochemical Study}

\begin{abstract}
The distribution of substance $P$ (SP) within the nerve fibres of the rat cornea and iris was studied using electron microscopic immunohistochemistry. Numerous SP-immunoreactive fibres were found throughout the corneal and iridal stroma. The most intense staining was found within varicosities containing numerous vesicles. Similar SP-immunoreactive varicosities were found in fibres in close proximity to the iris sphincter and dilator muscles. On account of previous ultrastructural work the SP-containing fibres and varicosities must be assumed to be of trigeminal origin. Additionally, the distribution of SP and calcitonin gene-related peptide (CGRP) in corneal and iridal fibres of rats is similar, suggesting that CGRP and SP are collocalized and may be coreleased from the same varicosities.
\end{abstract}

\section{Introduction}

The cornea and iris of rats are densely innervated by sensory nerve fibres that originate in the ophthalmic area of the ipsilateral trigieminal ganglion $3,22,23,38$. Light microscopic studies have demonstrated the presence of the neuropeptides calcitonin gene-related pepticle (CGRP) and substance $\mathrm{P}$ (SP) in these sensory fibres of rats and guinea pigs by immunohistochemical techniques $17,24,30,32,41$. In the iris, both neuropeptides have been described within a plexus of stromal nerve fibres, extending over both the sphincter and the dilator areas. In the cornea, SP and CGRP were found in a plexus of fibres within the corneal stroma, with some axons ascending into the corneal epithelium, branching between the epithelial cells. CGRP and SP were found to be partly colocalized within the same fibres of connea and iris, however, the CGRP-immunoreactive fibres outnumbered the SP-immunoreactive fibres $17,19,44$. In the guinea pig, nerve fibres immunoreactive only for CGRP were found in the cornea "while libres immunoreactive only for SP were found in both iris muscles ${ }^{17}$. Corresponding to the findings in the eye, colocalization of CGRP and SP was found within single cells of the trigeminal ganglion, with the CGRP-immunoreactive cells outnumbering the SP-immunoreactive cells ${ }^{17.19,41}$. Where cell bodies showed colocalization for SP and CGRP, the arising nerve was also immunoreactive for both neuropeptides 41 .

In a recent ultrastructural study ${ }^{3}$ it has been shown that CGRP in corneal and iridal nerve fibres of the rat is preferentially localized within varicosities, densely packed with clear vesicles and incidentally vesicles with small granules and containing dark mitochondria. These CGRP-immunoreactive varicosities were found in the corneal stroma and epithelium, and throughout the iris stroma. Additionally, small fibres with CGRP-immunoreactive varicosities 
were found in close proximity to the iris sphincter and dilator muscles. In rats, a close association between SP-immunoreactive nerve terminals and the irs sphincter muscle cells was described utrastructurally ${ }^{29}$. These terminals were found to contain numerous synaptic vesicles, however, synaptic contacts were not found in that study. In an ultrastructural study using guinea pigs was found that CGRP and SP were colocalized within vesicles of peripheral nerve fibres associated with the vascular system? "suggesting that CGRP and SP are costored and may be released together from peripheral axons.

The distribution of $\mathrm{SP}$ within corneal nerve fibres has not been described at the ultrastructural level. In the iris, the ultrastructure of SP-immunoreacive nerve fibres was only studied in the sphincter muscle region 29 . The distribution of SP-immunoreactive nerve fibres within the iris stroma and the dilator muscle region remains to be elucidated at the ultrastruciural level. To further investigate this, the distribution of SP in comeal and iridal nerves of rats was studied ultrastructurally using SP-immunohistochemistry.

\section{Materials and Methods}

Sixteen adult male Wistar rats, weighing between 200 and $300 \mathrm{~g}$, were used. The animals were killed with an overdose of Nembutal (Rousselot, Paris, France) and were transcardially perfused with $150 \mathrm{ml}$ phosphate-buffered saline (PBS), followed by 1 liter of a fixation solution containing $2.5 \%$ glutaraldehyde in $\mathrm{PBS}, \mathrm{pH} 7.4$, at room temperature. The rats were decapitated. The heads were postfixed for several hours in the same (fresh) fixation solution. The comeas and irides were dissected and rinsed in PBS. The corneas were cleaved into an anterior, posterior and sometimes an intermediate part at the stromal level. The irides were infiltrated with sucrose and subsequently sectioned at 20-50 um using a freezing microtome. After rinsing in incubation buffer (Amersham International plc, Amersham, UK) containing 1\% normal goat serum, for 30 min, the cleaved corneas and the iridal sections were transferred into incubation buffer supplemented with the diluted (1/1500) primary antiserum to SP (The Netherlands Institute for Brain Research, Amsterdam, The Netherlands) and $0.05 \%$ Triton X-100 (Merck, Darmstadt, Germany). They were incubated free floating overnight, at room temperature. Control experiments were performed in which the primary antiserum was left out

Fig. 1: Nomarski interference contrast micrograph of a SP-immunoreactive nerve fibre bundle (arrowheads) in a cleaved comea. Scale bar represents $0.05 \mathrm{~mm}$.

Fig. 2: Electron micrograph of an unmyelinated fibre bundle in the comeal stroma, showing several SP.immunoreactive nerve fibres, containing numerous neurotubuli, neurofilaments and mitochondria. The most intense staining is found within varicosities containing numerous vesicles (arrowheads). Scale bar represents $0.5 \mu \mathrm{m}$.

Fig. 3: Electron micrographs showing SP wimmunoreactive nerve varicosities containing numerous vesicles (arrowheads) in consecutive sections of an unmyelinated fibre bundle in the corneal stroma. SC, stromal collagen. Scale bars represent $0.5 \mu \mathrm{m}$. 

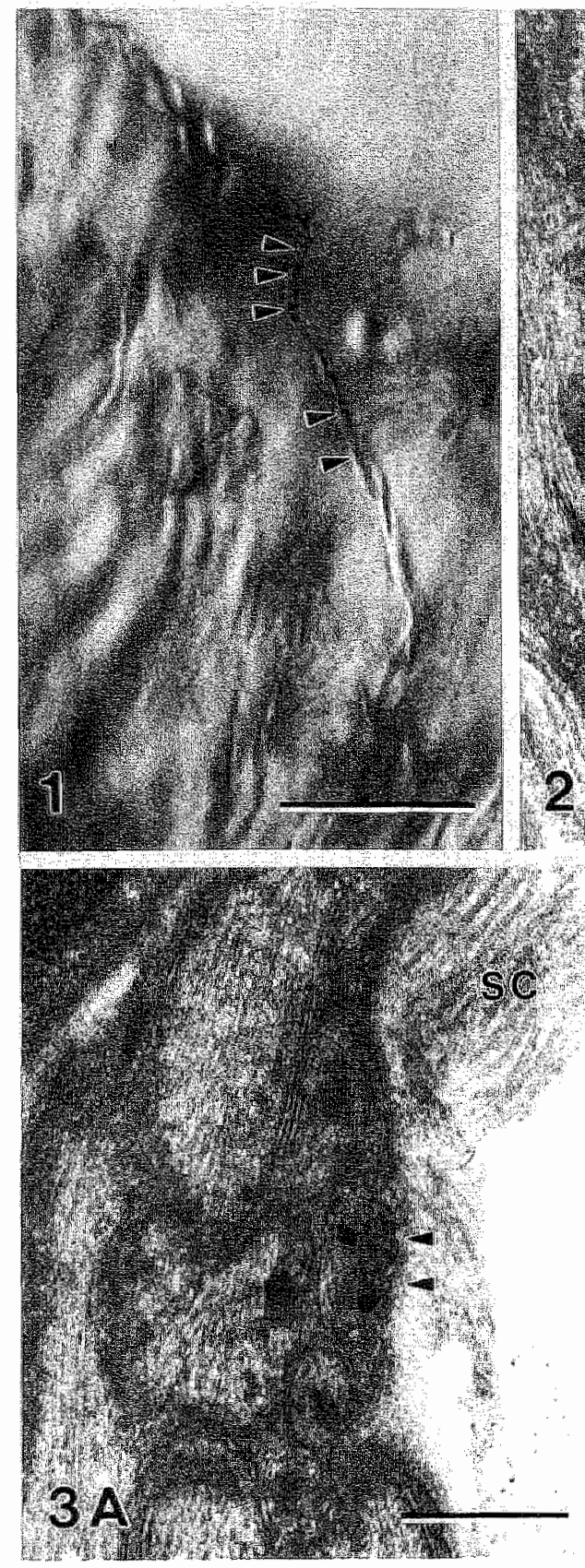
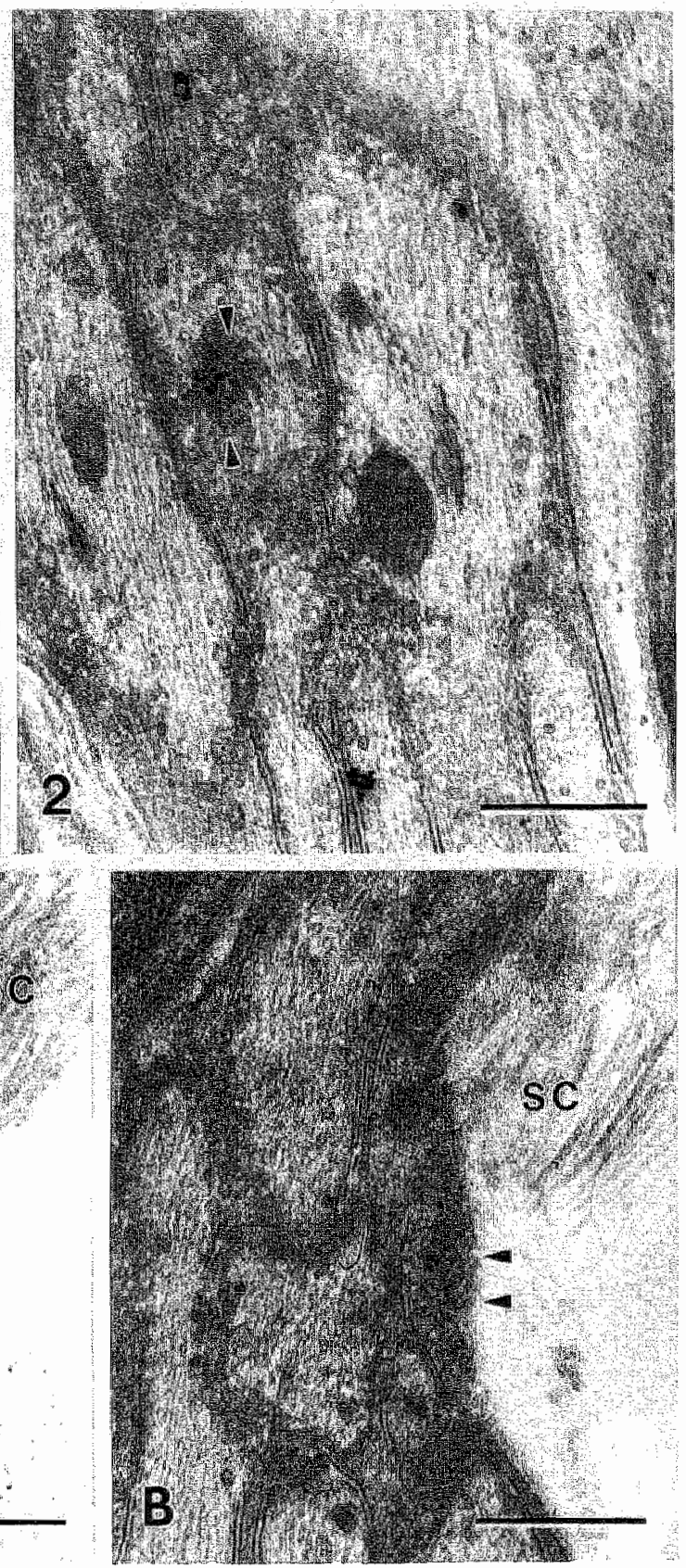
of the procedure. To visualize the arifgen, the peroxidase-antiroxidase (PAP) method 40 or the IntenSE M method (ImmunoGold Silver Staining (IGSS). Amersham Intemational plc, Amersham, UK) was used. After the PAP procedure, the specimens were incubated in $0.05 \%$ weightrolume diaminobenzidine (DAB) in Tris-buffered saline supplemented with $0.01 \%$ hydrogen peroxide $\left(\mathrm{H}_{2} \mathrm{O}_{2}\right.$, for 10 min. The $\mathrm{DAB}$ reaction product was intensified using a goldsubstituted silver peroxidase technique 26 . When the IGSS method was used, gold substitution was applied to stablize the silver reaction product. Following postixation in $1 \%$ osmium tetroxide (OsO 4 , supplemented with $1 \%$ potassium ferricyanide in $0.1 \mathrm{M}$ sodium cacodylate buffer, pH 7.4, for 20 min, the specimens were dehydrated in a graded series of ethanols and flat embedded in epoxy resin. Nerve fibres containing gold precipitation were light microscopically identified, after which these areas were dissected and mounted on pre-polymerized epoxy resin blocks. Ultrathin sections were cut of this material and after staining with uranyl acetate and lead citrate, these sections were inspected and photographed with a Philips 201 electron microscope (Philips Industries, Eindhoven. The Netherlands).

\section{Results}

Comea: In the cleaved corneas, numerous SP-immunoreactive nerve fibre bundles were found at the light microscopical level (Fig. 1). Ultrastructurally, these fibre bundles were unmyelinated and distributed throughout the comeal stroma (Figs. 2,3). They contained numerous neurotubuli, neurofilaments and mitochondria. A number of fibres within a fibre bundle stained positive for SP. In these fibres, the most intense staining was localized within varicosities containing mitochondria and numerous vesictes. No immunoreactive nerve fibres were found in the corneal epithelium.

Iris: In semithin sections of the iris, numerous SP-immunoreactive nerve fibre bundles were found (Fig. 4). Uitrastructurally, these fibres were unmyelinated and distributed throughout the (anterior and posterior) iris stroma (Fig. 5). The most intense staining was found within varicosities containing mitochondria and numerous vesicles. In comparison to the $\mathrm{SP}$ immunoreactivily in the comea, larger numbers of varicosities were found which were densely

Fig. 4: Nomarski interference contrast micrograph of a SP-immunoreactive nerve fibre bundle (arrowheads) in the iris. Scale bar represents $25 \mu \mathrm{m}$.

Fig. 5: Electron micrographs showing SP-immunoreactive nerve varicosities in the anterior (Fig. 5A) and the posterior (Fig. 5iB) stroma of the iris. The varicosities contain numerous vesicles (arrowheads) and mitochondria. Scale bars represent $0.5 \mu \mathrm{m}$.

Fig. 6: Electron micrograph of a SP-immunoreactive nerve varicosity containing numerous vesicles (arrowheads) in close proximity to smooth musele cells of the iris sphincter muscle (SM). The varicosity
partly lacks Schwann cell covering. Scale bar represents $0.5 \mu \mathrm{m}$.

Fig. 7: Electron micrograph showing $S$-immunoreactive nerve varicosities containing mitochondria and numerous vesicles (arrowheads) in the iris dilator area. Some varicosities contain numerous neurotubuli. DM, dilator muscle. Scaie bar represents $0.5 \mu \mathrm{m}$. 


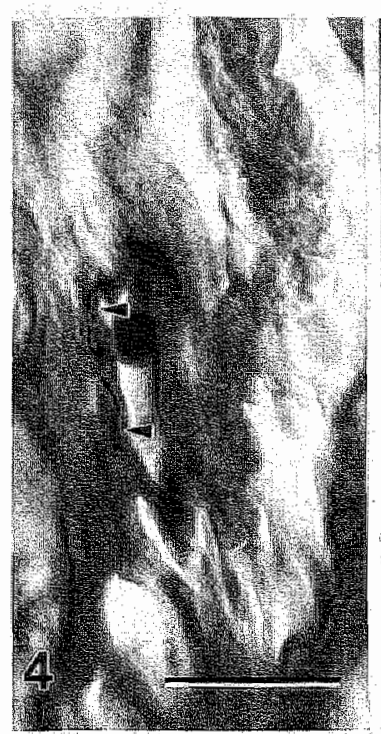

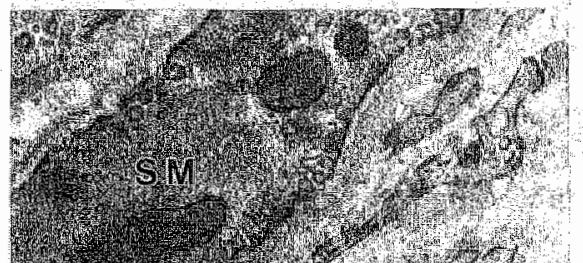

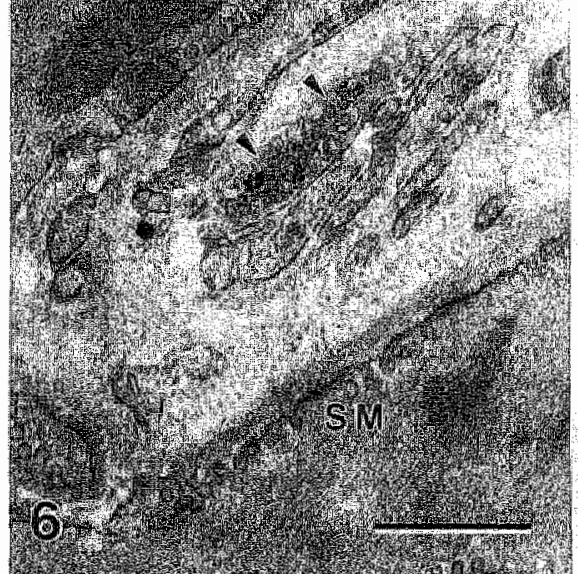

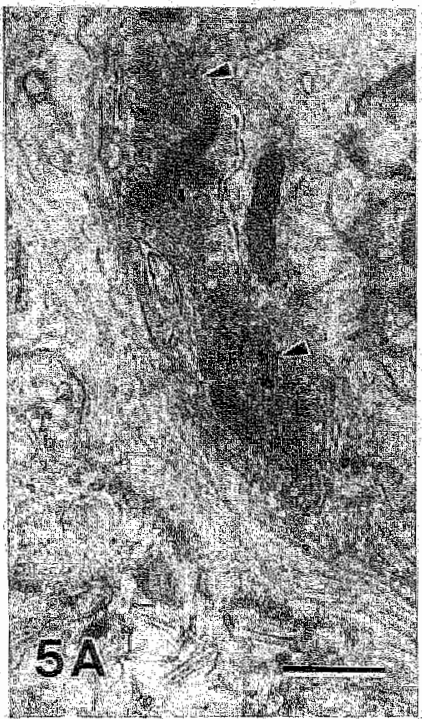

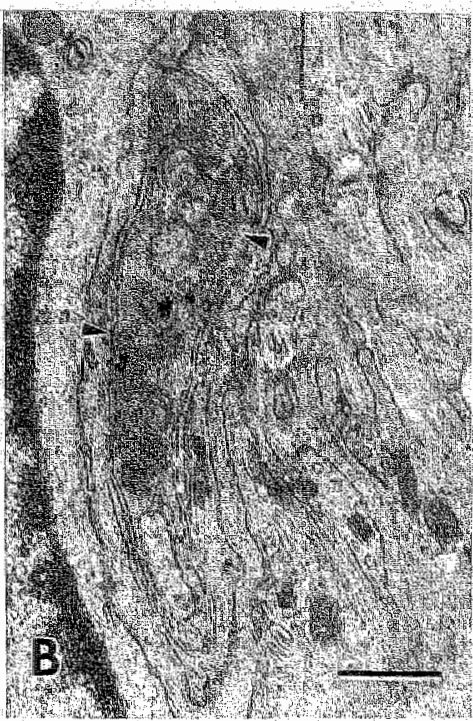

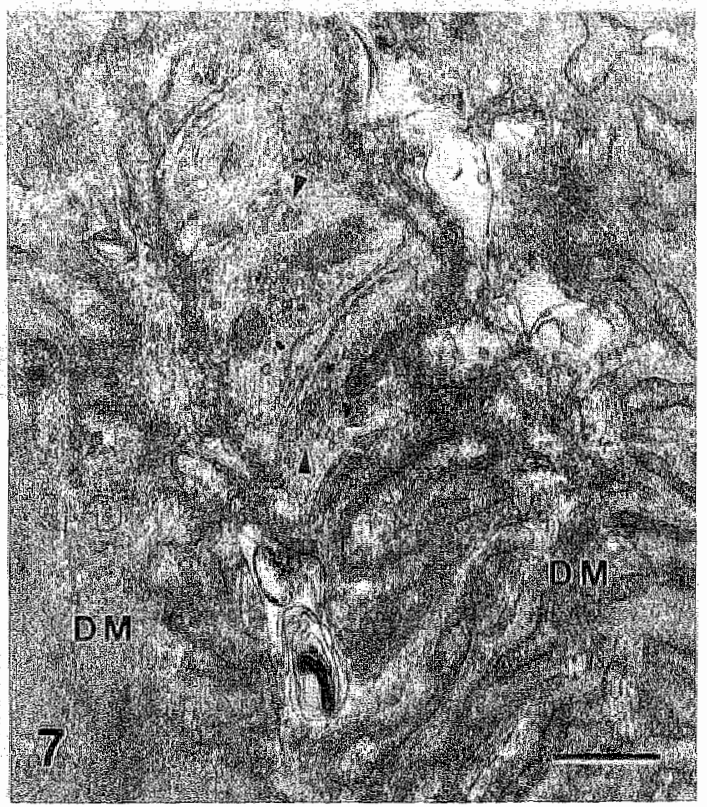


packed with vesicles. SP-immunoreactive varicosities containing numerous vesicles were also found in close proximity to the smooth muscle cells of the iris sphincter and dilator muscles (Figs . 6,7). These varicosities were often (partly) lacking Schwann cell covering. In all animals, the SP-immunoreactive staining of indal nerve fibres was more pronounced in comparison to the comea.

\section{Discussion}

The electron miciroscopic distribution of SP in nerve fibres of comea and iris is rather similar to the findings with CGRP as published in an earlier study ${ }^{3}$. CGRP and SP are both localized in nerve fibres distributed throughout the corneal and iridal stroma, including the iris sphincter and dilator regions, and are mainly stored in varicosities containing numerous vesicles. In the iris sphincter and dilator muscles, the varicosities were found in close proximity to the smooth muscle cells and were often lacking Schwann cell covering at these sites. In the previously mentioned study it was shown using anterograde tracing with Phaseolus vulgarisleucoagglutinin (PHA-L) that trigeminal nerve fibres of cornea and iris contain numerous varicosities, packed with vesicles ${ }^{3}$. The CGRP-immunoreactive fibres in that study contained similar varicosities with a similar distribution of these fibres in the cornea and iris. On account of the prominent ultrastructural resemblance of the PHA-L-labelled trigeminal fibres and varicosities and the CGRP-immunoreactive fibres, it was concluded that the CGRPimmunoreactive varicosities are of trigeminal origin. Considering the ultrastructural similarity and distribution of the SP- and CGRP-immunoreactive fibres in cornea and iris, it can be assumed that the SP-immunoreactive fibres are of trigeminal origin as well.

In the present study, the iridal nerve fibres showed much denser staining as compared to the corneal nerves. A similar phenomenon was observed in the earlier CGRP study ${ }^{3}$. The Triton $X-100$ concentration of $0,05 \%$, which was used in both studies, is necessary for optimal preservation of the ultrastructure but causes a less pronounced staining, especially in the cornea, as compared to the light microscopical studies in which concentrations of Triton $X-100$ of 0.1 to $0.5 \%$ are commonly used. In addition, the penetration of antibodies may be hampered by the specific organization of the corneal stroma. Antisera to SP from several laboratories were used in pilot studies. The antiserum provided by the Netherlands Institute for Brain Research was the only one by which acceptable results could be obtained. These technical problems may be the explanation why no SP immunoreactivity could be found in terminals of the corneal epithelium. Two methods have been used to visualize the SP-antigen. A denser staining of SP-immunoreactive nerves was obtained with the IGSS method, but optimal preservation of the ultrastructure of the vesicles in the varicosities was only obtained by the PAP method. Positively stained fibres were observed in consecutive sections, which indicates that the methods used were sensitive. Especially when using the PAP method, background staining was very low. 
The similarities in distribution of CGRP and SP in nerve fibres of comea and iris, and the previously light microscopically described colocalization of these neuropeptides ${ }^{17,19,4}$, make it tempting to speculate that CGRP and SP are costored and may be coreleased from the same nerve varicosities of comea and iris. In other peripherai nerve fibres, colocalization of CGRP and SP in the siame vesicular structures has already been shown in guinea pigs ${ }^{9}$. Costorage of CGRP and SP in the same nerve varicosities in comea and iris would even be more likely with regard to the argumented function of these neuropeptides. The function of CGRP is thought to be related to that of $\mathrm{SP}^{13}$. In the eye, intracameral administration of CGRP causes hyperemia, disruption of the blood-aqueous barrier; resulting in aqueous flare, and a rise in intraocular pressure 47 . SP administration alone induces aqueous flare, but this effect is enhanced when given together with CGRP. In the iris, both the sphincter and dilator muscles contain CGRP, but CGRP per se has no effect on the regulation of pupil size. However, SP causes miosis and CGRP has been described to intensify the miosis caused by intravitreall administration of SP. It is suggested that a stronger excitatory action of SP is facilitated by CGRP release. Light microscopic studies have demonstrated that the CGRP-immunoreactive nerve fibres of comea and iris outnumber the SP-immunoreactive fibres ${ }^{17,41}$. From this finding it may be assumed that the CGRP-immunoreactive varicosities outnumber the SP-immunoreactive varicosities as described in the present study in cornea and iris. Many CGRP-immunoreactive fibres might thus also act independently from SP. 


\section{REFERENCES}

1 Andersson SE: Responses to antidronic trigeminal nerve stimulation, substance P, NKA, CGRP and capsalcin in the rat eye. Acta Physiol Scand $1987 ; 131: 37:-376$.

2 Beckers HJM. Klooster J, Vrensen GFJM, Lamers WPMA: Ulitrastructural identification of trigeminal nerve terminals in the ptengopalatine ganglion of rats: an anterograde tracing and immunohistochemical study. Brain Res 1991; 557:22-30.

3 Beckers HJM, Kooster J, Vrensen GF JM, Lamers WPMA: Ultrastructural identification of trigeminal nerve endings in the rat cornea and iris. Invest ophthalmol Vis Sci 1992; 33: 1979-1986.

4. Bill A, Stjernschantz J, Mandahl A, Brodin E, Nilsson G: Substance P: Release on trigeminal nerve stimulation, effects in the eye. Acta Physiol Scand 1979; 106:371-373.

5 Duke-Elder S, Wybar KC: The autonomic system. In Duke-Elder (Ed), System of ophthalmology Vol. II, Kimpton, London, 1961, pp. 805-874.

6 Ekbom K, Hardebo JE, Waldenlind E: Mechanisms of cluster headache. In: Olesen J and Edvinsson L (Eds.), Basic Mechanisms of Headache, Elsevier. Amsterdam, 1988, pp. 463 476.

7 Gerfen CR, Sawchenko PE: The Phaseolus vulgaris-leucoagglutinin (PHA-L) anterograde axonal tract method. In: van Leewwen FW, Buils RM, Pool CW, Pach O (Eds.), Molecular Neuroanatomy, Etsevier Science Publishers B. V., 1988, pp. 361-373.

8. Groenewegen $\mathrm{HJ}$, Wouterlood $\mathrm{FG}$ : Light and electron microscopic tracing of meuronal connections with Phaseolus wulgaris-leucoagglutinin ( $\mathrm{PHA}-\mathrm{L}$ ), and combinations with other neuroanatomical lechniques. In: Björklund $A_{\mathrm{r}}$ Hökfeld $T$, Wouterlood FG, van den Pol AN (Eds.), Handbook of chemical neuroanatomy, Vol. 8 : Analysis of neuronal microcircuits and syraptic interactions, Elsevier Science Publishers B.V., 1990, p. 71 .

9 Gulbenkian S, Merighi A, Wharton J, Varndell IM, Polak IM: Calcitonin gene-related peptide and substance $P$ in secretory vesicles of peripheral nerves in the guinea pig. $J$ Neuracytol 1986; 15 ; $535-542$.

10 Hardebo JE: The involvement of trigeminal substance P neurons in cluster headache. An hypothesis. Headache 1984; $24: 294-304$.

11 Holzer P: Local effector functions of capsaicin-sensitive sensory nerve endings: involvement of tachykinins, calcitonin gene-related peptide and other neuropeptides. Neuroscience 1988; 24 : $739-768$.

12 Hoyes AD, Barber P: Ultrastructure of the coneall nerves in the rat. Cell Tissue Res $1976 ; 172$ : $133-144$.

13 Ishida-Yamamoto $A$, Tohyama M: Calcitonin gene-related peptide in the nervous tissue. Progress in Neurobiology 1989; 33 : $335-386$.

14 Konishi $S$, Tsunoo $A_{1}$ Yantihara $N$, Otsuka $M$ : Peptidergic excitatory and inhibitory synapses in mammalian sympathetic ganglia: roles of substance $P$ and enkephalin. Biomed Res $1980_{0}^{\circ} 1$ : $528-536$.

15 Kruger $L_{i}$ Silvermen $\mathrm{JD}_{\text {, }}$ Mantyh $\mathrm{PW}$, Sternini $\mathrm{C}_{\mathrm{i}}$ Brecha $\mathrm{NIC}$ : Peripheral patterns of calcitonin gene-related peptide general somatic sensory innervation: cutaneous and deep terminations. J Comp Neurol 1989; $280: 291-302$

16 Kruger L, Mantyh PW, Sternini C, Brecha NC, Mantyh CR: Calcitonin gene-related peptide (CGRP) in the rat central nervous system; patterns of immunoreactivity and receptor binding sites. Brain Res $1988 ; 463: 223-244$.

17 Kuwayama Y, Stone RA: Distinct substance $P$ and calcitonin gene-relited peptide immunoreactive nerves in the guinea pig eye. Invest Ophthalmol Vis Sci 1987; 28: 1947-1954.

18 Kuwayama $Y$, Terenghi $G$, Polak JM, Trojanowski JQ. Stone RA: A quantitative correlation of substance $P_{*}$, calcitonin gene-related peptide- and cholecys tokinin-like immunoreactivity with retrogradely labeled trigeminal ganglion cells innervating the eye. Brain Res 1987; 405: 220-226. 


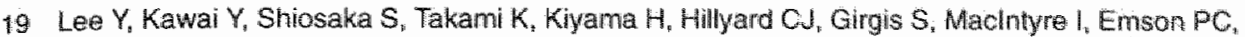
Tohyama $\mathrm{M}$ : Coexistence of calcitonin gene-related peptide and substance P-like peptide in single cells of the trigeminal ganglion of the rat: immunohistochemical analysis, Brain Research 1985; 330: $194-196$.

20 Lehtosalo Jl, Uusitalo $H_{2}$ Uusitalo $R_{i}$ Poranen A, Palkama A: Electron microscopic identification of trigeminal nerve fibers in the cillary body and the iris. Neurosci Lett 1983; $42 ; 239-242$

21 Lehtosialo $\mathrm{Jl}_{3}$ Lusitalo $\mathrm{H}_{3}$ Palkama $\mathrm{A}$ : Sensory supply of the anterior uvea: a light and electron microscope study. Exp Brain Res 1984; 55: 569 .

22 Marfurt CF, Del Toro DR: Corneal sensory pathway in the rat: a Horseradish peroxidase tracing study. J Comp Neurol 1987: 261: 450-459.

23 Marfurt CF, Kingsley RE, Echtenkamp SE: Sensory and sympathetic innerwation of the mammalian conea: a retrograde Iracing study. Invest Ophthalmol Vis Sci 1989; 30: 461-472.

24 Miller A, Costa M, Fumess JB, Chubb IW: Substance P immunoreactive sensory nerves supply the rat iris and comea. Neuroscience Letters 1981; $23: 243-249$.

25 Oksala $O$, Stjemschantz J: Effects of calcitonin gene-related peptide in the eye. A study in rabbits and cats. Invest Ophthalmol Vis Sci 1988; 29: 1006-1011.

26 Pol, wan den AN, Görcs T: Synaptic relationship between neurons containing vasopressin, gastrin-releasing peptide, vasoactive intestinal polypeptide, and glutamate decarboxylase immunoreactivity in the suprachiasmatic nucleus: dual ultrastructural immunocytochemistry with gold substituted silver peroxidase. J Comp Neurol 1986; 252: 507-521.

27 Prechti $\mathrm{JC}_{*}$ Powley TL: B-afferents: A fundamental division of the nervous system mediating homeostasis? Behavioral and Brain Siciences 1990; 13: 289-331.

28 Riuskell GL: Facial parasympathetic innervation of the choroidal blood vesseis in monkeys. Exp Eye Res 1971;12: 166-171.

29 Shimizu Y, ushimoto I, Shiosaka S, Kuwayama Y, Fukuda M, Inagaki S, Sakanaka M, Tohyama M: A direct contact of substance P-containing nerve fibers with pupillary sphincter muscles of the rat: an immunohistochemical analysis. Neuroscience Letters 1982; 33: 25-20.

30 Silverman JD, Kruger L: Calcitonin^gene-related-peptide-immunoreactive innervation of the rat head with emphasis on speclalized sensory structures. J Comp Neural 1989; 280: 303-330.

31 Smolen AJ: Marphology of synapses in the autonomic nervous system. J Electron Microscopy Technique 1988; 10: 187-204.

32 Stone RA, Kuwayama $Y$, Terenghi G, Polak JM: Calcitonin gene-related peptide: accurrence in comeal sensory nerves. Exp Eye Res 1986; 43: 279-283.

33 Suzuki $N$, Hardebo JE, Owman Ch: Origins and pathways of cerebrovascular vasoactive intestinal polypeptide-positive nerves in rat. J Cereb Blood Flow Metab 19:8; $8: 697-712$.

34 Suzuki N, Hardebo JE, Owman Ch: Trigeminal fibre collaterals storing substance P and calcitonin gene-related peptide associate with ganglion cells containing choline acetyltransterase and vasoactive intestinal polypeptide in the sphenopalatine ganglion of the rat. An axon reflex modulating parasympathetic ganglionic activity? Neuroscience 1989; 30: $595-604$.

35 Suzuki $N_{3}$ Hardebo JE Owman Ch: Origins and pathways of cerebrovascular nerves storing substance $P$ and calcitonin gene-related peptide in rat. Neuroscience 1989; $31: 427-438$.

36 Suzuki $N$, Hardebo JE, Skagerberg $G$, Owman Ch: Central origins of preganglionic fibers to the sphenopalatine ganglion in the rat. A lluorescent retrograde traceir study with special reference to its relation to central calecholaminergic syslems. J Autonomic Nerv Syst 1990; 30: 101-110.

37 Tusscher Ten MPM, Klooster $\mathbb{U}$, Vrensen GFJM: The innervation of the rabbit's anterior eye segment: a retrograde tracing study. Exp Eye Res 1988; $46: 717-730$.

38. Tusscher Ten MPM, Klooster J, Van der Want JJL, Lamers WPMA., Viensen GFJM: The allocaton of nerve fibres to the amterior eye segment and peripheral ganglia of rats. I. The sensory innervation. Brain Res 1989; 494: 95-104. 
39 Tusscher Ten MPM, Klooster J. Van der Want JU, Lamers WPMA, Vrensen GFJM: The allocation of nerve fibres to the anterior eye segment and peripheral ganglia of rats. H. The sympathetic innervation. Brain Pes 1989; 494: 105-113.

40 Tusscher Ten MPM, Klooster J, Balget B, Van der Werf F, Wrensen GFuM: Pre-and post-ganglionic nerve fibres of the pterygopalatine gangtion and their allocation to the eyeball of rats Brain Res 1990: $517: 315-323$.

41 Terenghi G, Polak JM, Ghatei MA, Mulderry PK, Buter JM, Unger WG, Bloom SR: Distribution and origin of calcitorin gene-related peptide (CGRP) immunoreactivity in the sensory innervation of the manmallan eye. J Comp Neurol $1985 ; 233: 506-516$.

42 Terwo T, Joo F, Huikuri KT, Toth I, Palkama A: Fine structure of sensory newes in the rat cornea: an experimental nerve degeneration study. Pain 1979:6:57-70.

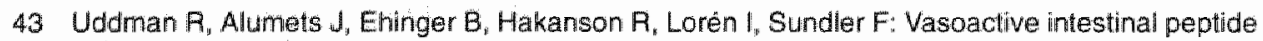
nerves in ocular and obital structures of the cat. Invest Ophthalmol Vis Sci 1978; 19: 878-885.

44 Unger WG: Review: Mediation of the ocular response to injury. J Ocular Pharmacol 1990; 6: $337-353$.

45 Uusitalo H, Krootlla K, Palkama A: Calcitonin gene-related peptide (CGRP) immunoreactive sensory nerves in the human and guinea pig uvea and comea. Exp Eye Res 1989; 48: 467-475.

46 Vandesande F: Peroxidase-antiperoxidase techniques. In: Cuello AC (Ed.), Immunohistochemistry, IBFO Handbook Series: Methods in Neurosciences, Vol. 3 , Wiley, New York, 1983, pp. 101-119.

47 Wahlestedt $\mathrm{C}$, Beding B, Ekman R, Oksala O, Stjernschantz J, Hakanson R: Calcitonin gene-related peptide in the eye: release by sensory nerve stimulation and effects associated with neurogenic intlammation. Regulatory Peptides 1986; 16:107-115. 


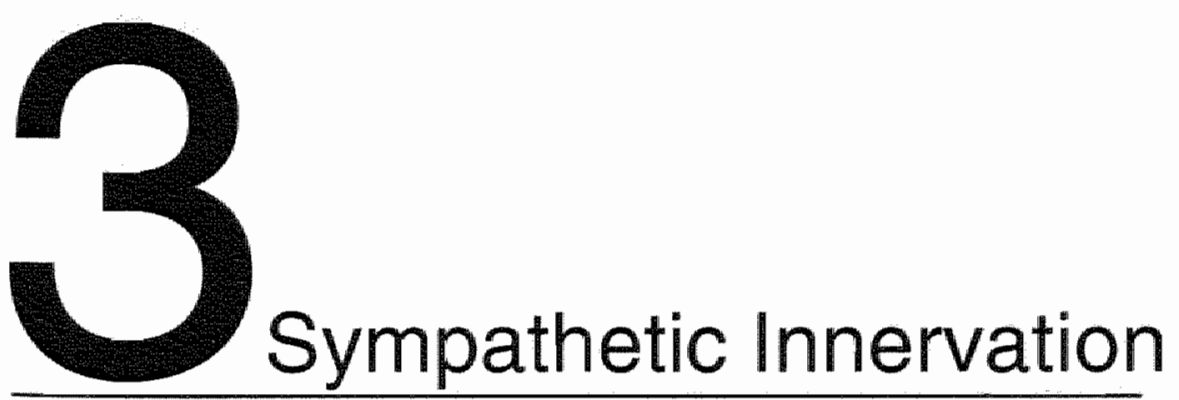





\section{Sympathetic Innervation \\ of the Rat's Eye and Peripheral Ganglia:}

\section{An Electron Microscopic Autoradiographic \\ Tracing Study}

\section{Abstract}

The sympathetic innervation of the anterior eye segment and related peripheral ganglia was studied in rats using light and electron microscopic autoradiography after anterograde tracing with ${ }^{3} \mathrm{H}$-leucine from the rostral pole of the superior cervical ganglion.

In the trigeminal and pterygopalatine ganglia, unmyelinated nerve fibres were labelled. Some fibres contained accumulations of vesicles. Close appositions of these labelled sympathetic fibres with other unmyelinated fibres were common, and were also observed at sites where accumulations of vesicles were found.

In the iris, ciliary body and trabeculum, numerous fibres and vesicle-containing varicosities were labelled, which all had a similar morphology. No labelling was found in the cornea.

Sympathetic fibres traversing the trigeminal and pterygopalatine ganglion are closely apposing other unmyelinated fibres and contain clusters of vesicles without forming classical synaptic contacts. However, non-synaptic information transfer will need further investigation. The tissues of the anterior eye segment, except the cornea, are densely innervated by sympathetic nerve terminals.

\section{Introduction}

The sympathetic innervation of the anterior eye segment from the superior cervical ganiglion has mainly been described by catecholaminergic fluorescence and denervation studies ${ }^{25}$. These studies have indicated the existence of a dense innervation of the rodent iris, with a plexus of nerve endings in the areas of the dilator and sphincter muscles, and nerve endings adjacent to blood vessels and iridic melanocytes $5,6,9,10,12,22,25$. It has also been suggested that axo-axonal contacts between adrenergic and cholinergic nerve endings are present in the iris $^{7}$

In addition, tracing studies from the superior cervical ganglion were performed, mainly at the light microscopic level. These studies have shown that in the rat iris, sympathetic fibres are mainly localized in the peripheral stroma and around blood vessels ${ }^{37}$. A dense plexus of fibres within the dilator area was found, with fibres entering the sphincter area ${ }^{19}$. In the cillary body, sympathetic fibres were found in the central stroma and in the stroma of the ciliary 
processes 37 . Few sympathetic fibres were found in the pectinate ligament and in the trabeculum.

Light microscopic tracing studies also revealed that sympathetic fibres trawerse other peripheral ganglia. In the trigeminal ganglion, bundles of sympathetic fibres seem to traverse the ganglion whereas isolated nerve fibres are localized in close proximity to cell bodies all over the ganglion. suggesting the presence of synaptic tranismission in the trigeminal ganglion ${ }^{37}$. However, no synapses have ever been described in the trigeminal ganglion.

The pterygopalatine ganglion is composed of a rostral triangular cellular mass with numerous. additional cell bodies in the nerve fibres extending from the ganglion into the orbit, and a caudal string of cells surrounding the major petrosal nerve up to the level of the trigeminal ganglion ${ }^{38}$. Recently, the rostral triangular part of the pterygopalatine ganglion was shown to consist of two different areass ${ }^{\dagger}$. Sympathetic fibres have been described to traverse both the rostral area and the caudal string of cell bodies ${ }^{37}$. Synaptic contacts of sympathetic origin with perikarya or dendrites have not been described in the pterygopalatine ganglion.

Catecholaminergic fluarescence studies give no definite proof of the sympathetic arigin of fibres ${ }^{4,14}$, and electron microscopic anterograde tracing studies from the superior cervical ganglion are scarce. Moreover, despite the presence of catecholaminergic fluorescent fibres in the comea ${ }^{5}$, there is still controversy whether this tissue receives a sympathetic innervation. To further unravel the structure of sympathetic terminals in the anterior eye segment, and to elucidate whether sympathetic fibres form terminals or other contacts in the trigeminal and pterygopalatine ganglia, anterograde tracing from the superior cervical ganglion was performed at the ultrastructural level. Since the satellite cells in autonomic ganglia have been shown to comprise a barrier for horseradish peroxidase (HRP) and wheatgerm agglutinin coupled to HAP (WGA-HRP) ${ }^{35}$, 3H-leucine was chosen as anterograde tracer. Following injection into the rostral pole of the superior cervical ganglion, the distribution of tracer in the anterior eye segment and the trigeminal and pterygopalatine ganglia was studied using light and electron microscopic autoradiography.

\section{Materials and Methods}

Five adult male Wistar rats, weighing between 200 and $300 \mathrm{~g}$, were used.

The rats were anaesthetized with Nembutal (Rousselot, Paris, France), 0.3 ml/kg i.p. and Hypnorm (Janssen, Tilburg, The Netherlands), $0.3 \mathrm{~m} / \mathrm{kg} \mathrm{i} . \mathrm{m}$. and placed upside down in a stereotaxic frame. The left superior cervical ganglion was reached by blunt dissection of the neck tissues 3 . Approximately $10 \mu \mathrm{l}$ of ${ }^{3} \mathrm{H}$-lleucine (total activity of $500 \mu \mathrm{Ci}$ ) was pressure injected into the rostral part of the superior cervical ganglion, using glass micropipettes (20 $\mu \mathrm{m}$ tip diameter) connected with a polyethylene tubing to a $10 \mu 1$ Hamilton syringe. 

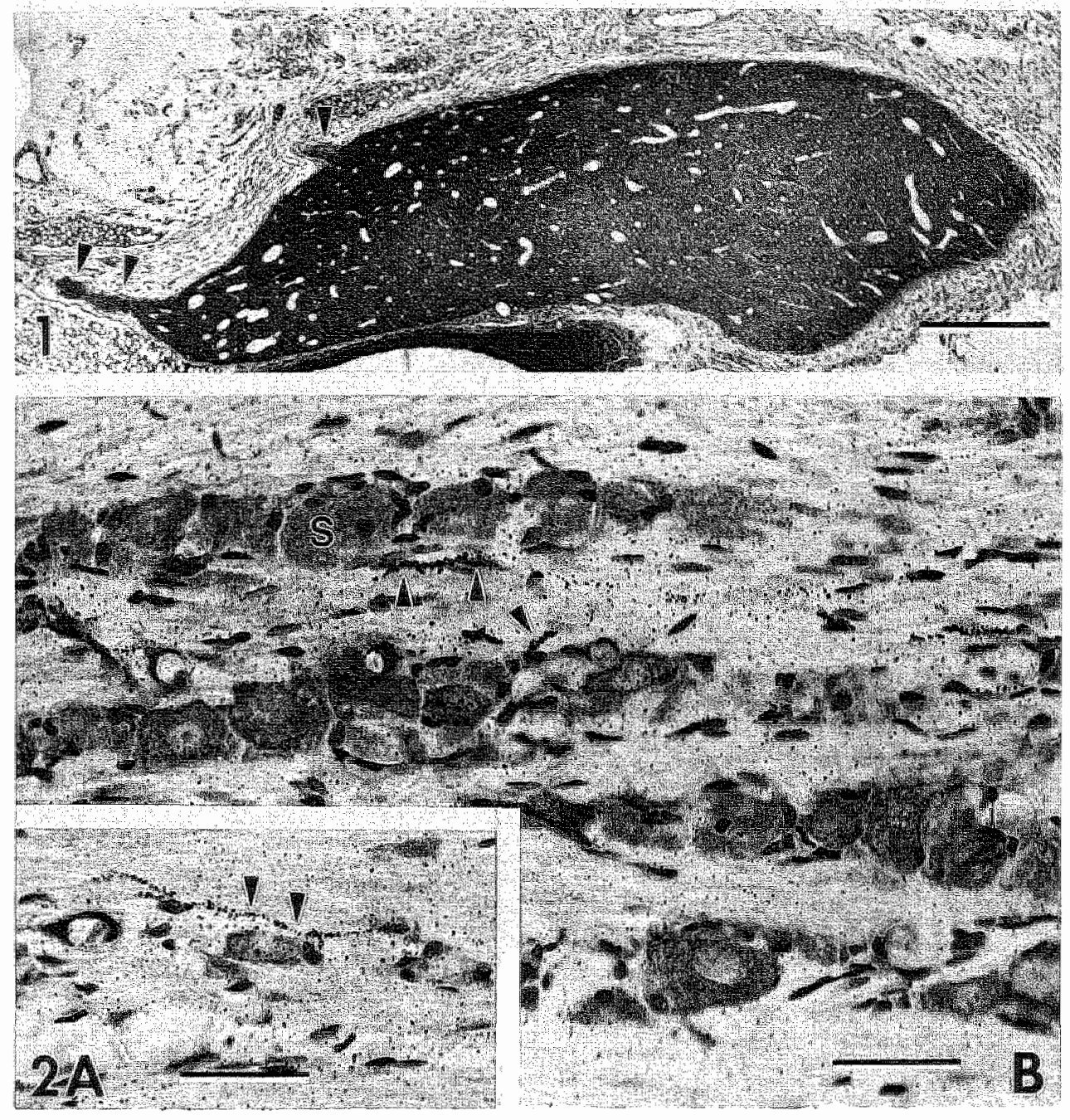

Fig. 1: Light micrograph showing the profuse labelling of the injected superior cervical ganglion. Labelling is most dense at the rostral pole. Fibre bundles leaving the ganglion rostrally are densely labelled (arrowheads). Scale bar represents $0.5 \mathrm{~mm}$.

Fig. 2: Light micrographs showing labelled fibres in the ipsilateral trigeminal ganglion. Somelabelled fibres course in close proximity to ganglion cell somata (arrowheads). $S$, soma. Scale bars represent $0.05 \mathrm{~mm}$. 

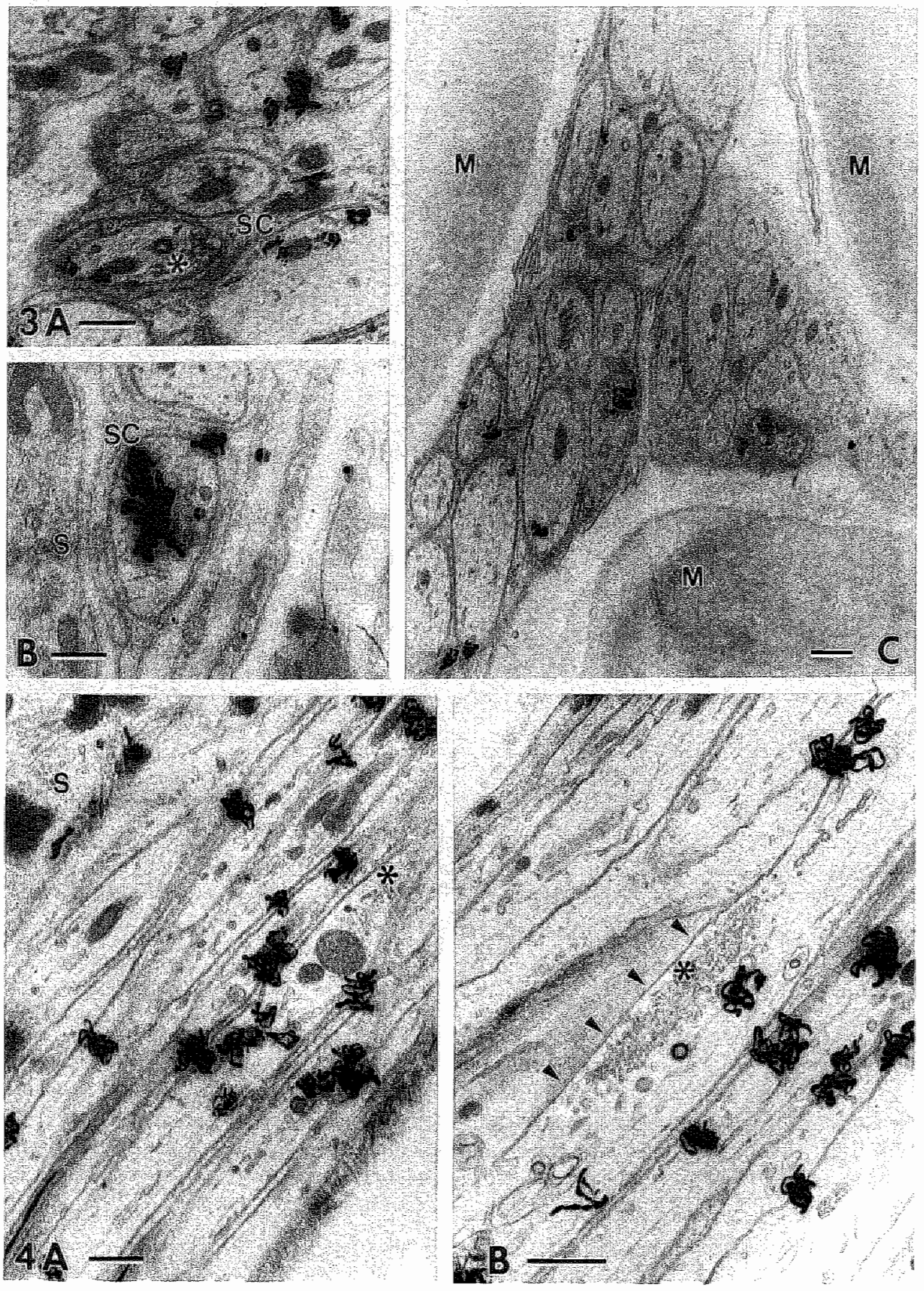
After a survival period of 8 days, the animals were killed with an overdose of Nembutal and transcardially perfused with $100 \mathrm{ml} 0.1 \mathrm{M}$ sodium cacodylate buffer, $\mathrm{PH} 7.4$, followed by 1 hter of a fixation solution containing $1 \%$ paratormaldehyde and $1.25 \%$ glutaraldehyde in $0.1 \mathrm{M}$ sodium cacodylate buffer, $\mathrm{pH} 7.4^{26}$. The heads were postfixed for 3 days, using the same fixation solution, and subsequently rinsed in buffer for 24 hrs. The superior cervicall, the trigeminal and the pterygopalatine ganglia and the eyes were dissected. The superior cervical and the right pterygopalatine ganglia were embedded in Technowit (Kulzer, Friedrichsdort, Germany), sectioned at $4 \mu \mathrm{m}$ and mounted. The trigeminal ganglia were sectioned at $20 \mu \mathrm{m}$ with a freezing microtome. Every second section was kept apart and numbered. The other sections were consecutively numbered and mounted. One third of the anterior eye segments (including the chamber angle) was embedded in Technowit, sectioned at $4 \mu \mathrm{m}$ and mounted. The mounted sections of the trigeminal ganglia, and the Technovit-embedded specimens were dipped at $32^{\circ} \mathrm{C}$ in Ifford G5 emuision (llford Limited, Mobberley, Cheshire, UK), dried, and stored in light-tight slide boxes, at $4^{\circ} \mathrm{C}$, for $4-6$ weeks. Following exposure, the autoradiographs were developed in D19b and fixed in $24 \%$ sodium thiosulfate at $18^{\circ} \mathrm{C}$. They were rinsed with tap water, stained with cresyl fast violet and light microscopically examined.

The remaining two-third of the anterior eye segments was divided into a number of parts, each containing cornea, iris, ciliary body and trabeculum. Together with the remaining sections of the trigeminal ganglia and the left pterygopalatine ganglia, these specimens were prepared for electron microscopic autoradiagraphy. They were postfixed in $1 \%$ osmium tetroxide $\left(\mathrm{OsO}_{4}\right)$ supplemented with $1 \%$ potassium ferricyanide in $0.1 \mathrm{M}$ sodium cacodylate buffer, $\mathrm{pH} 7.4$, for 1 hour, then dehydrated in a graded series of ethanols and embedded in epoxy resin. Ultrathin sections were cut and placed on Formvar (Merck, Darmstadt, Germany) coated slides, stained with uranyl acetate and lead citrate and coated with carbon $(5-8 \mathrm{~nm})$. The slides were dipped in liford L4 emulsion, dried, and stored for 2-6 months in light-tight slide boxes at $4^{\circ} \mathrm{C}$. Following exposure, the slides were developed in D19b and fixed in $24 \%$ sodium thiosulfate.

Fig. 3: Electron micrographs showing labelled unmyelinated nerve fibres in the trigaminal ganglion. $S$, soma; SC. Schwann cell covering; $M$, myelin sheath. A: Some labelled fibres contain accumulations of vesicles (asterisk). B: Labelled unmyelinated nerve fibre in close proximity to a soma in the frigeminal ganglion. The Schwann cell covering of the fibre is intact. $C$ : Intermingling of labelled unmyelinated ribre bundies between myelinated fibres in the trigeminal ganglion. Scale bars represent $0.5 \mu \mathrm{m}$.

Fig. 4: Electron micrographs showing labelled unmyelinated fibres in the pterygopalatine ganglion. $S$, soma. A: Densely labelled fibres in the vicinity of a soma. One contains an accumulation of vesicles (asterisk). B: Labelled fibre containing a large accumulation of vesicles (asterisk). At the site of the accumulation of vesicles, the Schwann cell covering of the fibre is lacking (arrowheads), the fibre thus theing in close apposition with another unmyelinated fibre. Scale bars represertt $0.5 \mu \mathrm{m}$. 

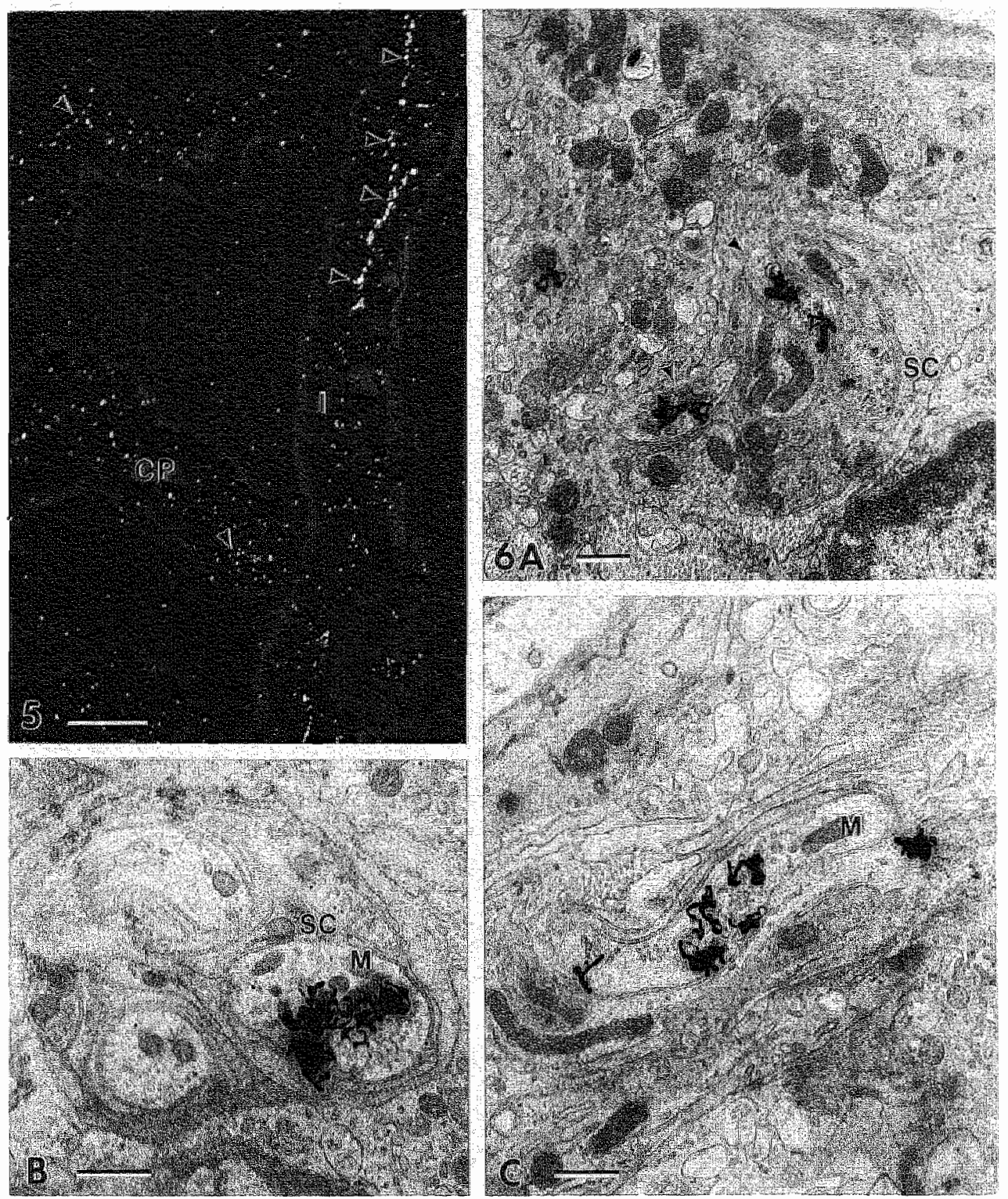

Fig. 5: Darkfield micrograph showing labelled nerve fibre bundles in the iris and ciliary processes (arrowheads). I, iris; CP, cillay process. Scale bar represents $0.05 \mathrm{~mm}$.

Fig. B: Electron micrographs showing labelled nerve fibres and varicosities containing numerous clear vesicles, in the iris stroma. SC, Schwann cell covering; $M$, mitochondrion. A: Unmyelinated fibre bundle with labelled varicosities containing numerous vesicles. Some varicosities lack Schwann cell covering (arrowheads). Vesicles are localized close to the plasma membrane. B,C: Labelled varicosities in unmyelinated fibre bundles containing numerous vesicles af different shape. Scale bars represent $0.5 \mu \mathrm{m}$. 

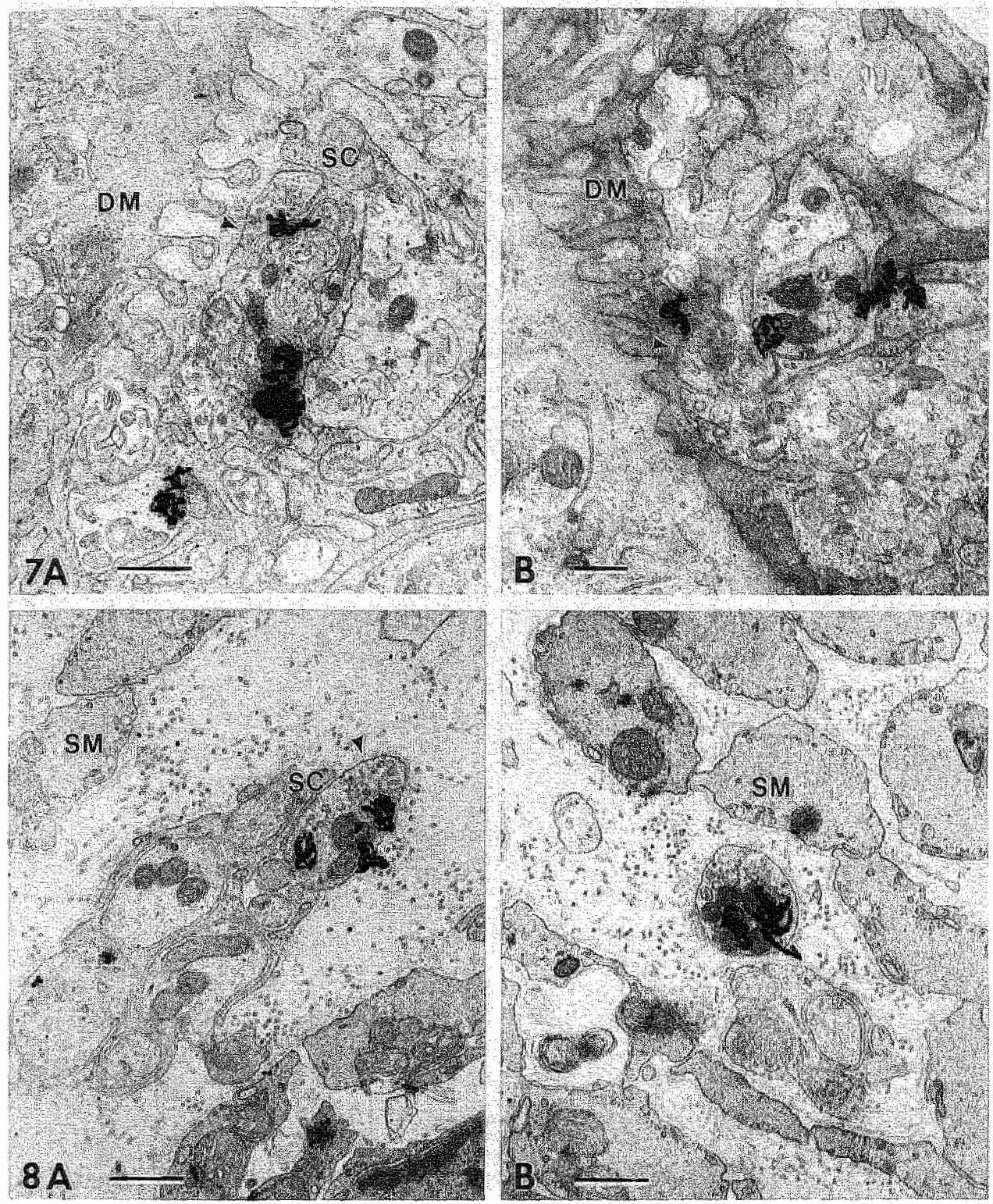

Fig. 7: Electron micrographs showing unmyelinated fibre bundles with labelled varicosities containing numerous vesicles in close proximity to the inis dilator muscle. The Schwann cell covering of the libre bundie is partly lacking at the side facing the muscle cells (arrowheads). DM, Diltator muscle; SC, Schwann cell covering. Scale bars represent $0.5 \mu \mathrm{m}$.

Fig. 8: Electron micrographs showing labelled varicosities containing vesicles in close proximity to muscles cells of the iris sphincter muscle. SM, Sphincter muscle; SC, Schwann cell covering. A: Labelled varicosity. partly without Schwann cell covering (arrowhead), in a libre bundle. B: Labelledisolated varicosity without Schwann cell covering. Scale bars represent $0.5 \mu \mathrm{m}$. 

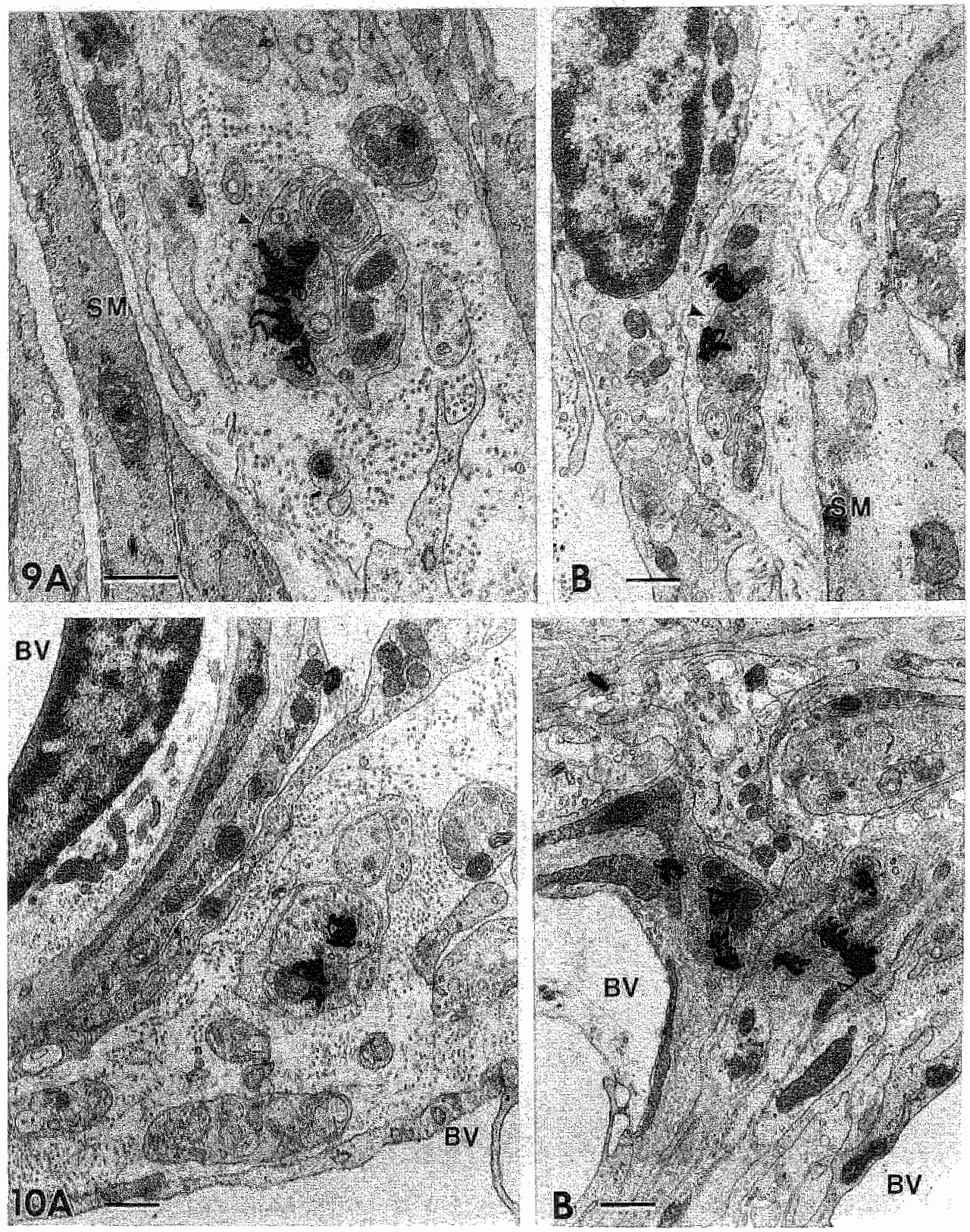
After rinsing in distilled water for 30 minutes, the Formvar films were lloated offog. The autoradiographic sections were mounted on parallel ruled grids and viewed in a Phillips 201 electron microscope (Philips Industries, Eindhoven. The Nethertands).

\section{Results}

\section{Injection site}

Light microscopic autoradiographs of the injected superior cervical ganglia showed profuse labelling with autoradiographic silver grains (Fig. 1). Labelling was found all over the glanglion, but was most dense at the rostrall pole. Axons leaving the ganglion rostrally were densely labellled.

\section{Trigeminal ganglion}

In all animals, numerous fibres were labelled in the ipsilateral trigeminal ganglion (Fig. 2A-B). Some labelled fibres coursed in close proximity to ganglion cell bodies. In electron microscopic autoradiographs, numerous labelled unmyelinated fibres were found (Fig. 3). Labelling was absent in myelinated fibres. Some labelled fibres contained areas with accumulations of vesicles of different shape (Fig. 3A). Labelled fibre bundles intermingled between myelinated fibres (Fig. 3C). Labelling was absent in myelinated fibres. Although some labelled fibres coursed in close proximity to ganglion cell badies (Fig. 3B), no terminals containing vesicles or other signs of synaptic contacts within the ganglion were observed. In the contralateral trigeminal ganglion, no labeiling was found.

\section{Pterygopalatine ganglion}

In electron microscopic autoradiographs of the ipsilateral pterygopalatine ganglia, numerous unmyelinated nerve fibres were labelled (Fig. 4). Labelling was found in fibres of the rostral cellular mass as well as in the caudal string of cells, but was most dense within the rostral part of the string of cells. Labelling was absent in myelinated fibres. Some labelled fibres contained

Fig. 9: Electron micrographs showing unmyelinated libre bundles with labelled varicosities containing numerous vesicles in close proximity to iris melanocytes in the sphincterarea. At the side of the varicosities facing the melanocytes, the Schwann cell covering is lacking (arrowheads). SM, sphincter muscle. Scale bars represent $0.5 \mu \mathrm{m}$.

Fig. 10A: Electron micrograph showing labelled varicosities containing numerous vesicles in an unmyelinated fibre bundle close to iridal blood vessels. BV, blood vessel. Scale bar represents $0.5 \mu \mathrm{m}$.

Fig. 10B: Electron micrograph showing labelled varicosities containing numerous vesicles in close proximity to an iridal blood vessell. BV, blood vessel. Scale bar represents $0.5 \mu \mathrm{m}$. 
accumulations of mainly clear vesicles of different shape. Close appositions between labelled and unilabelled fibres ware trequently observed. Occasionally, these close membrane appositions were lound at the site where the labelled fibres contained accumulation of vesicles (Fig. 4B). No synaptic contacts in a strict sense, i.e. With pre-and postsynaptic specializations, were found. In the contralateral pterygopalatine ganglion, no labelling was found.

\section{Iris and cornea}

As shown in the light microscopic autoradiograph of Fig. 5 , numerous labelled fibres were found in the ins. Ultrastructurally, labelling was found within unmyelinated fibre bundles and varicose terminals throughout the iris stroma, but was most dense in the posterior peripheral stroma (Flg. 6A-C). Labelled neve fibres were surrounded by Schwann cells. The varicasities contained vesicles of varying shape. Labelled varicosities otten were lacking Schwann cell covering. Vesicles often were localized close to the plasma membrane. Labelled varicosities containing vesicles of varying shape were found in close proximity to the smooth muscle cells of the dilator muscle (Fig. 7) and also, although less frequently, to the sphincter muscle (Fig. 8). Labelled fibres and varicosities were also found in close proximity to melanocytes in the region of the sphincter muscle (Fig. 9), and were observed adjacent to blood vessels (Fig. 10). The side of the labelled nerve varicosities facing melanocytes or muscle cells were lacking Schwann cell covering. The absence of melanin granules in the melanocytes is due to the fact that Wistar abino rats were used. No labelling was found adjacent to or in the iris epithelium.

Labelled fibres were found in the limbus, but despite extensive screening of large numbers of autoradiographs, no labelling at all was found in the cornea.

Fig. 11: Electron micrograph showing labelled varicosities containing numerous vesicles in a fibre bundle coursing just underneath the basal membrane of the ciliary body epithelium. At the side of the varicosity facing the ciliary body apithellum, the Schwann cell covering is lacking (arrowheads). ep cillary body epithelium. Scale bar represents $0.5 \mu \mathrm{m}$.

Fig. 12A, B: Electron micrographs showing unmyelinaled fibre bundles in the ciliary body with labelled varicosities containing numerous vesicles in close proximity to ciliary muscle cells. The side of the varicosities facing the cilliary muscle cells lack Schwann cell covering (arrowheads). CM, ciliary muscle cell. Scale bars represent $0.5 \mu \mathrm{m}$.

Fig. 12C: Electron micrograph showing a labelled varicosity as part of a fibre bund in the central stroma of the ciliary body. The Schwann cell covering is partly lacking (arrowhead). Scale bar represents $0.5 \mu \mathrm{m}$.

Fig. 13: Electron micrograph showing an unmyelinated fibre bundle with a labelled varicosity containing numerous vesicles in close proximity to a blood vessel in the pectinate ligament. Scale bar represents $0.5 \mu \mathrm{m}$. 

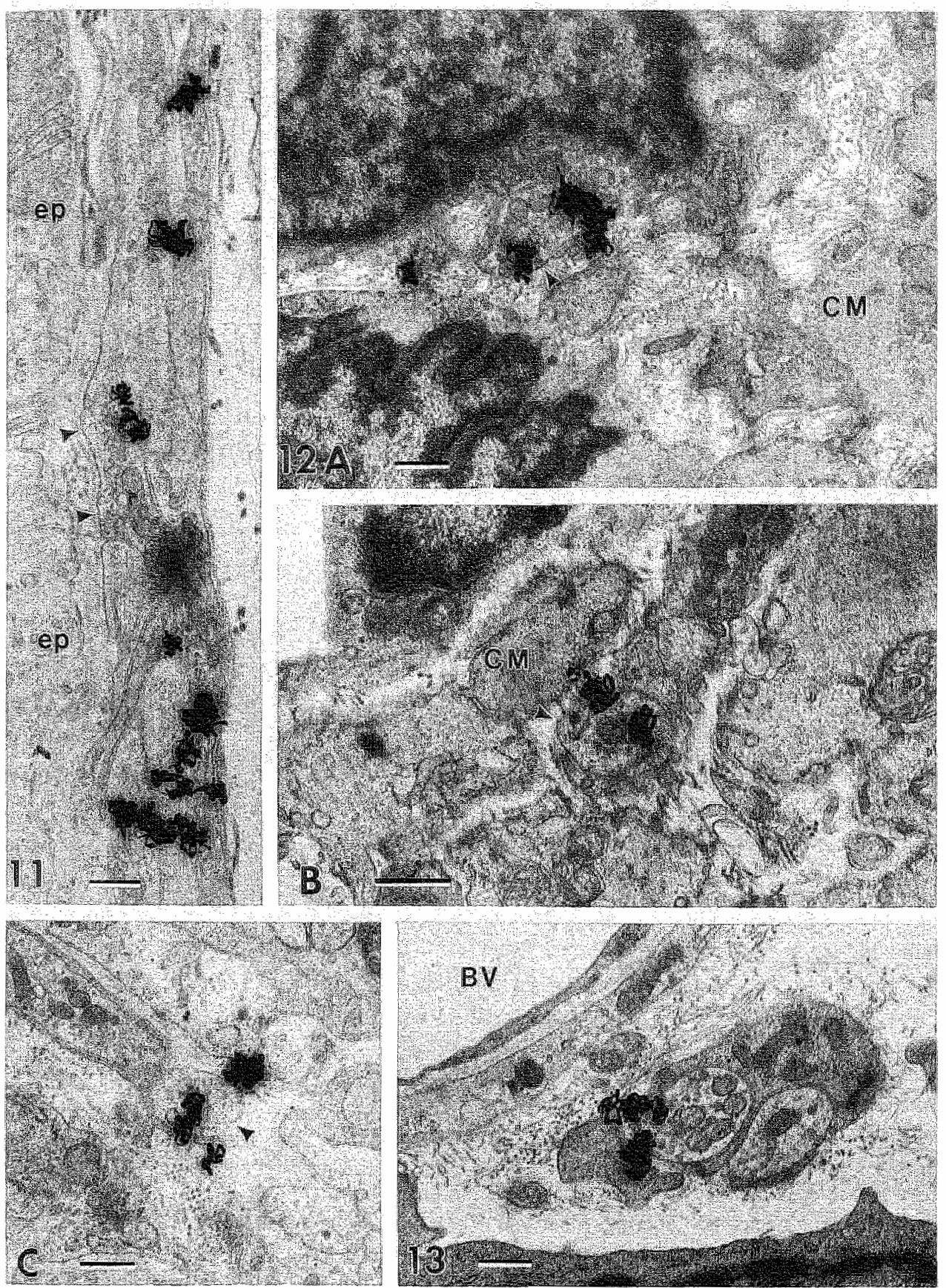

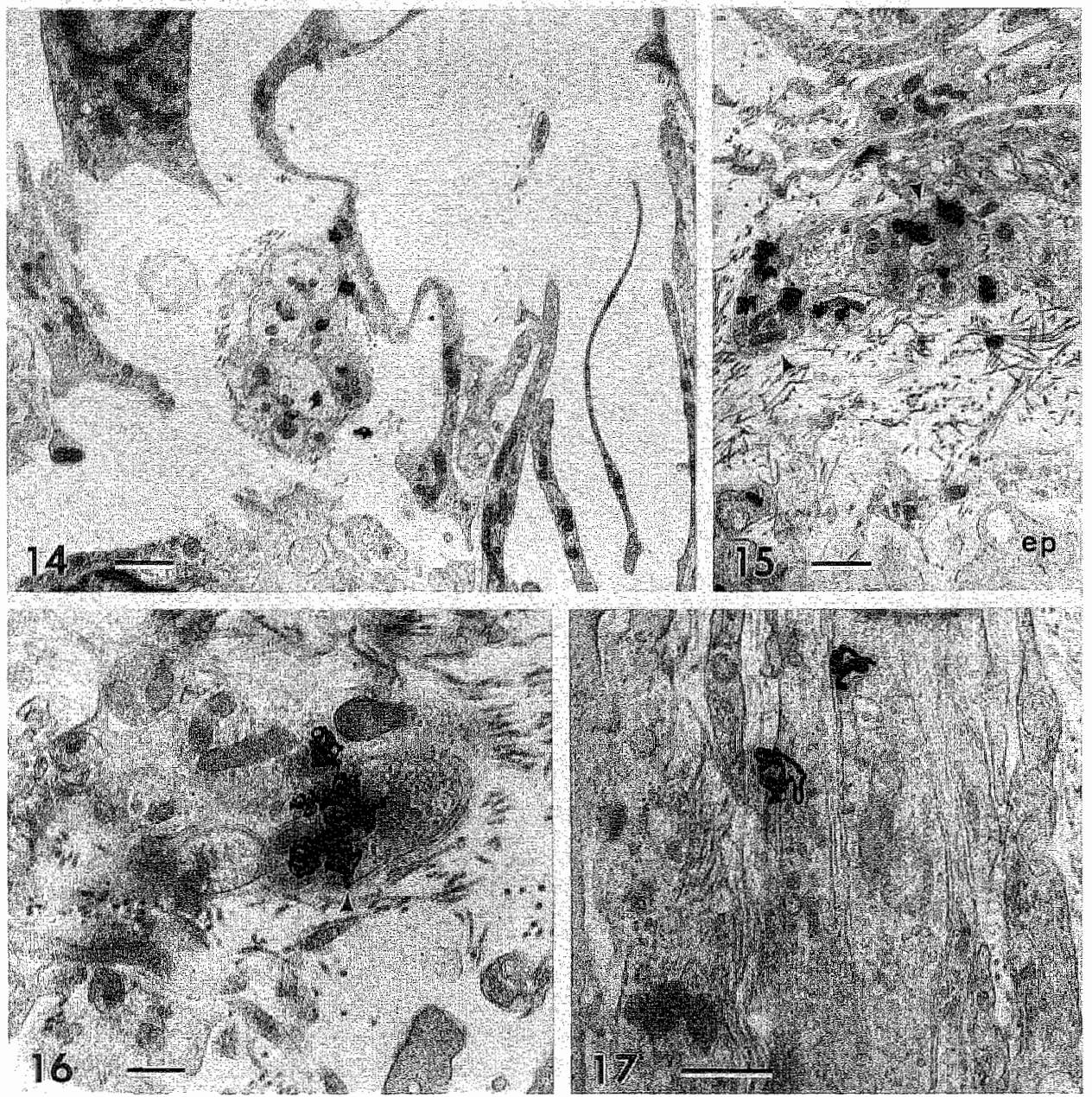

Fig. 14: Electron micrograph showing an unmyelinated fibre bundle containing several labelled fibres in the uval trabeculum. Scale bar represents $1 \mu \mathrm{m}$.

Fig. 15: Electron micrograph showing an unmyelinated fibre bundle with several labelled varicosities containing vesicles in the uveal part of the trabeculum. The varicosities partly lack Schwann cell covering (arrowheads). ep, cilliary body epithelium. Scale bar represents $1 \mu \mathrm{m}$.

Fig. 16: Electron micrograph showing a densely labelled varicosity containing vesicles, partly lacking Schwann cell covering (arrowhead), as part of a fibre bundle in the uveal trabeculum. Scale bar represents 0.5 um.

Fig. 17: Electron micrograph showing labelled varicosities containing vesicles in the corneoscleral trabeculum. Scalle bar represents $0.5 \mu \mathrm{m}$. 


\section{Ciliary body and trabeculum}

In the ciliary body, numerous unmyelinated fibres and varicosities were labelled (Figs. 11-13). Labelling was found in the central stroma of the cillary body and in the stroma of the cillary processes (Fig. 12C). Although labelled fibres and terminals were observed in the stroma just underneath the basal membrane of the cillary body epithelium (Fig. 11), no labelling was found in between the epithelial cells.

The labelled varicosities contained vesicles of varying shape. Labelled varicosities were found in close proximity to the smooth muscle cells of the ciliary muscle (Fig. 12A-B), and to blood vessels (Fig. 13). Labelled fibres were surrounded by Schwann cells, but varicosities in the stroma and facing smooth muscle cells often lacked this Schwann cell covering.

Unmyelinated nerve fibres and varicosities were labelled in the trabeculum (Figs. 14-17). The labelled varicosities contained vesicles of varying shape (Figs. 15-16). Labelling was found in the corneoscleral (Fig. 17) as well as in the uveal trabeculae. The morphological aspect of the labelled varicosities was essentially the same as those labelled in the ciliary body and the iris.

\section{Discussion}

Radioactive amino acid tracing of neuronal pathways depends on the incorporation of the amino acids in proteins and subsequent transport along the axons and dendrites. Since the incorporation is restricted to the cell body, this tracing method is exclusively anterograde with no labelling of passing fibres or terminals present in the injection site ${ }^{28}$, in addition, the electron microscopic autoradiographic approach allows a detailed analysis of fibres, varicosities and terminals. Therefore, the present study unambigiously proves that the sympathetic neurons of the superior cervical ganglion project to the ipsilateral trigeminal and pterygopalatine ganglion and to all investigated structures lining the anterior eye chamber except the cornea. Apart from the absence of corneal labelling and labelling of the contralateral pterygopalatine ganglion $48,21,38$, this study corroborates previous studies on this subject using other tracing methods, catecholaminergic fluorescence or denervation $23,25,30,32,33,37$. A minor labelling of the contralateral ganglion was obtained with WGA-HRP as tracer. It is well-known that WGA-HRP also labells passing fibres ${ }^{20}$.

In spite of the light microscopical observations of sympathetic fibres coursing in close proximity to sensory ganglion cells, no synaptic contacts, vesicle containing terminals or varicosities were found in the trigeminal ganglion. In the trigeminal as well as in the pterygopalatine ganglion, labelled fibres with accumulations of vesicles were found. It is known that sympathetic fibres sometimes contain accumulations of vesicles ${ }^{11}$. These vesicles are supposed to contain noradrenaline $e^{3,8,11,13,16}$. In addition, areas of close membrane apposition between unmyelinated fibres are not uncommon in the peripheral nervous system ${ }^{24}$. In the present study, such close appositions were found between labelled and unlabelled fibres in the 
pterygopalatine ganglion and were also found at the sites of accumulation of small pleomorphic vesicles, suggesting some kind of non-classical synaptic information traniffer. Similar findings have been reported in non-ocular tissues ${ }^{15,17}$. It is described in electrophysiological studies that ephaptic transmission between adjacent fibres in the peripheral nervous system occurs in pathological conditions ${ }^{27}$. Direct membrane appositions between structures of the neurons have been considered the morphological substrate for this phenomenon ${ }^{31}$. It may be that the accumulations of vesicles in the present study contain noradrenaline. Direct membrane appositions bordered by vesicle accumumulations in the pterygopalatine ganglion may also indicate some kind of interneuronal communication. The relevance of this needs further investiglation. In previous papers it has been shown that the pterygopalatine ganglion is synaptically innervated by sensory fibres originating from the ophthalmic part of the trigeminal ganglion 1,36 . As parasympathetic fibres arising from the pterygopalatine ganglion have thus already been modulated by sensory fibres, it is tempting to speculate that they are also sympathetically modulated by fibres originating from the superior cervical ganglion.

In the present study, the sympathetic terminal varicosities in the iris, ciliary body and trabeculum all had a similar ultrasiructural morphology. Chan-Palay formulated the congruity hypothesis stating that terminals originating from a common fibre system in the cerebellum all have a characteristic and constant ultrastructural morphology ${ }^{2}$. Apparently, this hypothesis also applies for the peripheral nervous system. The non-synaptic character of the varicosities

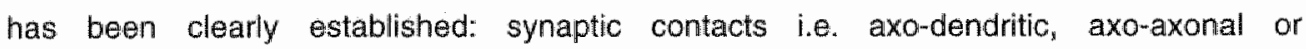
neuromuscular synapses have not been found. The Schwann cell covering of the varicosities was often lacking at the site of labelling. Therefore, this study gives evidence that sympathetic fibres terminate in the cilliary body and trabeculum, and do not just pass through these structures.

Syrnpathetic innervation of the cornea was not found despite extensive screening of the

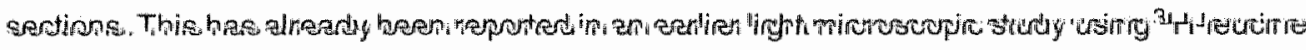
as a tracer ${ }^{37}$, but is in contradiction with other tracing studies using HRP and WGA-HRP 18,21 , and histofluorescence studies describing catecholaminergic fibres in the cornea ${ }^{5}$. As mentioned above, HRP and WGA-HRP tracing have the inherent drawback of uptake of tracer by passing fibres and terminals at the injection site ${ }^{20}$. It has been clearly shown by retrograde tracing from the cornea that labelling of cell bodies in the superior cervical ganglion only occurred after survival times of more than 48 hrs following application of WGA-HRP to the cornea of rabbits, indicating that this labelling must be due to the leakage of tracer into the anterior chamber ${ }^{34}$. After similar survival times, cell bodies in the cillary and pterygopalatine ganglion were also labelled, however, a parasympathetic innervation of the cornea has never been described. Much shorter survival times have shown the absence of labelling in the superior cervical ganglion ${ }^{34}$ "Concerning the anterograde tracing, the satellite cells in the superior cervical ganglion comprise a barrier for HRP and WGA-HRP35. Sufficient labelling of cell bodies with HRP or WGA-HRP at the injection site can only be obtained by 
making several injections. This damages the ganglion tissue, which will make the tracing less trustworthy. In the present study, massive labelling of sympathetic fibres was found in the iris, ciliary body and trabeculum. In an electron microscopic study regarding the sympathetic innervation of the ciliary muscle in mankeys, it was found that less than $1 \%$ of the terminal varicosities of the ciliary muscle were sympathetic ${ }^{29}$. Although there may be differences between species, this indicates that the method used at present is very sensitive. It has been demonstrated that catecholaminergic fluorescent fibres remain in the rat iris after superior cervical ganglionectomy ${ }^{25}$. These fibres disappeared after trigeminal ganglionectomy, indicating that they are most likely of sensory trigeminal origin. Moreover, it has been shown that primary sensory neurons can express catecholaminergic characteristics in rats ${ }^{14}$. Recently, it has been hypothesized that catecholaminergic sensory fibres regulate sensory transmission through the dorsal horn of cats ${ }^{4}$. On account of these data from literature and the present observations, it can be emphasized that the nerve fibres in the cornea are exclusively sensory, originating from the trigeminal ganglion, and partly have a catecholaminergic nature. 


\section{REFERENCES}

1 Beckers HJM, Kooster J, Vrenisen GFJM Lamers WPMA: Uttrastructural identification of trigeminal neve terminals in the pterygopalatine ganglion of rats an anterograde tracing and immunohigitochemical siudy. Brain Res 1991; 557: 22-30.

2 Chan-Palay V: Cerebellar dentate nucleus, onganization cytology and transmitters. Springer Verlag, Berlin, 1977, pp. 212-237.

3 Dahlstrom A: Observations on the accumulation of noradrenaline in the proximal and fistal parts of peripheral adrenergic nerves after compression. J Anat 1965; 99:677-689.

4 Doyle CA, lhaxwell D.j: Catecholaminergic innevation of the spinal dorsal horn: a correlated light and electron microscopic analysis of tyrosine thydroxylase-immunoreactive fibres in the cat. Neuroscience $1991 ; 45: 161-176$.

5 Ehinger B: Ocular and orbital vegetative nerves. Acta Physiol Scand (Suppl) 1966; 67: 1-35.

6 Ehinger B, Falck B: Innervation of iridic melanophores, Z Zellforsch 1970; 105: $538-542$.

7 Ehinger B, Falck B, Sporrong B: Possible axo-axonal synapses between peripheral adrenergic and cholinergic nerve terminals. Z Zellforsch, $1970 ; 107: 508-521$.

8. Geffen LB, Ostberg A: Distribution of granular vesicles in nomal and constricted sympathetic neurones. J Physiol 1969; 204: 583-592.

9 Hedlund $\mathrm{K}-\mathrm{O}$, Ayer-Lelievre $\mathrm{C}$, Björklund $\mathrm{H}$, Hultgren L, Seiger A: Uitrastructural and histochemical studies of the rat iris: identifled neuronal inputs and supportive glia. $ل$ of Neurocytol $1984 ; 13$ : $703-725$.

10 Hökfelt T: Electron microscopic observations on nerve terminals in the intrinsic muscles of the albino rat ir's. Acta Physiol Scand 1966; 67: 255-256.

11 Hökfelt T: Distribution of noradrenaline storing particles in peripheral adrenergic neurons as revealed by electron microscopy. Acita Physiol Scand 1969; 76: 427-440.

12. Hobkfelt T, Nilsson $O$ : The relationship between nerves and smooth muscle cells in the rat iris. II. The sphincter muscie. Z Zellforsch 1965; 66: 848-853.

13. Kapeller $K$, Mayor D: An electron microscopic study of the early changes proximal to a constriction in sympathetic neves. Proc Roy Soc B 1969; 172: 39-51.

14 Katz DM, Adler JE, Black IB: Catecholaminergic primary sensory neurons: autonomic targets and mechanisms of transmitter regulation. Federation Proc 1987; 46: 24-29.

15 Kummer W. Mayer B: Nitric oxide synthase-immunoreactive axons innervating the guinea-pig lingual artery: an ultrastructural immunohistochemical study using elastic brightield imaging.

Histochemistry $4993 ; 99: 175-179$.

16 Lascar $\mathrm{G}$ : Ultrastructural identification of catecholamine-containing vesicles in the ligated sciatic nerve of the rat. Comparison with sympathetic nerve terminals. Cell Tissue Fes 1980; 209: $433-454$.

17 Manber L, Gershon MD: A reciprocal adrenergic-cholinergic axoaxonic synapse in the mammalian gut. Am J Physiol 1979; 236: E738-E745.

18 Marfurt CF: Sympathetic innervation of the rat comea as demonstrated by the retrograde and anterograde transport of horseradish peroxidase-wheatgerm agglutinin. $J$ Comp Neurol 1988; 268: $147-160$.

19 Marturt CF, Zaleski EM, Adams CE, Welther CL: Sympathetic nerve fibres in rat orofacial and cerebral tissues as revealed by the HAP.WGA tracing technique: a light and electron microscopic study. Brain Res 1986; 366: 373-378.

20 Mesulam MM: Tracing neural connections with horseradish peroxidase. In: Smith AD (Ed.), Methods in neurosciences, IBRO handbook series, Wiley, New York, 1982, pp. 3-247. 
21 Morgan $C_{\text {, }}$ DeGroat WC, Jannetta P.: Sympathetic innervation of the cornea from the superior cervical ganglion. An HRP study in the cat. J Auton Nerv Syst 1987; 20: 179-183.

22 Nilsson $O$ : The relationship between nerves and smooth muscle cells in the rat ins. I. The dilator muscle. Z Zellforsch 1964; 64: 166-171.

23 Nomura T, Smelser GK: The identification of adrenergic and cholinergic nerve endings in the trabecular meshwork. Inv Ophthalmol 1974; 13: 525-532.

24 Ochoa J: The unmyelinated newe fibre. In: Landon DN (Ed.), The peripheral heve, Chapman and Hall, London, John Wiley \& Sons Inc, New York, 1976, pp.106-158.

25 Olson L, Ayer-Le Lievre C, Björklund H, Ebendal T, Granholm A-Ch, Hedilund K-O, Hökfelt T, Melander T, Seiger $A$, Stromberg I: The innervation apparatus of the rodent uris. In: Björklund $A$, Hökfelt $T$, Owman C (Eds.), Handbook of chemical neuroanatomy. Vol. 6: The peripheral nenous system, Elsevier, Amsterdam, 1988, pp. 545-597.

26 Peters $\mathrm{A}$ : The fixation of central nervous tissue and the analysis of electron micrographs of the neuropil with special reference to the cerebral cortex. In: Nauta W.JH, Ebbeson SOE (Eds.), Contemporary research methods in neuroanatomy, Springer-Verlag, Berlin, 1970, pp. 56-76.

27 Rasminsky M: Ectopic impulse generation in pathologic nerve fibers. In: Dyck PJ, Thomas PK, Lambert EH, Bunge R (Eds.), Peripheral neuropathy, Vol. 1, W.B. Saunders Company, Philadellphia USA, 1984 , pp. 911-918.

28 Rogers AW: Techniques of autoradiography. Elsevier Scientific Publishing Company, Amsterdam, London, New York, 1973, pp. 1-372.

29 Ruskell GL: Sympathetic innervation of the ciliary muscle in monkeys. Exp Eye Res 1973; 16: $183-190$.

30 Ruskell GL: The source of nerve fibres of the trabeculae and adjacent structures in monkey eyes. Exp Eye Res 1976; 23: 449-459.

31 Schuster T, Serfling R: Morphologische Korrelate elektrischer Interaktionen zwischen Neuronen im limbischen System. J Hirnforsch 1985; 26: 635-649.

32 Stone RA, Laties AM.. Neuroanatomy and Neuroendocrinology of the Chamber Angle. In: Kriegistein GK (Ed.), Glaucoma Update III, Springer-Verlag, Berlin Heidelberg, 1987, pp. 1-16.

33 Sugita A, Hisaharu Y: Nerve fibers in trabecular meshwork surface. Jpn J Ophthalmol 1984; 28 : $248-253$.

34 Tusscher ten MPM, Klooster J, Vrensen GFJM: The innervation of the rabbit"s anterior eye segment: A retrograde tracing study. Exp Eye Res 1988; 46: 717 -730.

35 Tusscher ten MPM, Klooster J, Vrensen GFJM: Satellite cells as bloodl-ganglion barrier in autonomic ganglia. Brain Fes 1989; 490: 95-102.

36 Tusscher ten MPM, Klooster J, Want van der JJIL, Lamers WPMA, Vrensen GFJM: The allocation of nerve fibres to the anterior eye segment and peripheral ganglia of rats. Part l: the sensory innervation. Brain Res 1989; 494: 95-104.

37 Tusscher ten MPM, Klooster J, Want van der JJL, Lamers WPMA, Vrensen GF.JM: The allocation of nerve fibres to the anterior eye segment and peripheral ganglia of rats. II. The sympatthetic innervation. Brain Res 1989; 494: 105 113 .

38. Tusscher ten MPM, Klooster J, Ballet B, Wert van der F, Vrensen GF.MM: Pre- and post-ganglionic nerve fibres of the pterygopalatine ganglion and their allocation to the eyeball of rats. Brain Res $1990 ; 517: 315-323$.

39 Vrensen GFJM, Groot de D: Some new aspects of efficiency of electron microscopic autoradiography with tritium. J Histochem Cytocherm 1970; 18: 278-290. 


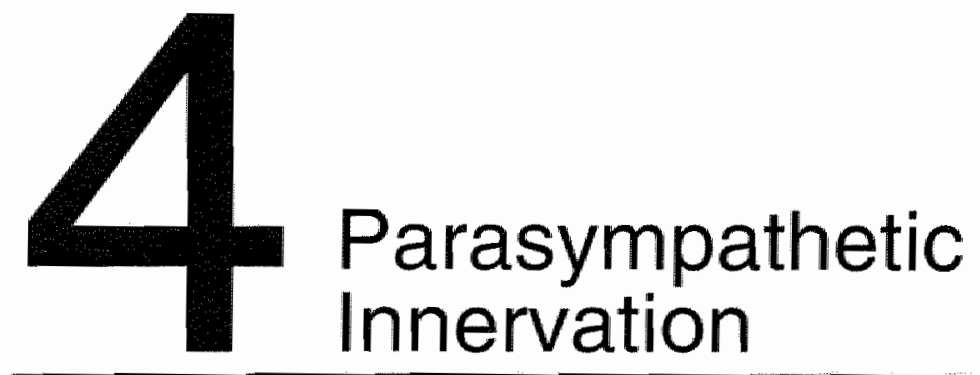




\title{
Facial Parasympathetic Innervation of the Rat Choroid, Lacrimal Glands and Ciliary Ganglion:
}

\author{
An Ultrastructural Pterygopalatine Tracing and \\ Immunohistochemical Study
}

\begin{abstract}
The pterygopalatine parasympathetic innervation of the rat choroid, lacrimal glands and ciliary ganglion was ultrastructurally studied by anterograde ${ }^{3} \mathrm{H}$-leucine tracing. Numerous unmyelinated fibres and vesicle-containing terminals were labelled in these structures. No direct synaptic contacts were found. In the choroid, similar terminals were immunoreactive to vasoactive intestinal polypeptide (VIP). A regulatory feedback loop within the eye-related peripheral nervous system is endorsed by the present results. The finding of fibres and terminals of pterygopalatine origin in the lacrimal glands agrees with earlier studies in cats and monkeys. In the ciliary ganglion, pterygopalatine terminals most likely influence the ganglion cells by nonsynaptic release of neurotransmitters or neuromodulators including VIP.
\end{abstract}

\section{Introduction}

The eye is parasympathetically innervated by nerve fibres of oculomotor and additionally of facial (pterygopalatine) origin ${ }^{9,10,19,20,21}$. In a recent report, the pre- and postganglionic nerve fibres of the pterygopalatine ganglion and their allocation to the eyeball of rats was studied using anterograde and retrograde tracing at the light microscopic level ${ }^{31}$. In that study, nerve fibres of pterygopalatine origin were observed in the choroid, the limbal area, the conjunctiva and the lacrimal gland. In addition, fibres were found to pass through the ciliary ganglion. The pterygopalatine ganglion has been found to consist of a rostral cell mass, in which two areas can be distinguished, and a caudal string of cell bodies extending up to the trigeminal ganglion ${ }^{1,31}$. The pterygopalatine ganglion was found to be somatotopically organized along the rostral-caudal $a \times 1 s^{31}$.

Light microscopic immunohistochemical and ultrastructural tracing studies have shown that trigeminal fibres of rats, containing substance $P(S P)$ and/or calcitonin gene-related peptide (CGRP), synaptically innervate pterygopalatine ganglion cells containing vasoactive intestinal polypeptide (VIP) and choline acetyltransferase (ChAT) 1,26,29. VIP and ChAT have been described in fibres innervating cerebral blood vessels of rats, in which they have a vasodilatory effect $^{25}$. VIP has also been found in nerve fibres of the choroid of cats and guinea pigs ${ }^{27,33}$ where it probably mediates vasodilatation ${ }^{13}$. From these findings, the question arises whether within the eye related peripheral nervous system a regulatory feedback loop exists, in which the pterygopalatine ganglion regulates choroidal blood flow under the modulatory influence of sensory trigeminal input from the eye. 
To study the fine structure of facial parasympathetic nerve fibres passing through the choroid, the lacrimal glands and the ciliary ganglion, and to find out whether nerve terminals are present in these pathways, anterograde tracing from the pterygopalatine ganglion was undertaken at the ultrastructural level. Since it was found that autonomic ganglion cells have a Schwann cell barrier to horseradish-peroxidase 28 , 3 H-leucine autoradiography was used to trace these pathways. H-leucine was injected into the rostral part of the pterygopalatine ganglion and the labelling of efferent nerves was studied. Moreover, the localization and distribution of VIP within choroidal fibres was ultrastructurally investigated using immunohistochemistry.

\section{Materials and Methods}

\section{H-leucine tracing}

Six adult male Wistar rats, weighing between 200 and $300 \mathrm{~g}$, were used. They were anaesthetized with Nembutal (Rousselot, Paris, France), $0.3 \mathrm{ml} / \mathrm{kg}$ i.p. and Hypnorm (Janssen, Tilburg, The Netherlands), $0.3 \mathrm{ml} / \mathrm{kg}$ i.m. and placed in a stereotaxic frame. The left pterygopalatine ganglion was reached from the dorsal side by gently pulling the orbital contents and the maxillary nerve aside ${ }^{31}$. Approximately $10 \mu \mathrm{l}$ of ${ }^{3} \mathrm{H}$-leucine (total activity of $500 \mu \mathrm{Ci}$ ) was pressure-injected into the rostral part of the pterygopalatine ganglion, using glass micropipettes ( $20 \mu \mathrm{m}$ tip diameter) connected with a polyethylene tubing to a $10 \mu \|$ Hamilton syringe.

After a survival period of 8-10 days, the animals were killed with an overdose of Nembutal and transcardially perfused with $100 \mathrm{ml} 0.1 \mathrm{M}$ sodium cacodylate buffer, $\mathrm{pH} 7.4$, followed by 1 liter of a fixation solution containing $1 \%$ paraformaldehyde and $1.25 \%$ glutaraldehyde in $0.1 \mathrm{M}$ sodium cacodylate buffer, $\mathrm{pH} 7.4^{14}$. The heads were posttixed for 3 days, using the same fixation solution, and subsequently rinsed in buffer for $24 \mathrm{hrs}$. The eyes, the pterygopalatine and the ciliary ganglia and the extraorbital and infraorbital lacrimal glands were dissected. The pterygopalatine ganglia, the right choroids, the right ciliary ganglia, the right lacrimal glands and pleces of the left choroids and lacrimal glands were embedded in Technovit (Kulzer, Friedrichsdorf, Germany), sectioned at $4 \mu \mathrm{m}$ and mounted. The Technovit-embedded sections were dipped at $32^{\circ} \mathrm{C}$ in llford $\mathrm{G} 5$ emulsion (llford Limited, Mobberley, Cheshire, UK), dried, and stored in light-tight slide boxes, at $4^{\circ} \mathrm{C}$, for $6-8$ weeks. Following exposure, the autoradiographs were developed in D19b and fixed in $24 \%$ sodium thiosulfate at $18^{\circ} \mathrm{C}$. They were rinsed with tap water, stained with cresyl fast violet and light microscopically examined.

The remaining parts of the left choroids, the left ciliary ganglia and the left lacrimal glands were prepared for electron microscopic autoradiography. They were postfixed in $1 \%$ osmium tetroxide $\left(\mathrm{OSO}_{4}\right)$ supplemented with $1 \%$ potassium ferricyanide in $0.1 \mathrm{M}$ sodium cacodylate buffer, $\mathrm{pH} 7.4$, for 1 hour, then dehydrated in a graded series of ethanols and embedded in 

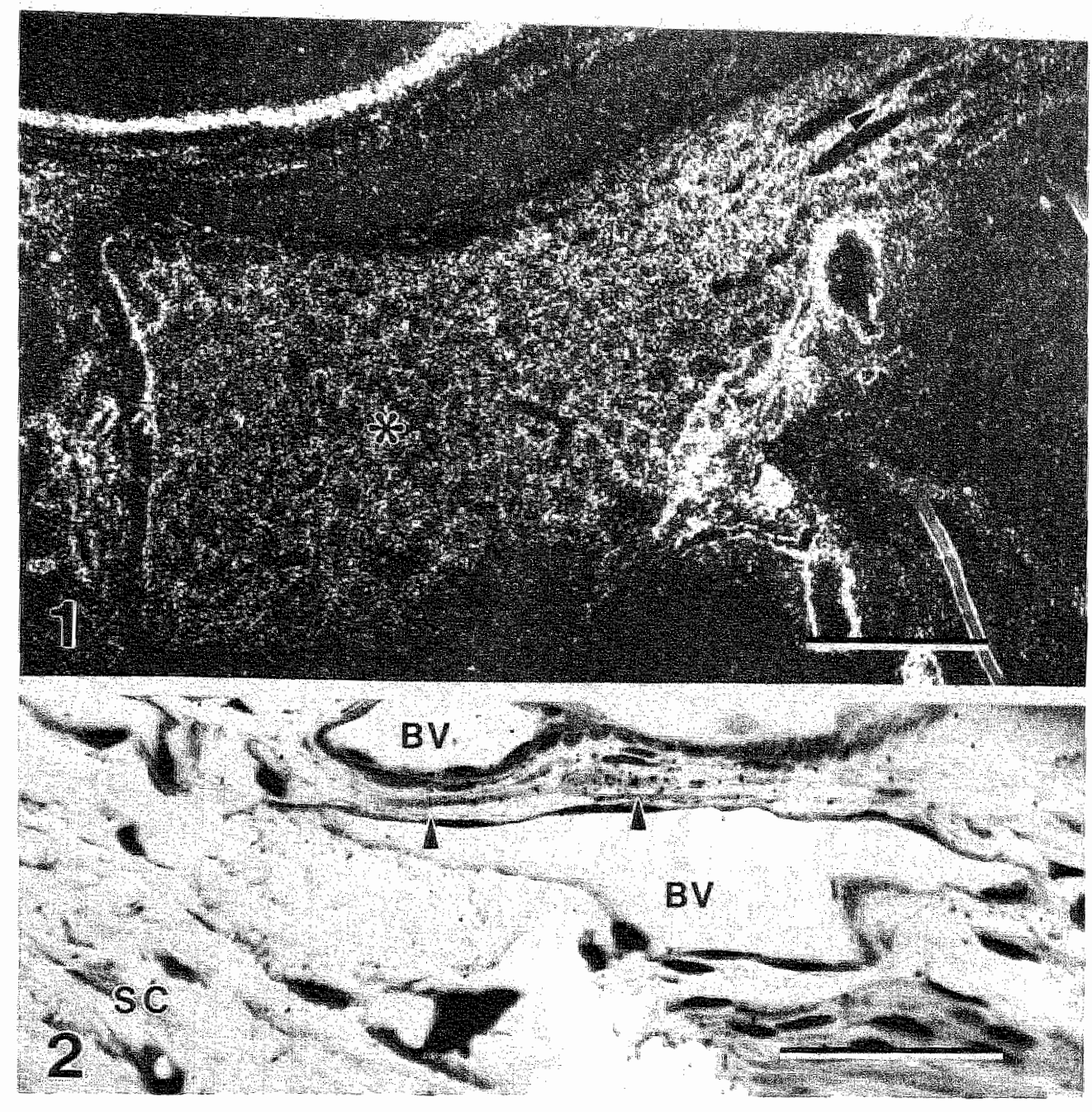

Fig. 1: Light micrograph showing the abundant autoradiographlc labeling of the injected pterygopalatine ganglion. The distal triangular cell mass (asterisk) with part of the proximal string of cells (arrowhead) is shown. Scale bar represents $0.2 \mathrm{~mm}$.

Fig. 2: Light micrograph showing a labelled fibre bundle (arrowheads) coursing between choroldal blood wessels. BV, blood vessel, Sc, sclera. Scale bar represents $0.05 \mathrm{~mm}$.

epoxy resin. Ultrathin sections were cut and placed on Formvar-coated slides (Merchk Darmstadt, Germany), stained with uranyl acetate and lead citrate and coated with carbon (5-8 nm). The slides were dipped in lfford L4 emulsion, dried, and stored for 2-6 months in light-tight slide boxes at $4^{\circ} \mathrm{C}$. Following exposure, the slides were developed in $\mathrm{D} 196$ and fixed in $24 \%$ sodium thiosulfate. After rinsing in distilled water for 30 minutes, the Formvar films were 
floated off ${ }^{35}$. The autoradiographic sections were mourted on parallel-ruled grids and viewed in a Philps EM 201 electron microscops (Philips Industries, Eindhoven, The Netherlands).

\section{VIP Immunohistochemistry}

Three rats were killed with an overdose of Nembutal and were transcardially perfused with 150 mil phosphate-buffered saline (PBS) followed by 1 liter of fixation solution containing $2.5 \%$ glutaraldehyde in PBS, pH 7.4, at room temperature. After decapitation, the heads were postfixed for half an hour in the same fixation solutions. The chorolds of both eyes were dissected. After rinsing in PBS, they were incubated, free floating, overnight in a buffered solution containing the diluted (1/1600) antiserum to VIP (Cambridge Research Blochemicals, Northwich, UK), supplemented with $0.05 \%$ Triton X-100 (Merck, Darmstadt, Germany).

The peroxidase-antiperoxidase (PAP) method was used to visualize the VIP antigen ${ }^{34}$. The choroids were incubated in $0.05 \%$ w/v diaminobenzidine (DAB) in Tris-buffered saline (TBS) supplemented with $0.01 \%$ hydrogen peroxide $\left(\mathrm{H}_{2} \mathrm{O}_{2}\right)$ for $10 \mathrm{~min}$. After rinsing in TBS, the DAB reaction product was intensified with a gold-substituted silver peroxidase technique ${ }^{15}$. The specimens were postfixed in $1 \%$ asmium tetroxide $\left(\mathrm{OsO}_{4}\right)$ supplemented with $1 \%$ potassium ferricyanide in $0.1 \mathrm{M}$ sodium cacodylate buffer, $\mathrm{pH} 7.4$, for $20 \mathrm{~min}$, diehydrated in a graded series of ethanols and flat embedded in epoxy resin. Control experiments were performed in which the incubation in the primary antiserum-containing solutions was left out of the procedure.

Nerve fibres containing peroxidase-staining product were light microscopically identified, after which these areas were dissected and mounted on prepolymerized epoxy resin blocks. Ultrathin sections were cut stained with uranyl acetate and lead citrate and viewed in a Philips EM 201 electron microscope.

\section{Results}

\section{$3 \mathrm{H}$-leucine tracing}

Injection site: The injected pterygopalatine ganglia showed abundant labelling of the distal triangular cell mass and the major part of the proximal string of cell bodies (Fig. 1).

Chorold: Light microscopically, numerous labelled fibre bundles were observed in the choroid, often coursing in close proximity to blood vessels (Fig. 2). At the ultrastructural level, these fibres proved to be unmyelinated and were mainly found within fibre bundles localized throughout the lamina vasculosa of the choroid. Labelled terminals containing numerous clear vesicles, a few small dense vesicles, small dense mitochondria and rarely a large dense vesicle were also found. These terminals were often found in close apposition to the choroidal 


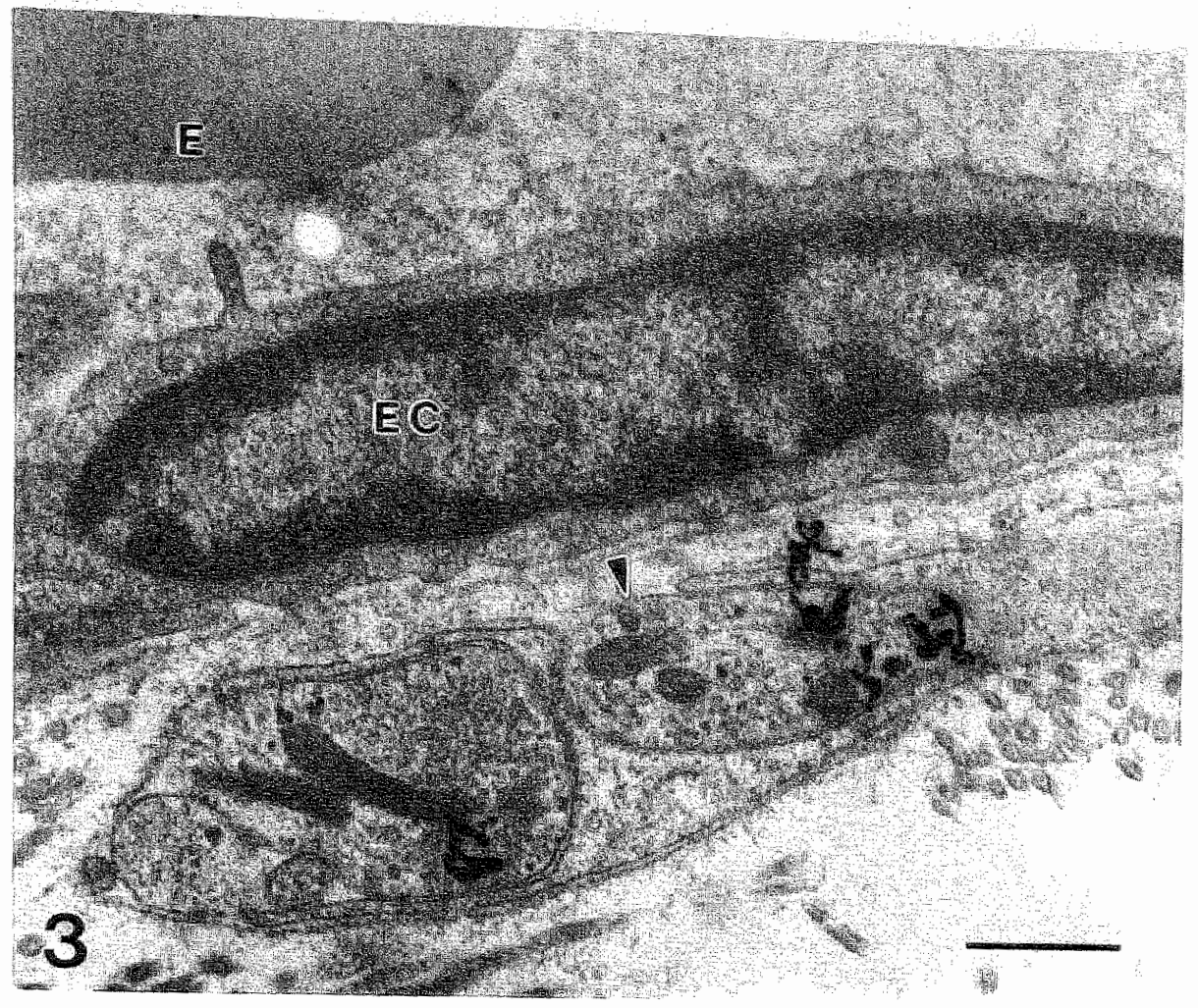

Fig. 3: Electron micrograph showing an unmyelinated fibre bundle with two labelled terminals in close proximity to a choroldal vein. The terminals contain numerous clear vesicles, a few small dense vesicles, one large dense vesicle and dense mitochondria. The Schwann cell covering is partly lacking (arrowhead). E, erythrocyte; $E C$, endothelial cell. Scale ball represents $0.5 \mu \mathrm{m}$.

veins (Fig. 3) and arteries (Fig. 4). The site of the terminals facing the blood vessels often (partly) lacked Schwann cell covering (Figs. 3,4). No direct synaptic contacts were tound.

Lacrimal glands: Light microscopically, labeiled fibre bundles were found in the extraorbital as well as in the infraorbital lacrimal glands, however, labelling was more intense in the infraorbital glands (Fig. 5). At the ultrastructural level, labeling was found within unmyelinated fibres and within terminals containing numerous clear vesicles, a few small dense vesicles, small dense mitochondria and rarely a large dense vesicle. These fibres and terminals were found in the connective tissue between the acini and in close proximity to acinar cells (Fig. 6). Few labelled fibres were observed penetrating between the acinar cells. 
Chary ganglion: Labelled fibres were found coursing through the ciliary ganglion (Fig. 7A). These fibres were mainly unmyelinated and trequently localized in the vicinity of cell bodies. Labelling was also found within terminals containing numerous clear vesicles (Fig. 7B). Direct synaptic contacis were not found.

In none of the investigated tissues was labelling of fibres and terminals found at the contralateral side.

\section{VIP Immunohistochemistry}

Light microscopically, numerous VIP-immunoreactive fibre bundles were found in close proximity to the choroidal biood vessels (Fig. 8). Ultrastructurally, VIP-immunoreactivity was found within unmyelinated fibre bundles of mainly the lamina vasculosa. VIP-immunoreactive terminals containing numerous clear vesicles and electron-dense mitochondria were found within these fibre bundles (Fig. 9, 10), and were often localized in close proximity to the arteries and veins (Fig. 10). These terminals contained numerous clear vesictes. The side of the terminals facing the blood vessels often (partly) lacked Schwann cell covering.

\section{Discussion}

Radioactive amino acid tracing of neuronal pathways depends on the incorporation of the amino acids in proteins within the cell body and subsequent transport along the axons and dendrites. Therefore, this tracing method is exclusively anterograde with no labelling of passing fibres or terminais present in the injection site 18 . The present tracing study proves at the ultrastructural level that the rat choroid, lacrimal glands and ciliary ganglion are innervated by facial parasympathetic nerve fibres originating in the pterygapalatine ganglion. The terminals within these nerve fibres all contain numerous clear vesicles, a few small dense vesicles, small dense mitochondria and rarely a large dense vesicle. No direct synaptic contacts were observed.

Ultrastructural studies on VIP within the choroid are scare?2. The present study showed mumerous VIP-immunoreactive fibres and terminals in the rat choroid. The fibres and terminals were quite densely immunostained while the ultrastructure was well preserved. Staining could be observed in consecutive sections, indicating that the method used was sensitive. Background staining was very low.

These observations partly confirm those of Terenghi et al. ${ }^{27}$ in the guinea pig, in as far as choroidal terminals contain VIP. However, in contrast with our observations, VIP-containing terminals in that study were characterized by the presence of numerous large dense vesicles.

In the chorold, 3H-leucine-labelled terminals were found in close proximity to the choroidal arteries and veins. Terminals exhibiting a similar ultrastructure were found to be immunoreactive to VIP and showed a similar local distribution as the terminals labelled with 

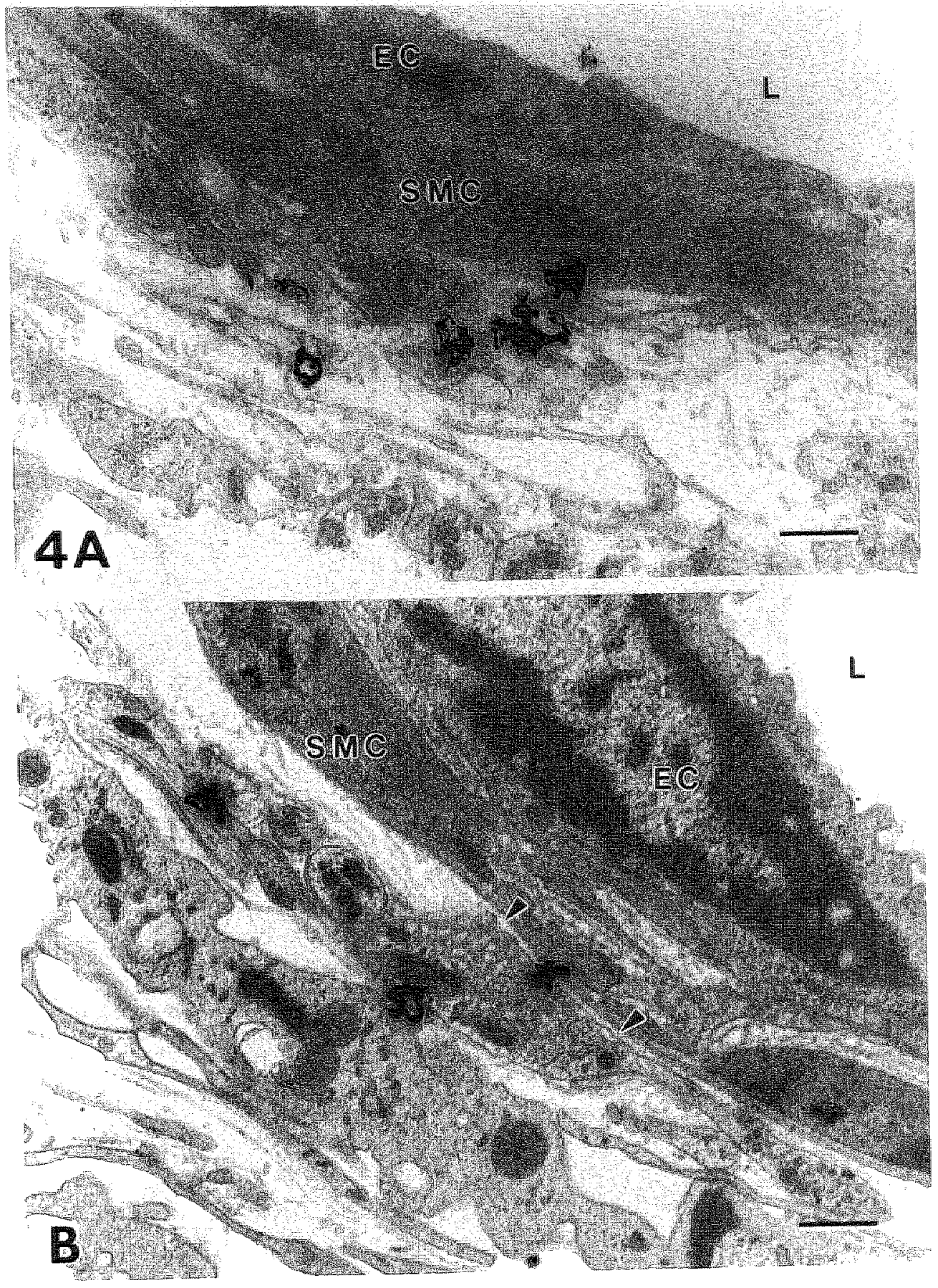

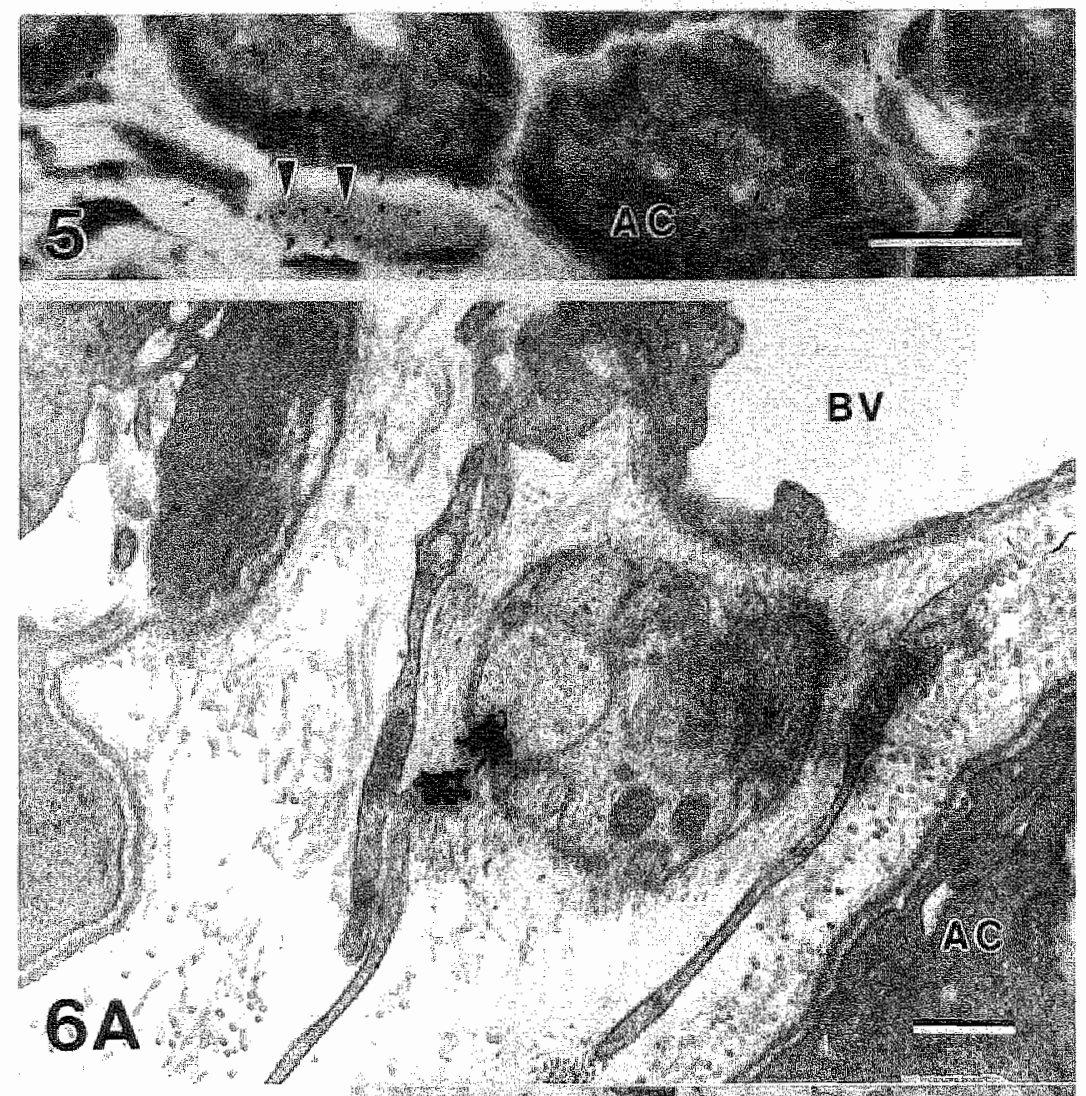

\section{BV}

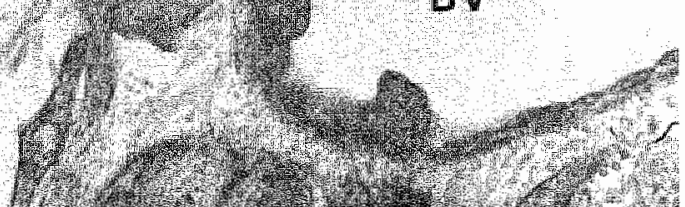

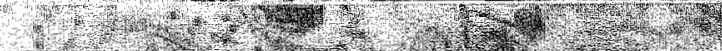

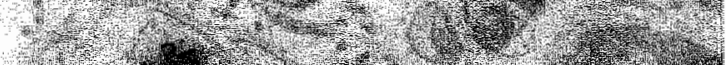

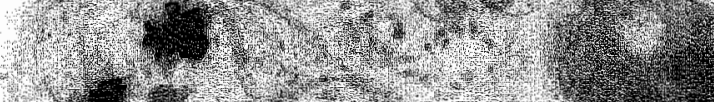

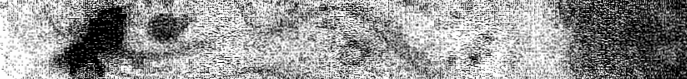

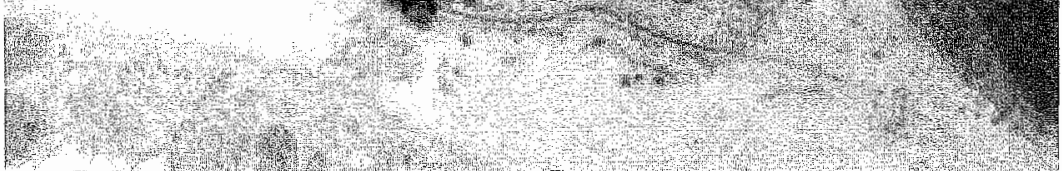
SG

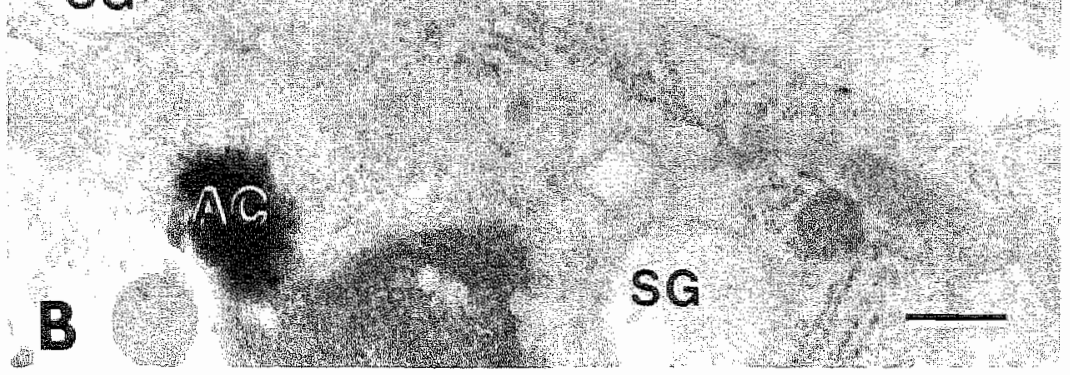



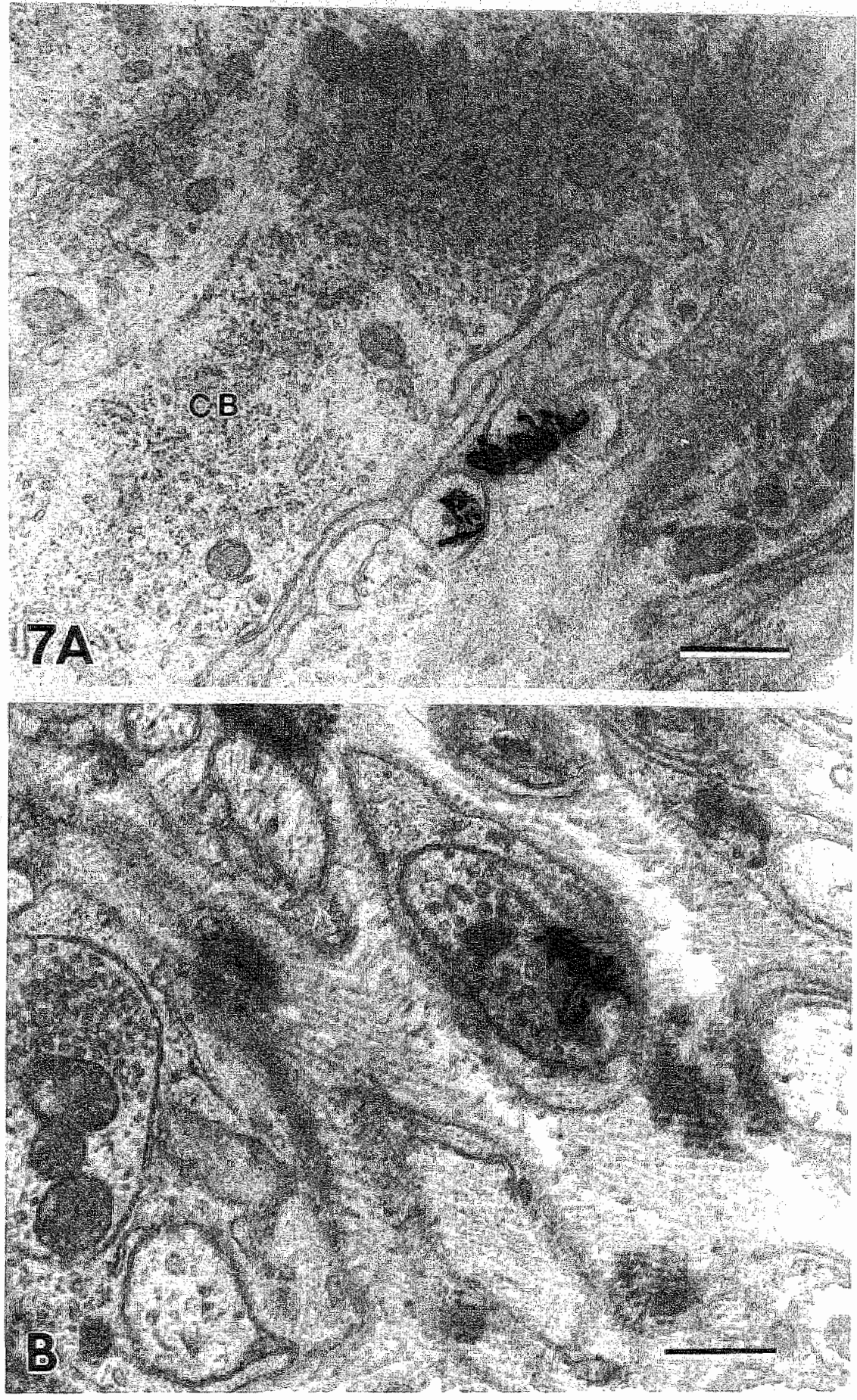


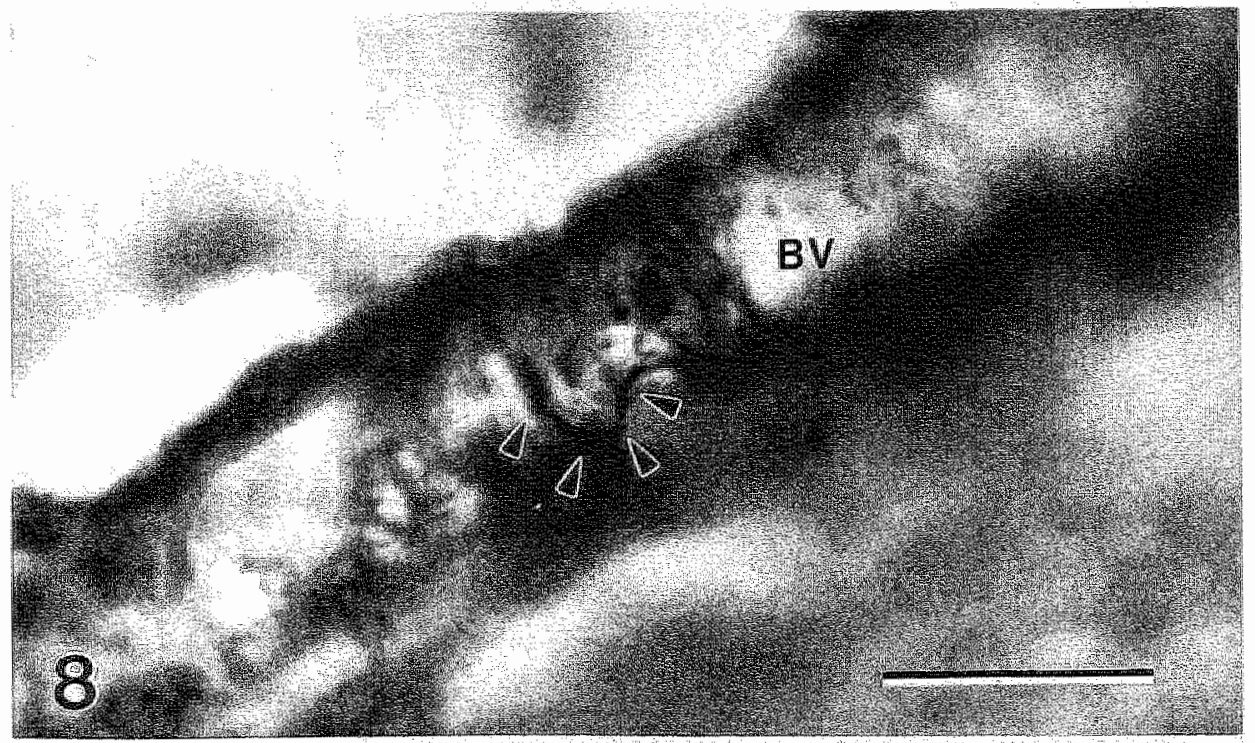

W. 1
$\mathrm{~V}$

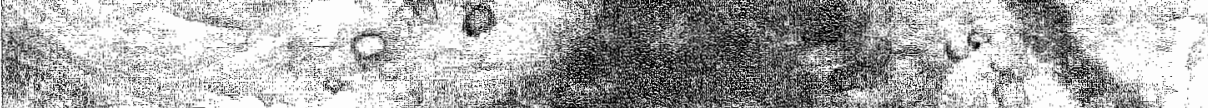

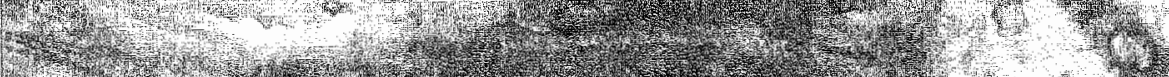

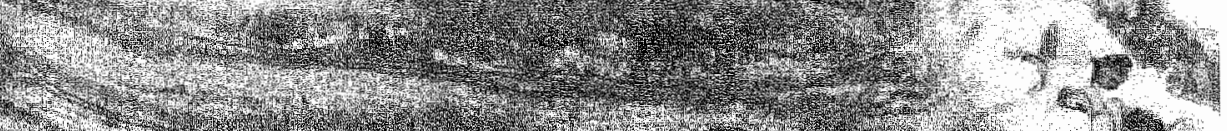

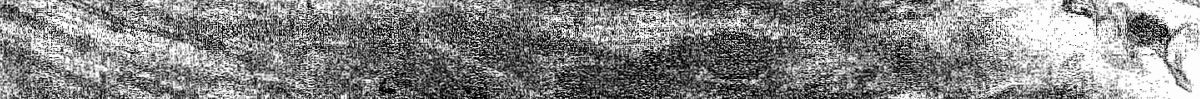

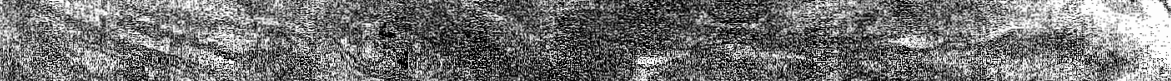

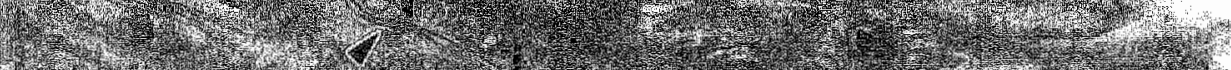

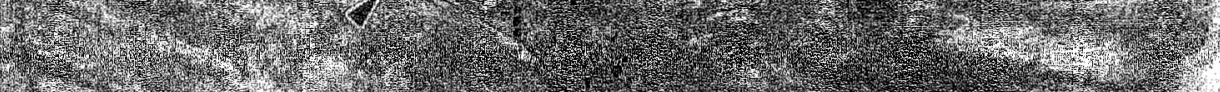

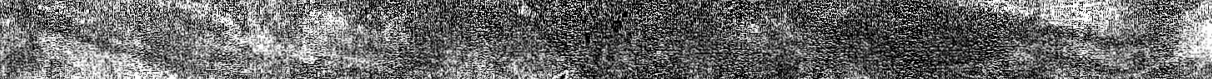

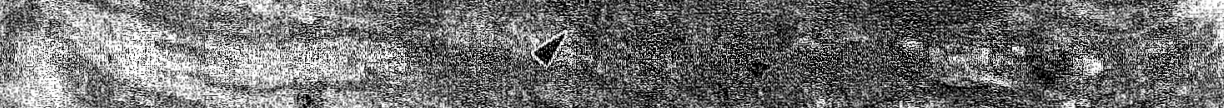

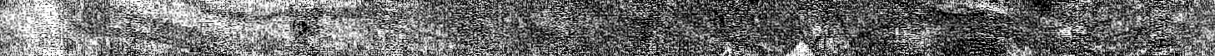

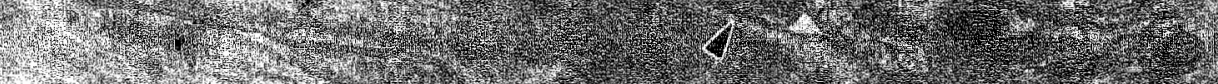

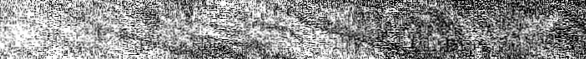
1.7.

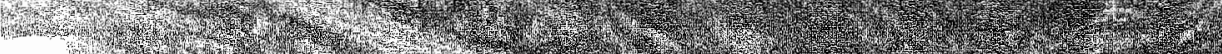

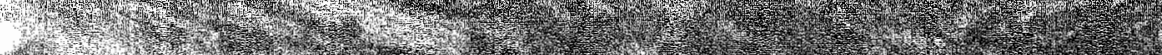

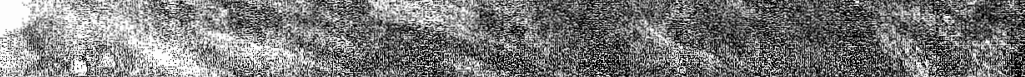

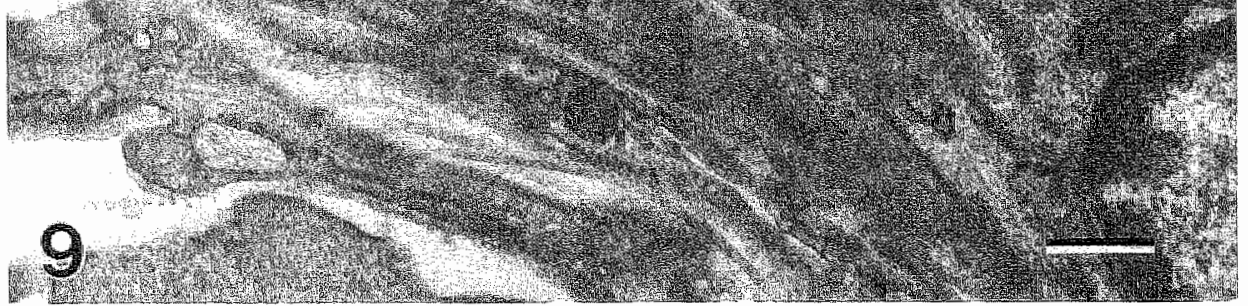



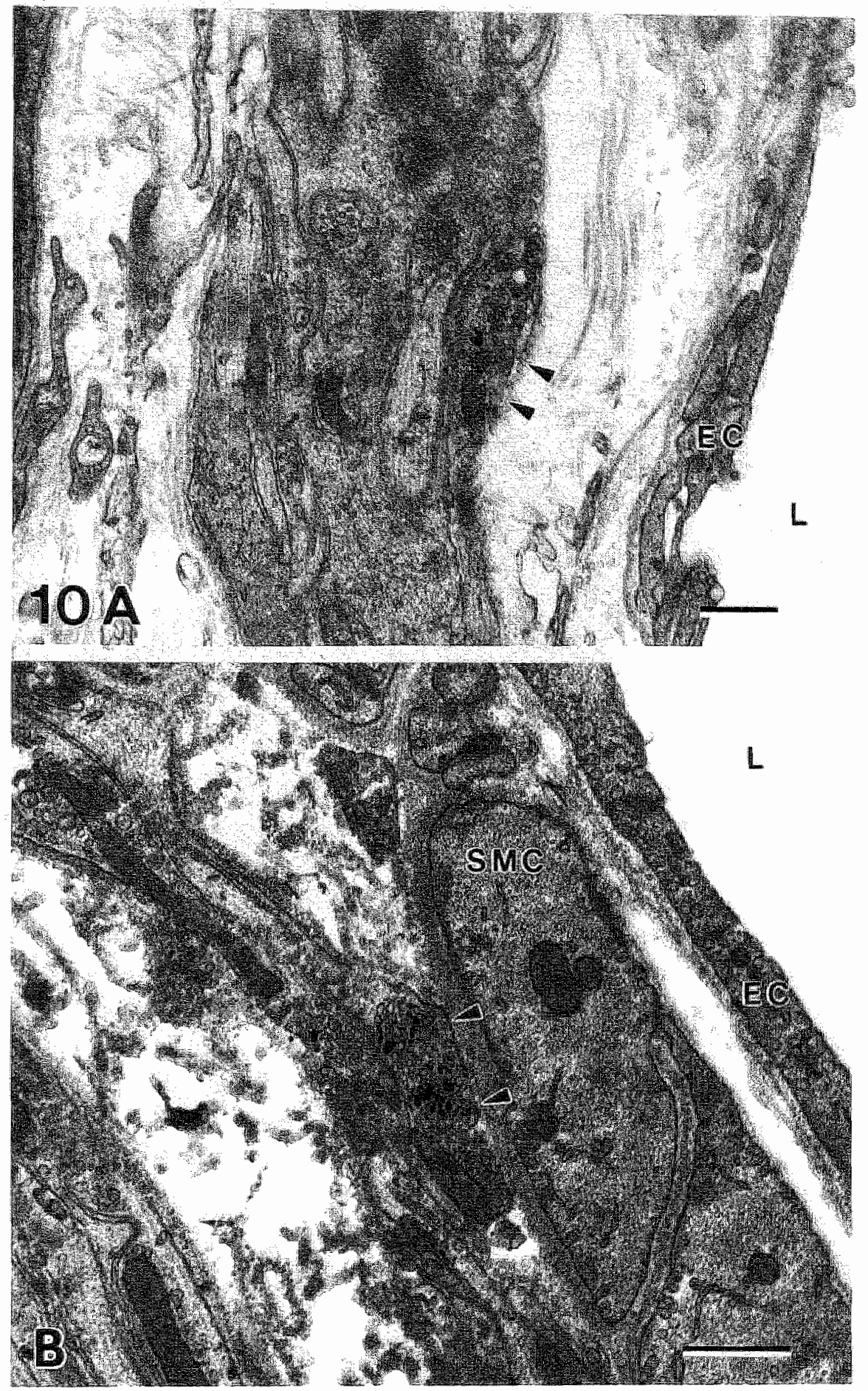
Fig. 4A: Electron micrograph showing a labelled fibre bundle whth two wesicle-containing terminals in close proximify to a choroidal antery. SMC, smooth muscle cell; $E C$, endothelial cell; $L$, fumen. $B$ : Electron micrograph showing a labelled teminal containing numerous clearffat wesicles, a few smali dense vesiclles. one large dense vesicle and dense mitochondra within a fibre bundle in close proximity to a choroidal artery. The lerminal partly lacks Schwann cell covering (arrowheads). SMC, smooth muscle cell; EC, endothelial cell; $L$, lumen. Scale bars represent $0.5 \mu \mathrm{m}$.

Fig. 5in Light micrograph showing a labelled fibre bundle (arrowheads) in the intraorbital lacrimal gland. $A C$, acinus. Scale bar represents $20 \mu \mathrm{m}$.

Fig. 6: Electron micrographs showing labelled terminals containing numerous clear vesicles within unmyelinated fibre buindles in the connective tissue between the acini (A) and in close proximity to acinar cells (B) in the infraorbital lacrimal gland. AC, acinar cel; BV, blood vessel; SG, secretory granules. Scale bars represent $0.5 \mu \mathrm{m}$.

Fig. 7A: Electron micrograph showing labelled unmyelinated fibres in close proximity to a neuronal cell body in the ciltary ganglion. $\mathrm{CB}$, cell body. $\mathrm{B}$; Electron micrograph showing a labelled terminall containing thumerous vesicles in the ciliary ganglion. Scale bars represent $0.5 \mathrm{\mu m}$.

Fig. 8: Light micrograph showing a VIP-immunoreactive fibre bundle (arrowheads) in close proximity to a choroidal blood vessel. BV, blood vessel. Scale bar represents $20 \mu \mathrm{m}$.

Fig. 9: Electron micrograph showing a VIP-immunoreactive terminal containing numerous clear vesicles (arrowheads) within an unmyelinated fibre butndle coursing through the choroidal lamina vasculosa. Scalle bar represents $0.5 \mu \mathrm{m}$.

Fig. 10: Electron micrographs showing VIP-immunoreactive terminals containing numerous clear vesicles in close proximity to a choroidal vein (A) and a choroidal artery (B). The terminals partly lack Schwann cell covering at the side facing the blood vessels (arrowheads). SMC, smooth muscle cell; EC, endothelial cell, L. lumen. Scale bars represent $0.5 \mu \mathrm{m}$.

3 H-leucine. So, it is tempting to assume that pterygopalatine nerve endings innervating the choroidal blood vessels contain VIP. Definite proof for this should be obtained by a combination of anterograde ${ }^{3} \mathrm{H}$-leucine labelling and VIP immunohistochemistry. This is technically complicated, however, since the application of the emulsion will largely hamper immunostaining after autoradiography and immunostaining prior to autoradiography will lead to a high background due to the gold-silver accumulation. It has been described in earlier studies that trigeminal fibres synaptically innervate pterygopalatine ganglion cells $1,26,29$. SP and CGRP may act as neurotransmitters or neuromodulators in that pathway 1,26 . The pterygopalatine ganglion cells have been shown to contain VIP and ChAT26. As the plerygopalatine fibres in turn innervate the choroid, with VIP as a possible neurotransmitter or neuromodulator, a regulatory feedback loop in the eye related peripheral nervous system is endorsed in which choroidal blood flow is modulated in response to sensory impulses mediated by the trigeminal innervation of the pterygopalatine ganglion cells. This point of view is partly supported by the observations of Terenghi et al ${ }^{27}$ that trigeminal coagulation leads to a peripheral decrease in SP' but does not affect VIP. It has been shown in earlier studies that VIP exerts a vasodilatory effect ${ }^{13}$. It can be concluded from the present study that the vasodilatory effect is established by modulating blood flow in both the choroidal arteries and weins. 
The present study also shows pterygopalatine terminals labelled with ${ }^{3} \mathrm{H}$-leucine in the ciliary ganglion. These terminals were never found to make synaptic contacts. In previous connection tracing studies it has been shown that the rat ciliary ganglion does not contain sympathetic fibres originating in the superior cervical ganglion or sensory fibres of trigeminal origin 29,30 . Thus, the cilliary ganglion contains only parasympathetic nerve fibres of oculomotor and facial origin. At the light microscopic level, VIP has been demonstrated within cillary ganglion cells of rats $^{9}$. It can be hypothesized that both the ciliary and the pterygopalatine ganglion supply the rat eye with VIP-immunoreactive nerves. In addition, the fibres of pterygopalatine origin most likely modulate the ciliary ganglion cells via nonsynaptic release of neurotransmitters or neuromodulators, possibly VIP.

The finding of ${ }^{3} \mathrm{H}$-leucine-labelled fibres and terminals in the infraorbital and extraorbital lacrimal glands agrees with previous studies of cats and primates in which the pterygopalatine ganglion had been described as the source of parasympathetic innervation of these glands 3,22 . It can be concluded from the present study that, in rats, most of the fibres and terminals are localized in the connective tissue surrounding the acini or are adjacent to the acinar cells. SP. and VIP-immunoreactive fibres have been demonstrated light microscopically within nerve fibres of the rat lacrimal gland ${ }^{12}$. In the latter studly the SP-immunoreactive fibres were mainly found around secretory ducts, whereas the VIP-immunoreactive fibres were located around acini. On account of these observations and the present finding of pterygopalatine terminals adjacent to acinar cells, it can be suggested that the fibres and terminals in the lacrimal glands of pterygopalatine origin in the present study may contain VIP. 


\section{The Peripheral Projections of the Edinger-Westphal Nucleus in the Rat}

Duke-Elder ${ }^{5}$ described the parasympathetic pathway innervating the anterior eye segment that is involved mediating pupil constriction and lens accommodation. Neurons located in the Edinger-Westphal nucleus (EW), the parasympathetic component of the oculomotor complex, project to the cilliary ganglion running with the aculomotor nerve. The secondary neuron of this pathway, located in the cillary ganglion, innervates the musculature of the ciliary body and iris. Anatomical evidence, however, suggested that, peripherally, the Edinger-Westphal neurons project directly to the intrinsic musculature of the eye $e^{4,7}$.

In the present study, the anterograde tracer Phaseolus vulgaris-leucoagglutinin (PHA-L) was applied iontophoretically to the rostal part of the EW for re-evaluation of the efferent projections. The ultrastructural organization of the peripheral efferents was analyzed using electron microscopy.

The experiments were performed on eight male Wistar rats weighing between 200 and $300 \mathrm{~g}$. The animals were anaesthetized with Nembutal $0.3 \mathrm{ml} / \mathrm{kg}$ i.p. (Rousselot, Paris, France) and Hypnorm $0.3 \mathrm{ml} / \mathrm{kg} \mathrm{i.m.} \mathrm{(Janssen,} \mathrm{Tilburg,} \mathrm{The} \mathrm{Netherlands).} \mathrm{In} \mathrm{a} \mathrm{dorsal,} \mathrm{stereotaxic} \mathrm{apploach}$ $2.5 \%$ PHA-L (Vector, Burlingame, CA) in sodium phosphate- buffered saline, pH 8, was injected iontophoretically $(6.5-6.9 \mu \mathrm{A}$, alternating positive current for $10 \mathrm{~min}$ ) into the $\mathrm{EW}$ using glass micropipettes with an inner tip diameter of $15 \mu \mathrm{m}$. After a survival period of one week, the animals were killed with an overdose of Nembutal and transcardially perfused with $150 \mathrm{ml}$ phosphate-buffered saline (PBS), followed by 1.5 liter aldehyde fixative (2.5\% glutaraldehyde and $1 \%$ paraformaldehyde in $0.05 \mathrm{M}$ phosphate buffer, $\mathrm{pH} 7.4$, at room temperature). After decapitation, the eyes and its adnexa including the ciliary ganglion were dissected and postfixed overnight in the same fixation solution.

After rinsing in Tris-buffered saline (TBS), the ciliary ganglia and whole mounts of the iris and choroid were transferred into buffered solutions containing diluted (1/2000) primary antiserum to PHA-L (Vector, Burlingame, CA). The peroxidase-antiperoxidase method (PAP) ${ }^{34}$ was used to visualize the PHA-L antiserum complex. The tissues were incubated in $0.05 \%$ diaminobenzidine (DAB) in Tris solution supplemented with $0.01 \%$ hydrogen peroxide $\left(\mathrm{H}_{2} \mathrm{O}_{2}\right)$. for 10 min. After rinsing, the DAB reaction product was intensified with a gold substituted silver peroxidase technique (GSSP) ${ }^{15}$. The ganglia and orbital contents were postfixed in $1 \%$ osmium tetroxide $\left(\mathrm{OsO}_{4}\right.$ ) in $0.1 \mathrm{M}$ sodium cacodylate buffer $\mathrm{pH}^{7.4}$, supplemented with $1.5 \%$ potassium ferricyanide, for $20 \mathrm{~min}$. Subsequently, they were dehydrated in a graded series of ethanols and flat embedded in epoxy resin. Ultrathin sections were stained with uranylacetate and lead citrate. These sections were analyzed in a Philips EM 201 electron microscope. Whole mounts of the iris and choroid were treated with the PAP and GSSP method and air-dried on gelatin coated slides, stained with Cresyl Fast Violet (Gurr), dehydrated and coverslipped with Entellan (Merck), after which they were light microscopically examined. 

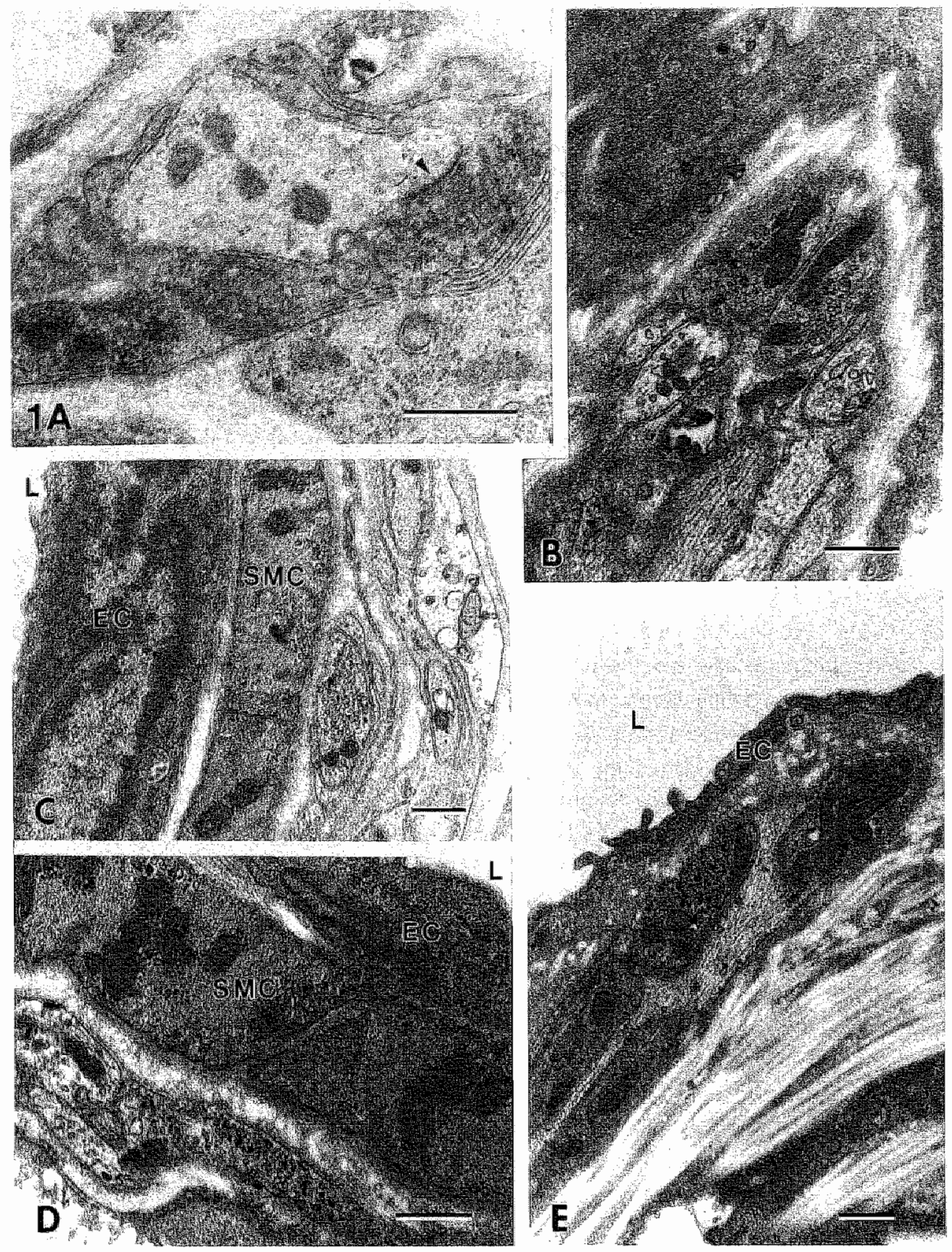
The peripheral pathway leaving the EW was found to consist of one ipsitateral fibre bundle. The labelled fibres left the EW ventrally, running together with the oculomotor nerve" and terminating in the ipsillateral ciliary ganglion, and in close proximity to vessels associated with the ipsilateral ciliary ganglion. No labelling was found in the contralateral ciliary ganglion.

No labelling was present in whole mount preparations of the iris and the choroid.

In the cilliary ganglion, the terminals originating from the EW were found to make asymmetric synaptic contacts on dendrites. The labelled terminals contained round vesicles and elecron densse mitochondria (Figs. 1A,B). The terminals in the cillary ganglion were isolated and enwrapped by glial elements (Fig. 1A). Nonsynaptic, labelled terminals were found directly adjacent to the smooth muscle cells of ciliary ganglion associated arterioles and in close proximity of cillary ganglion associated venules (Figs. 1C-E). These labelled terminals also contained round vesicles of irregular sizes and small electron dense mitochondria.

In the present study, the efferent projections of the EW were studied with small-sized injections of an anterograde tracer. No direct projection to the iris was found. This is in contrast to the findings of Jaeger and Benevento ${ }^{7}$ and Burde ${ }^{4}$, who observed labelled EW somata after horseradish peroxidase (HRP) and wheat germ agglutinin conjugated to horseradish peroxidase (WGA-HRP) injections in the anterior eye segment. This may be due to leakage of the tracer, although Burde 4 suggested a transsynaptic transport in the ciliary ganglion. The use of tracers in the peripheral nervous system has many pitfalls ${ }^{6,28}$. Ten Tusscher et. al, 28 described a satellite cell barrier in autonomic ganglia that prevents the uptake of lectins by the autonomic ganglion cells. This barrier may also prevent the uptake of lectins by terminals. The existence of such a barrier may explain the observations of only few retrogradely labelled meurons in the EW after injection of HAP into the ciliary ganglion 32 . Apart from variety of methods, species differences might offer an explanation for the observed differences.

The anterograde tracing experiments from EW resulted in terminal labelling in the ciliary ganglion and along bloodvessels associated with the ciliary ganglion. The whole mount preparations of the choroid were free of labelling. This absence is in agreement with the idea that the mammalian parasympathetic innervatioin of the choroid originates exclusively from the

Fig. 1A: Electron micrograph showing three labelled terminals in the ciliary ganglion. One labelled terminall with round vesicles makes asymmetric contact (arrowhead) with a dendritic profile, both profiles are surrounded by glial elements. B: Electron micrograph showing labelled terminals, in the ciliary ganglion, filled with round, electron lucent vesicles and electron dense mitochond ria.

C. D: Electron micrographs showing labelled non-synaptic terminals, filled with round vesicles, directly adjacent to the smooth muscle cells of cillary ganglion associated anterioles. E: Electron micrograph showing a labelled nonsynaptic terminal in close proximity to a ciliary ganglion assoclated vein. SMC, smooth muscle cell: EC, endothelial cell; L, iumen. Scale bars represent $0.5 \mu \mathrm{m}$. 
pterygopalatine ganglion ${ }^{2}$. However, it is in contrast to the avian parasympathetic innervation in which the ciliary ganglion innervates the anterior eye segment as well as the choroid ${ }^{11,16}$. This dual innervation could be the explanation for the observation of two types of terminals that were found in the avian ciliary ganglion ${ }^{17}$. In the present study, only a single type of EW terminal in the rat ciliary ganglion was observed. The finding of a direct innervation of the ciliary ganglion associated blood vessels by EW neurons is unprecedented. For the regulation of intraocular pressure, a feedback loop has been suggested, consisting of a sensory afferent pathway, a regulatory centre in the central nervous system, and an efferent pathway through the autonomic nervous system ${ }^{23}$. The innervation of the ciliary ganglion associated blood vessels by EW neurons suggests the existence of a direct autonomic loop that could be relevant for a homeostatic mechanism involved in the regulation of intraorbital pressure. 


\section{REFERENCES}

1 Beckers HJM, Klooster J, Vrensen GFJM, Lamers WPMA: Utrastructurat identification of trigentinal nerve terminals in the pterygopalatine ganglion of rats: An anterograde tracing and immunohistochemical study. Brain Res 1991; 557: 22-30.

2 Beckers HJM, Klooster J, Vrensen GFJM, Lamers WPMA: Facial parasympathetic innervation of the rat choroid; lacirmal glands and cifiary ganglion: An ultrastructural ptengopaletine tracing and immunohistochemical study. Ophthalmic Ries 1993; in press.

3 Botelho SY, Hisada M. Fuenmayor N: Functional innervation of the lacrimal gland in the cat. Arch Ophthal 1966; 76: 581-588.

4 Burde RM: Direct parasympathetic pathway to the eye: revisited. Brain Res 1988; $463: 158-162$.

5 Duke-Elder S, Wybar KC: The autonomic system. In: Duke-Elder (Ed), System of Ophthalmology, Vol. II, Kimpton, London, 1961, pp. 805-874.

6 Fox AE, Powley TL: False-positive artifacts of tracer strategies distort autonomic connectivity maps. Brain Res 1989; 14: 53-77.

7 Jaeger RJ, Benevento LA: A horseradish peroxidase study of the innervation of the internal structures of the eye. Invest Ophthaimol Vis Sci 1980; 19:575-583.

8 Klooster J, Beckers HJM, Vrensen GF.JM, Want vain der JJL: The peripheral and central projections of the Edinger-Westphal nucleus in the rat: a light and electron microscopic tracing study. Brain Res, in press.

9 Kuwayama $Y$, Grimes $P A$, Ponte $B$, Stone RA: Autonomic neurons supplying the rat eye and the intraorbital distribution of vasoactive intestinal polypeptide (VIP)-like immunoreactivity. Exp Eye Res 1987; 44: $907-922$.

10 Lin T, Grimes A, Stone RA: Nerve pathways between the pterygopalatine ganglion and the eye in cats. Anat Rec 1988; 222: 95-102.

11 Marwitt R, Pilar G, Weakly JN: Characterization of two ganglion cell populations in avian ciliary ganglion. Brain Res $1971 ; 25: 317-334$.

12 Nikkinen A, Lehtosalo J!. Uusitalo $\mathbb{H}$, Palkama $A_{4}$ Panula P: The lacrimal glands of the rat and the guinea pig are innervated by merve fibers containing immunoreactivities for substance $P$ and vasoactive intestinal polypeptide. Histochemistry $1984 ; 81: 23-27$.

13 Nilsson SFE, Bill A: Vasoactive intestinal popypeptide (VIP): effects in the eye and on regional blood flows. Acta Physiol Scand 1984; 121:385-392.

14. Pelers $A$ : The fixation of central nervous tissue and the analysis of electron micrographs of the neuropil with special reterence to the cerebral cortex. \#n: Nauta WJH, Ebbeson SOE (Eds.). Contemporary research methods in neuroanatomy, Springer-Verlag, Berin, 1970, pp 56-76.

15 Pol van den AN, Görcs T: Synaptic relationship between neurons containing vasopressin, gastrin-releasing peptide, vascactive intestinal polypepticle, and glutamate decarboxylase immunoreactivity in the suprachiasmatic nucleus: dual ultrastructural immunocytochemistry with gold substituted silver peroxidase. J Comp Neural 1986; 252: 507-521.

16 Reiner A: The presence of substance P/CGRP-containing fibers, VIP-Gontaining fibers and numerous cholinergic fibers on blood wessels of the avian choroid. Invest Ophthaimol Vis $8 \mathrm{ci} 1987$; 28 (suppli.): 81.

17 Reiner A, Erichsen JT, Cabot JB, Evinger C, Fitzgerald MEC, Karten HJ: Neurotransmitter organization of the nucleus of Edinger-Westphal and its projection to the avian ciliary ganglion. Visual Neurosci $1991 ; 6: 451-472$.

18 Rogers AW: Techniques of autoradiography. Elsevier Scientific Publishing Company, Amsterdam, London, New York, 1973, pp 1-372. 
19 Puskell GL: An ocular parasympathefic newe pathway of facial nerve origin and its influence on intraocular pressure. Exp Eye Res 1970; 10: 319-330.

20 Ruskell GL: The orbital branches of the pterygopalatine ganglion and their relationship with internal carotid nerve branches in primattes. I Anat 1970; 106: 323-329.

21 Auskell GL: Facial parasympathetic innerwation of the choroidall blood vessels in monkeys. Exp Eye Res $1971 ; 12: 166-172$.

22 Ruskell GL: The distribution of autonomic post-ganglionic nerve fibres to the lacrimal gland in monkeys. A Anat 1971:109:229-242

23 Stone $\mathrm{AA}$, Kuwayama $Y$ : The nervous system and intraocular pressure. In: Ritch $\mathrm{R}_{0}$ Shields MB, Krupin Thi (Eds.), The Glaucomas Vol. I. Mosiby Company, St. Louis, 1989, pp. 257-279.

24 Sugimoto $T_{n}$ Itoh $K$, Mizuno $N$ : Localization of neurons giving rise to the oculomotor parasympathetic outflow: a HRP study in cats. Neurosci Lett 1977; 7: 301-305.

25 Suzuki $N$, Hardebo JE, Owman Ch: Origins and pathways of cerebrowascular vasoactive intestinal polypeptide-positive nerves in rat. J Cereb Blood Flow Metab 1988; 8:697-712.

26. Sužuki N, Hardebo JE, Owman Ch: Trigeminal fibre collaterals storing substance $P$ and calcitonin gene-related peptide associate with ganglion cells containing choline acetyltransferase and vasioactive intestinal polypeptide in the sphenopalatine ganglion of the rat. An axon reflex modulating parasympathetic ganglionic activity? Neuroscience $1989 ; 30: 595-604$.

27 Terenghi $G$, Polak JM $M_{s}$ Probert L, McGregor GP, Ferri GL, Blank MA, Butler JM, Unger WG, Zhang $S_{n}$ Cole DF, Bloom SA: Mapping, quantitative distribution and origin of substance $P$ - and VIP-containing nerves in the uvea of the guinea pig eye. Histochemistry 1982; 75: 399-417.

28 Tusscher ten MPM, Klooster J, Vrensen GFJM: Satellite cells as bload-ganglion barrier in autonomic ganglia. Brain Res 1989; 490: 95-102.

29 Tusscher ten MPM, Klooster J, Want van der JJL, Lamers WPMA, Vrensen GFJM: The allocation of nerve fibres to the anterior eye segment and peripheral ganglia of rats. I. The sensory innervation. Brain Res 1989; 494; 95-104.

30 Tusscher ten MPM, Klooster J, Want wan der d.lL, Lamers. WPMA, Vrensen GFJM: The allocation of nerve fibres to the anterior eye segment and peripheral ganglia of rats. II. The sympathetic innervation. Brain Res 1989; 494: 105-113.

31 Tusscher ten MPM, Klooster J, Baljet B, Werf van der F, Vrensen GFJM: Pre-and post-ganglionic nerve fibres of the pterygopalatine ganglion and their allocation to the eyeball of rats. Brain Res $1990,517: 315-323$.

32 Toyoshima $K$, Kawana $E_{\text {, Sakai }} H$ : On the neuronal origin of the afferents to the ciliary ganglion in cat. Brain Fes 1980; 185: 67-76.

33 Uddman R, Alumets d, Ehinger B. Håkanson A, Lorén I, Sundler F: Vasoactive intestinal peptide nerves in ocular and orbital structures of the cat. Invest Ophthalmoll Vis Sci 1980; 19: 878-885.

34 Vandesande F: Peroxidase antperoxidase techniques. In: Cuello AC (Ed.), Immunohistochemistry, IBPO Handbook Series: Methods in Neurosciences. Wiley, New York "1983, Voll 3 $p p$ 101-119.

35 Vreinsen GFJM, Groot de D: Some new aspects of efficiency of electron microscopic autoradiography with tritium. J Histochem Cytochem 1970; 18: 278-290. 


\section{Summary and Discussion}


To understand the homeostatic mechanisms involved in the regulation of intraocular pressure (IOP), it is necessary to identify the elements of the central and peripheral nervous system involved in this control mechanism. In chapter 1, the data concerning the innervation of the eye related peripheral ganglia and the anterior eye segment, as reviewed by ten Tusscher (1989), are schematically summarized and extended by the most important recent data. In addition, the main immunohistochemical data concerning the light microscopic observations on the distribution of a selected number of neuropeptides within eye related nervous elements are summarized. Comments are made on the possible function in the regulation of IOP by these neuropeptides. The exact function of neuropeptides in the innervation pathways of the central and peripheral nervous system is extremely complex and remains largely to be elucidated.

In the piresent thesis, the interganglionic circuitry of the eye related peripheral ganglia was studied, both at the light and electron microscopic level, together with the innervation of the anterior eye segment. For these purposes, anterograde tracing experimeints were performed in rats using Phaseolus vulgaris-leucoagglutinin (PHA-L) and ${ }^{3} \mathrm{H}$-leucine autoradiography. In addition, immunohistochemistry was undertaken at the light and electron microscopic level to study the distribution of several neuropeptides in the investigated pathways.

\section{Interganglionic circuitry (Fig. 1)}

The parasympathetic pterygopalatine ganglion is synaptically innervated by sensory nerve terminals of fibres originating in the ophthalmic part of the trigeminal ganglian (chapter 2). Adjacent to the rostral part of the pterygopalatine ganglion, an additional minor part was found. Cell bodies within this part were found to be more spherical, with irregular outlines. The glial enwrapment of the nerve terminals seemed to be more loosely arranged in comparison to that in the major rostral part of the pterygopalatine ganglion. The sensory nerve terminals were distributed throughout the ganglion and were found to be immunoreactive to $\mathrm{SP}_{\text {, whereas only }}$ a few CGRP-immunoreactive terminals were found. Nerve fibres were inmunoreactive for both neuropeptides.

Sympathetic nerve fibres of superior cervical origin course through the trigieminal and the pterygopalatine ganglion (chapter 3). No synaptic contacts, vesicle containing terminals or varicosities were found in these ganglia. However, labelled sympathetic fibres with accumulations of vesicles were found in both the trigeminal and the pterygopalatine ganglion. Close appositions between labelled and unlabelled fibres were found in the plerygopalatine ganglion and were also found at the sites of accumulation of vesicles. This finding may indicate some kind of interneuronal communication.

Parasympathetic fibres of pterygopalatine origin course through the ciliary ganglion (chapter 4). These fibres were mainly unmyelinated and were frequently localized in close proximity to cell bodies of the ciliary ganglion. Pterygopalatine terminals containing numerous vesicles 


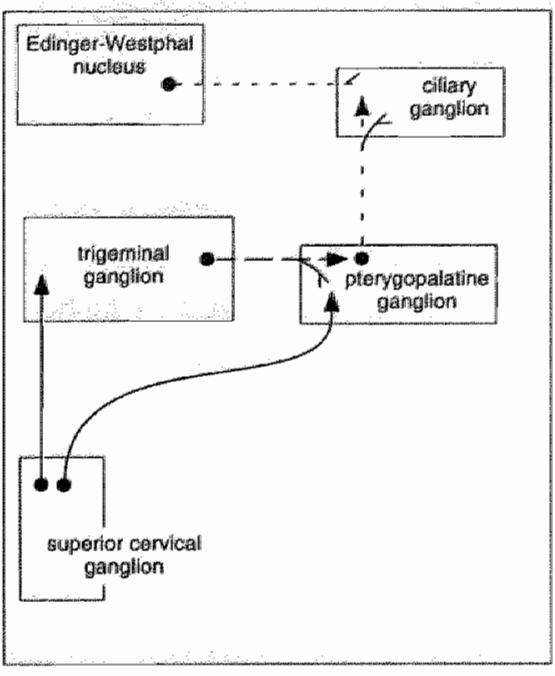

Fig. 1: Interganglionic circuitry showing the sensory innervation (interrupted lines)" the sympathetic innervation (solid lines), and the parasympathetic innervation (dashed lines).

were also found within the ciliary ganglion. However, no direct synaptic contacts were found. It can be suggested that in the ciliary ganglion, pterygopalatine terminals most likely influence the ganglion cells by non-synaptic release of neurotransmitters or neuromodulators. On the account of previous literature, VIP seems to be a candidate for this.

In addition to the pterygopalatine innervation, it was found that parasympathetic neurons, localized within the Edinger-Westphal nucleus (EW), synaptically innervate the ciliary ganglion cells (chapter 4). The ciliary ganglion does not contain sympathetic or sensory nerve fibres.

\section{The innervation of the anterior eye segment (Fig. 2)}

Trigeminal nerve fibres in the cornea and iris stroma are unmyelinated and contain numerous varicosities packed with vesicles (chapter 2). Similar vesicle-containing varicosities in the comea and iris stroma were found to be immunoreactive to calcitonin gene-related peptide (CGRP) and substance P (SP). CGRP-. and SP-immunoreactive varicosities packed with vesicles were also found directly adjacent to the sphincter and dilator muscles in the iris. Additionally, CGRP-immunoreactive varicosities containing vesicles were found in the corneal epithelium. These vesicle-containing varicosities of cornea and iris most likely represent sensory nerve terminals, from which the neuropeptides SP and CGRP are released in response to (harmful) stimuli in the eye.

Sympathetic nerve fibres originating in the superior cervical ganglion densely innervate the tissues of the anterior eye segment, with exception of the cornea, with terminals containing numerous vesicles of varying shape (chapter 3 ). The terminals in the iris, ciliary body and trabeculum all had a similar morphology. Since the cornea is not innervated by sympathetic fibres, the only source of corneal innervation is the sensory trigeminal ganglion. 
The choroid and lacrimal glands are innervated by facial parasympathetic nerve fibres and vesicle-containing terminals originating in the pterygopalatine ganglion (chapter 4). Within the choroid, the arteries as well as the veins are innervated by pterygopalatine nerve terminals. In addition, numerous terminals of similar ultrastructure, localized in close proximity to the choroidal arteries and veins, were found to be immunoreactive to vasoactive intestinal polypeptide (VIP). The infraorbital lacrimal gland is more denselly innervated by pterygopalatine nerve fibres and terminals as compared to the extraorbitall lacrimal gland. These terminalls, which may contain VIP, were mainly localized within the connective tissue between the acini and also in close proximity to the acinar cells.

In the present study the innervation of the conjunctiva was not studied at the ultrastructural level. However, earlier light microcopic studies (ten Tusscher, 1989) have indicated a dense innervation of the conjunctiva. These findings have been included in fig. 2 .

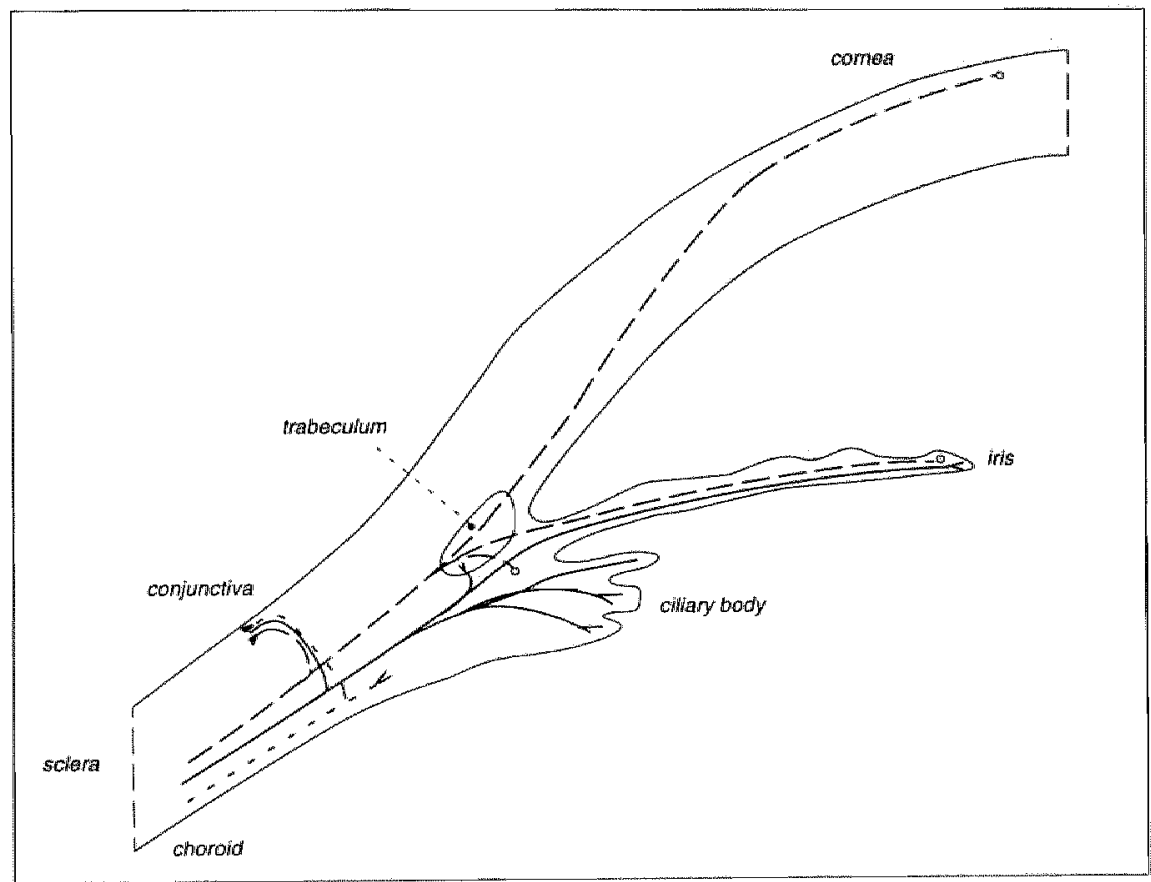

Fig. 2: Anterior eye segment innervation showing the sensory innervation (interrupted lines). the sympathetic innervation (solid lines), and the parasympathelic innervation (dashed lines). The innervation of the conjunctiva was only studied at light microscopic level.

The findings of the present thesis further endorse that the pterygopalatine ganglion could be am important relay centre in the regulation of intraocular pressure (IOP). A peripheral reflex loop within the eye related peripheral nervous system may exist apart from a regulatory centre in the 
central nevvous system (Fig. 3). Sensory input from the eye, which may be modulated by the neuropeptides SP and CGRP, is transferred to the trigeminal ganglion via the trigleminal nerve. Trigeminal nerve fibres synaptically innervate pterygopalatine ganglion cells. SP and CGRP may act as neurotransmitters or as neuromodulators in this pathway. In turn, pterygopalatine herve tibres innervate the choroidal arteries and veins, with VIP as a possible neurotransmitter or neuromodulator. According to the vasodilatory effect of $V \| P$, blood flow could be regulated by establishing vasodlatation in both the choroidal arteries and veins.

Sympathetio newe fibres may influence IOP by the release of neurotransmitters or neuropeptides such as neuropeptide $Y$ (NPY) and adrenaline. They may modulate the suggested peripheral reflex loop either in the trigeminal ganglion or in the pterygopalatine ganglion.

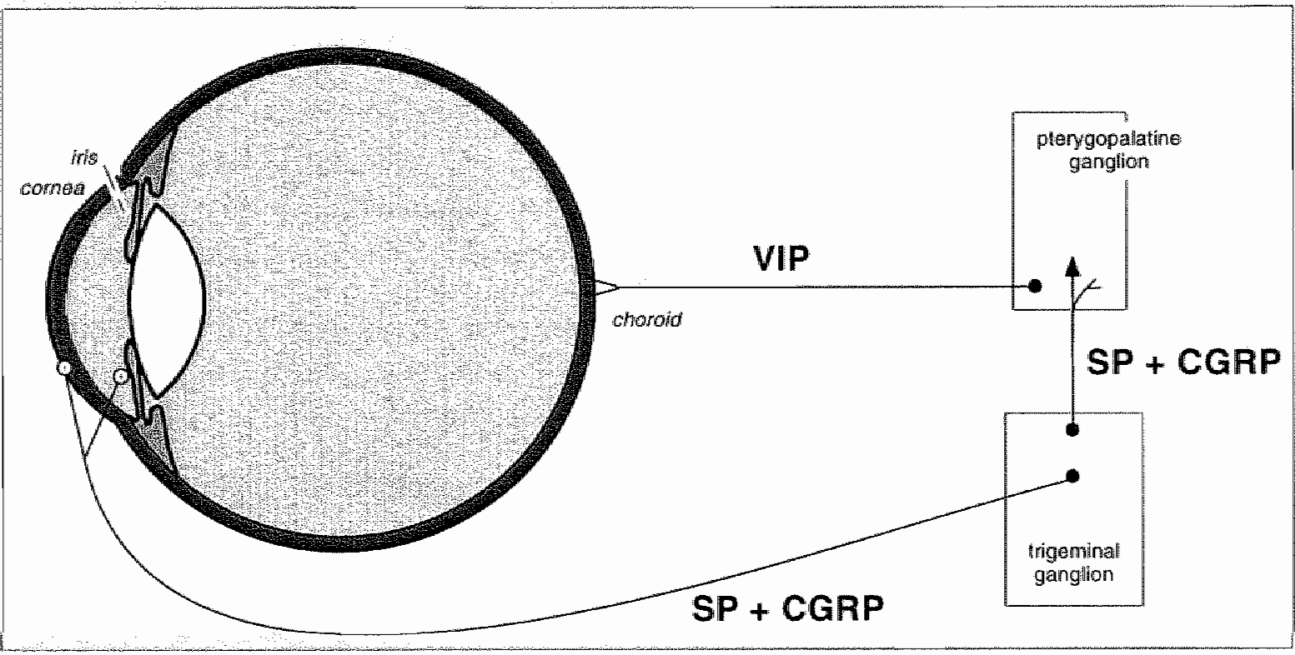

Fig. 3: Posisible reflex loop within the eye rellated peripheral nerwous system

The direct innervation of cilliary ganglion associated blood vessels by nerve fibres originating in the Edinger-Westphal nucleus (EW) also suggests the existence of a homeostatic mechanism involved in the regulation of intraorbital pressure. For example, the venous resistance of the blood wessels into which the aqueous veins drain may be modulated by such a mechanism.

Parasympathetic nerve fibres of pterygopalatine origin also innnervate the lacrimal gland. Harmful stimuli to the eye trigger the peripheral release of SP and CGRP from sensory nerve fibres giving rise to the ocular injury response. It seems likely that the peripheral reflex loop, as described above, would also be triggered, excitating pterygopalatine neurons including those innervating the lacrimal gland. In this way tear secretion regulated by a peripheral reflex loop 
would accompany the local response to irritative ocular stimuli. Choroidal vasodilatation could also be a part of this mechanism. Changes in IOP could be epiphenomena.

At present however, in spite of all the speculations on the existence of reflex loops, it is still unclear how peripheral nerve fibres are capable of influencing other nerve fibres. Apart from direct excitation by synaptic contacts more diffuse modulation of cells exists. Ephaptic transmission between adjacent fibres in the peripheral nervous system accurs in pathological conditions. Additionally, numerous neuropeptides have been described quite recently. As mentioned earlier, the function of most of these neuropeptides still is unknown. Moreover, the peptidergic characteristics of nerve fibres have been shown to alter in certain conditions. Clearly further investigation is needed to elucidate which neuropeptides are involved in the innervation of the eye and eye related peripheral ganglia. In addition "the precise mechanism by which neurons of different origin and different peptidergic characteristics interact remains to be elucidated. 


\section{SAMENVATTING}

Orn de homeostatische mechanismen te kunnen begrijpen die betrokken zijn bij de regulatie van de oogdruk, is het belangrijk om de onderdelen van hel centralle en perifere zenuwstelsel te kennen die hierbij een rol spelen. In hoofdstuk 1 is gepoogd om de belangrijkste gegevens samen te vatten die betrekking hebben op de innervatie van de aan het oog gerelateerde perifere ganglia en het voorste oogsegment. Ook worden hierin lichtmicroscopische bevindingen op een rijtje gezet, die handelen over de aanwezigheid van diverse neuropeptiden in zenuwen die met de innervatie van het oog te maken hebben. Deze neuropeptiden zijn mogelikk betrokken bij de regulatie van de oogdruk, maar hun precieze functie bij de innervatie van centrale en perifere systemen is zeer complex en nog steeds vrijwel onbekend.

In dit proulschrift werd de onderlinge innervatie van de aan het oog gerelateerde perifere ganglia samen met de innervatie van het voorste oogsegment bestudeerd in de rat, op licht- en electronenmicroscopisch niveau. Hiertoe werden twee anterograde tracer- technieken toegepast. Ook werden immunohistochemische technieken gebruikt om de lakalisatie van diverse neuropeptiden in de onderzochte verbindingen vast te stellen, eveneens op licht- en ellectronenmicroscopisch niveau.

\section{Interganglionair circuit (Fig. 1A)}

Het parasympatische ganglion pterygopalatinum wordt geïnnerveerd door sensore zenuweindigingen afkomstig uit het ganglion trigeminale. Deze zenuweindigingen bevatten vele synapsen (hoofdstuk 2). Naast het rostrale gedeelte van het ganglion pterygopalatinum bleek nog een klein apart ganglion gedeelte te liggen. De cellichamen in dit gebied hadden een vrij onregelmatige ronde vorm. De zenuweindigingen in dit gebied werden zeer losjes omgeven door satellietcellen, in tegenstelling tot de meer compacte omhulling door satellietcellen in het grote rostrale gedeelte van het ganglion pterygapalatinum. De sensore zenuweindigingen werden in het gehele ganglion gevonden. Vele van deze sensore zenuweindigingen in het ganglion pterygopalatinum bleken SP te bevatten, terwijl CGRP slechts in een beperkt aantal zenuweindigingen gevonden werd. Zenuwvezels bevatten beide neuropeptiden.

Sympatische zenuwvezels afkomstig wit het ganglion cervicale superior lopen door het ganglion trigeminale en het ganglion pterygopalatinum (hoofdstuk 3). Synaptische contacten werden echter niet gevonden. Wel bleek een aantal ongemyeliniseerde zenuwvezels ophopingen van blaasjes te bevatten op plaatsen waar ze dicht tegen elkaar waren gelegen. Dit suggereert dat er toch een vorm van informatie overdracht in deze ganglia zou kunnen bestaan.

Parasympatische zenuwvezels afkomstig uit het ganglion pterygopalatinum lopen door het, eveneens parasympatische, ganglion ciliare. Deze vezels bleken voomamelijk ongermyeliniseerd te zijn en werden frequent dichtbij cellichamen van het ganglion ciliare 
aangetroffen. Zenuweindigingen met blaasjes werden ook gevonden in het ganglion cilliare, maar deze maakten geen synaptisch contact. Deze parasympatische zenuweindigingen zouden de cellen in het ganglion cillare kunnen beïnvloeden door middel var vrije affifte van neurotransmitters of neuromodulatoren zoals VIP.

Buiten de parasympatische innervatie vanuit het ganglion pterygopalatinum, innerveren parasympatische neuronen, die gelegen zijn in de nucleus wain Edinger-Westptral (EW), de cellen in het ganglion ciliare door middel van synaptische contacten (hoofdstuk 4). Door het ganglion ciliare lopen geen sympatische of sensore vezels.

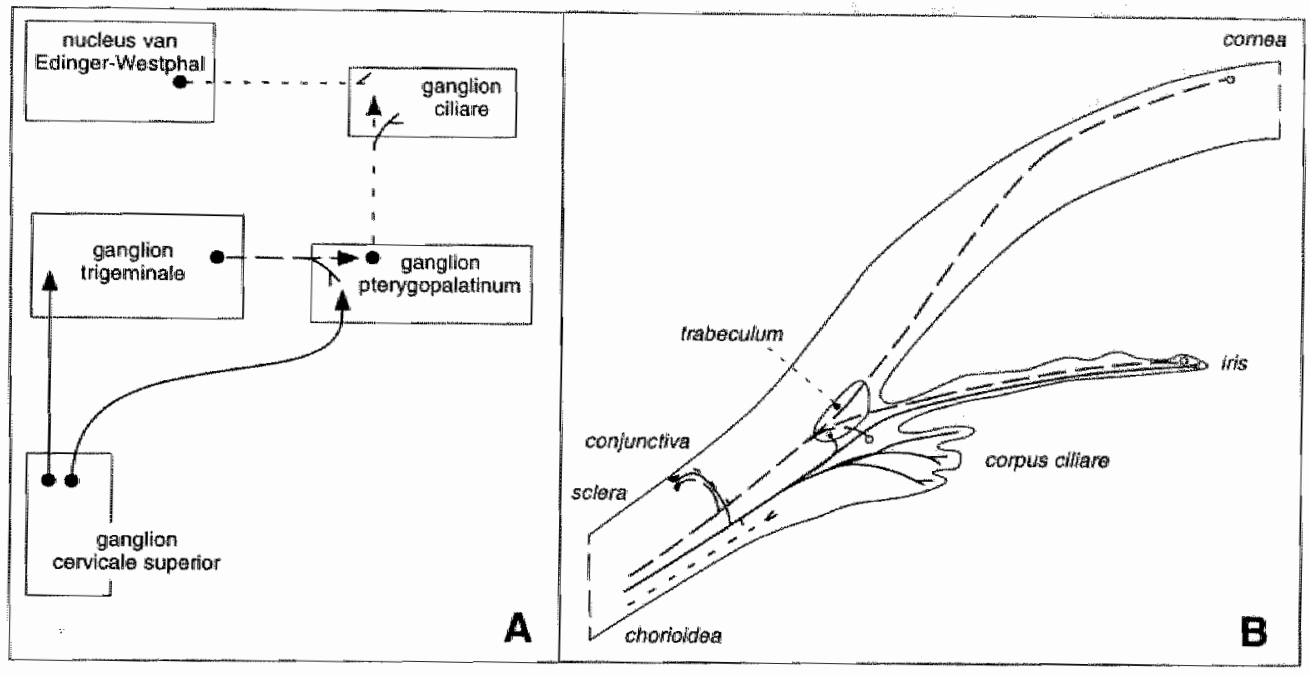

Fig. 1: Interganglionair circuit (A) en de innervatie van het woorste oøgsegment (B). De sensore innervatte (onderbroken lijnen), de sympatische innervatie (getrokken lijnen) en de parasympatische innervatie. (stippellijnen) zijn weergegeven. De innervatie van de conjunctiva werd alleen op licht- microscopisch niveau bestudeerd.

\section{De innervatie van het voorste oogsegment (Fig. 1B)}

Trigeminale (sensore) zenuwvezels in het stroma van cornea en iris zijn ongemyeliniseerd en bevatten vele verwijdingen met blaasjes (hoofdstuk 2). In soortgelijke verwijdingen met: blaasjes in comea en iris werden de neuropeptiden calcitonin gene-related peptide (CGRP) en substance $P$ (SP) aangetoond. CGRP en SP werden ook aangetoond in zenuwverwijdingen met blaasjes die wlak naast spiercellen van de iris sphincter en dilatator spieren gelegen waren. Tevens werd CGRP aangetoond in zenuwverwijdingen met blaasjes gelegen in het cornea-epitheel. Deze blaasjes-bevattende zenuwverwijdingen in comea en iris stellen waarschijnlijk sensore zenuweindigingen voor, die de neuropeptiden SP en CGRP bevatten en die kunnen afgeven in geval van beschadigende impulsen in het $0 \circ g$. 
Sympatische zenuwvezels afkomstig uit het ganglion cervicale superior, innerveren het gehele voorste oagsegment, met uitzondering van de comea. De zenuweindigingen bevatten vele blaasjes (hoofdstuk 3 ) en hebben dezelfde morfologische kenmerken in iris, corpus cillare en trabeculum. De cornea wordt allieen geïnnerveerd door sensore zenuwvezels afkomstig uit het ganglion trigeminale.

De chorioldea en de traanklieren worden geïnnerveerd door parasympatische zenuwvezels afkomstig uit het ganglion pterygopalatinum (hoofdstuk 4). Zowel de chorioideale arteriën als de venen worden geinnerveerd door deze parasympatische zenuweindigingen. Het neuropeptide vasoactive intestinal polypeptide (VIP) werd aangetoond in soortgelijke zenuweindigingen in de chorioidea. In vergelijking met de extraorbitale traanklier wordt de infraorbitale traanklier rijker geïnerveerd door parasympatische zenuweindigingen van pterygopalatinerge oorsprong. Deze zenuweindigingen werden het meest frequent aangetoond in het bindweefsel tussen de acini en in de directe nabijheid van acinus-cellen. 


\section{Curriculum Vitae}

Henny Beckers werd op 19 mei 1962 geboren te Echt. Na het behalen van het Atheneum-B diploma in 1980, werd in 1982 een aanvang gemaakt met de studie geneeskunde aan de Rijksuniversiteit Limburg. Het doctoraalexamen werd behaald in 1986, het artsexamen in 1988. Na het behalen van het artsdiploma was ze van november 1988 tot februari 1989 werkzaam bij de afdeling Onderwijsontwikkeling en Onderwijsresearch van de Rijksuniversiteit Limburg. Van maart 1989 tot maart 1993 werden de werkzaamheden die leidden tot dit proefschrift uitgevoerd als arts-onderzoeker bij de afdeling Morfologie van het Interuniversitair Oogheelkundig Instituut te Amsterdam. Ze is thans werkzaam als arts-assistent in opleiding tot oogarts in het Academisch Ziekenhuis te Maastricht. 

Si non nobis saltem posteris 